\author{
UNIVERSIDADE DE SÃO PAULO \\ ESCOLA DE ENGENHARIA DE SÃO CARLOS \\ INSTITUTO DE FÍSICA DE SÃO CARLOS \\ INSTITUTO DE QUÍMICA DE SÃO CARLOS
}

FABRÍCIO APARECIDO DOS SANTOS

\title{
Processamento de Grafeno Oxidado na forma de filmes ultrafinos e aplicações em sensores
}





\section{Processamento de Grafeno Oxidado na forma de filmes ultrafinos e aplicações em sensores}

Dissertação apresentada ao Programa de Pós-Graduação Interunidades em Ciência e Engenharia de Materiais da Universidade de São Paulo para obtenção do título de Mestre em Ciências e Engenharia de Materiais.

Área de Concentração: Desenvolvimento, Caracterização e Aplicação de Materiais.

Orientador: Valtencir Zucolotto

Versão Original 
AUTORIZO A REPRODUÇÃO E DIVULGAÇÃO TOTAL OU PARCIAL DESTE TRABALHO, POR QUALQUER MEIO CONVENCIONAL OU ELETRÔNICO PARA FINS DE ESTUDO E PESQUISA, DESDE QUE CITADA A FONTE.

Aparecido dos Santos, Fabrício ultrafinos e aplicações em sensores / Fabrício Aparecido dos Santos; orientador Valtencir Zucolotto. São Carlos, 2012.

Dissertação (Mestrado) - Programa de Pós-Graduação Interunidades em Ciências e Engenharia de Materiais e Área de Concentração em Desenvolvimento Caracterização e Aplicação de Materiais -- Escola de Engenharia de São Carlos; Instituto de Física de São Carlos; Instituto de Química de São Carlos, da Universidade de São Paulo, 2012 .

1. Grafeno Oxidado. 2. ELBL. 3. Sensor. 4. Potenciometria. I. Título. 
Aos meus pais, Aparecida e Fábio, a quem devo muito por estar aqui e a Fabiola minha companheira de todas as horas, dedico esta dissertação. 


\section{FOLHA DE APROVAÇÃO}

Fabrício Aparecido dos Santos

Dissertação apresentada ao Programa de Pós-Graduação em Ciência e Engenharia de Materiais da Universidade de São Paulo para obtenção do título de Mestre em Ciência e Engenharia de Materiais. Área de Concentração: Desenvolvimento, Caracterização e Aplicação de Materiais.

Aprovado em 21.01.2013

Comissão Julgadora

Prof(a). Dr. (a). Valtencir Zucolotto

Instituição: IFSC/USP

Assinatura

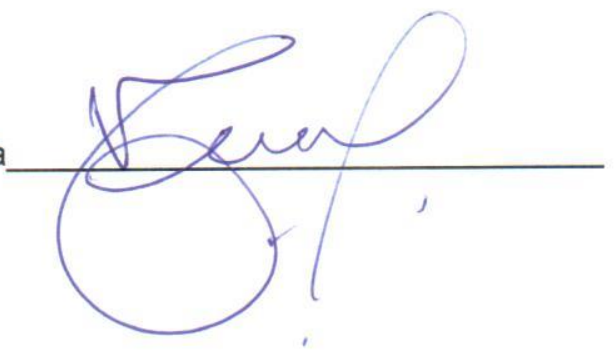

Instituição: EMBRAPA/São Carlos

Assinatura

Prof(a). Dr. (a). Francisco Eduardo Gontijo Guimarães

Instituição: IFSC/USP

Assinatura

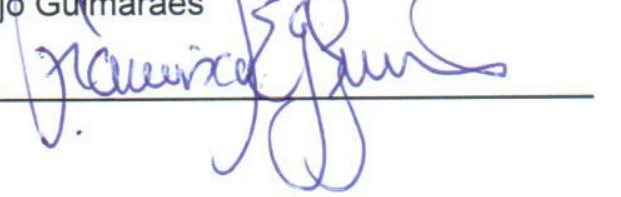


Agradeço primeiramente a minha família, pilar e apoio que não encontrarei em nenhum lugar e em nenhuma amizade.

A Aparecida, mãe e batalhadora, que lutou para me educar e estar aqui hoje defendendo esta dissertação.

Ao professor Valtencir Zucolotto, mestre e amigo, pela orientação e amizade, nesses anos.

A Fabiola, minha namorada e companheira de todas as horas, mesmo estando a $4000 \mathrm{~km}$, conseguiu ter paciência e carinho, estando sempre presente para o que der vier.

Aos amigos do Laboratório de Nanomedicina e Nanotoxicologia, pelas risadas, horas de almoço, churrascos, conversas, congressos: Rodrigo, Wagner, Camilo, Thalita, Jaciara, Valéria, Ju, Veronica, Lilian, Edson, Nirton, Bruno, Luís, Denise, Ieda, IC's.

Aos amigos da Biofísica molecular

Aos técnicos, Bel, Andressa, João Possato, a secretaria Ester e Juliele.

Ao Instituto de Física de São Carlos, pela excelente infraestrutura, funcionários, professores.

A CAPES pelo suporte financeiro.

Aos meus amigos e irmãos da república Aquarius, que sempre estiveram comigo e vão estar comigo sempre e em todo lugar, não importa onde estiver. "Doutor meu coração é aquariano".

A todos aqueles que contribuíram direta ou indiretamente com este trabalho. 
"Eu tentei, eu consegui"

William Kamkwamba, garoto malawi, analfabeto, pobre e camponês, conseguiu alimentar e tirar a sede de sua família, apenas olhando figuras em livros de física. 


\section{RESUMO}

SANTOS, F. A. Processamento de Grafeno Oxidado na forma de filmes ultrafinos e aplicações em sensores. 2012. 110 p. dissertação (Mestrado) - Instituto de Física de São Carlos, Instituto de Química de São Carlos, Escola de Engenharia de São Carlos, Universidade de São Paulo, São Carlos, 2012.

Dentre as formas alotrópicas do carbono, o grafeno merece destaque. Este material consiste de uma monocamada atômica de carbono $\mathrm{sp}^{2}$ disposta em uma rede bidimensional cristalina hexagonal tipo "favo de mel". Uma das formas de se obter o grafeno é pela esfoliação química, que consiste da oxigenação do grafite policristalino em um ambiente altamente oxigenado, formando um produto intermediário chamado de grafeno oxidado (GO). Por este método, gera-se um produto altamente estável e solúvel em água, podendo ser utilizado na construção de filmes ultrafinos. Uma das aplicações possíveis do grafeno oxidado é em sensores e biossensores, área de aplicações de novos materiais que viabilizem o diagnostico rápido, preciso, seletivo e de baixo custo, principalmente os do tipo, "point-of-care". O grafeno é um forte candidato, nessa área, devido a sua alta performace e seu baixo custo de processamento. Neste trabalho, a técnica de automontagem "eletrostatic layer-by-layer" (ELBL) foi utilizada na construção de filmes de grafeno oxidado, juntamente com o policátion dendritico poli(amido amina) geração 4 (PAMAM-G4) em uma plataforma potenciométrica, utilizando um amplificador de instrumentação comercial AD620 como transdutor em um sensor de pH para caracterização da sensibilidade do dispositivo. Diversas técnicas espectroscópicas, óticas e morfológicas foram utilizadas para caracterizar a esfoliação química do grafite e dos filmes automontados. Através destas caracterizações mostrou-se que a esfoliação ocorreu satisfatoriamente concordando com resultados já existentes na literatura. A construção dos filmes ultrafinos ocorreu pela rápida adsorção do GO em camadas alternadas de PAMAM-G4, e o monitoramento do crescimento dos filmes foi realizado utilizando espectroscopia no UV-Vis, onde o crescimento é linear a partir da décima camada. Por microscopia de força atômica, mostrou-se que a adsorção das folhas de grafeno se dá primeiramente pelas folhas de menor número de camada (1 e 2 camadas) de GO e para camadas de número superior tem-se uma morfologia totalmente diferente da primeira. Por espectroscopia no infravermelho, mostrouse a interação entre os dois polieletrólitos, onde há formação de ligações do tipo "cross-linking" entre as camadas. Medidas de potenciometria indicam a sensibilidade máxima em torno de $57 \mathrm{mV} / \mathrm{pH}$ em um substrato de ouro( sensibilidade Nerstiana), o que evidencia a sua aplicabilidade em sensoriamento e também a sua aplicação em biossensores.

Palavras chaves: Grafeno oxidado, esfoliação química, potenciometria, ELBL. 



\section{ABSTRACT}

SANTOS, F. A. Processing of Oxidized Graphene in the form of thin films and applications in sensing. 2012. 110 p. dissertação (Mestrado) - Instituto de Física de São Carlos, Instituto de Química de São Carlos, Escola de Engenharia de São Carlos, Universidade de São Paulo, São Carlos, 2012.

Among the allotropic forms of carbon, graphene deserves special attention. This material consists of one atomic monolayer of $\mathrm{sp}^{2}$ carbon arranged in a twodimensional hexagonal lattice type, namely "honeycomb". One common method to obtain graphene is -=by chemical exfoliation, which consists of oxygenation of polycrystalline graphite in a highly oxygenated medium, forming an intermediate product namely graphene oxide (GO). This method generates a highly stable and water soluble GO that can be used in the fabrication of ultrathin films. Graphene is a strong candidate for sensing, due to its high performance and low cost processing. In this dissertation, GO was obtained via chemical routs and processed in the form of ultrathin films in conjunction with polyamidoamine dendrimer (PAMAM G4) in a layered fashion using the Electrostatic Layer-byLayer (ELBL). The GO/PAMAM films were deposited on potentiometric platforms and used as $\mathrm{pH}$ sensors using a commercial amplifier AD620 instrumentation as the detection technique. GO and the LbL films were characterized via spectroscopic, optical and morphological techniques. Film growth was monitored via UV-Vis spectroscopy and revealed a linear adsorption up to the tenth GO/PAMAM bilayer. AFM analyses revealed that graphene sheets containing 1 or 2 layers occurred adsorbed first on the substrates. Potentiometric measurements indicated a maximum sensitivity of ca. $57 \mathrm{mV} / \mathrm{pH}$ for GO/PAMAM films deposited on gold substrates (Nernstian Sensitivity), which demonstrates the applicability of the films in sensing and biosensing.

Keywords: Graphene oxide, chemical exfoliation, potentiometry, ELBL. 



\section{LISTA DE FIGURAS}

Figura 1: Exemplos de efeitos quânticos e superficiais de nanopartículas, dimensões possíveis, 0D, 1D, 2D e 3D, imagem adaptada das referências, [24$26]$

Figura 2: Tipos de hibridização possíveis para o carbono, a) hibridização sp, b) hibridização $\mathrm{sp}^{2}, \mathrm{c}$ ) hibridização $\mathrm{sp}^{3}$.

Figura 3: Grafeno, a mãe das formas grafíticas, onde temos a formação de fulerenos, nanotubos e grafite, figura retirada da referência (12). 31

Figura 4: Grafeno esfoliado mecanicamente. 32

Figura 5: Número de publicações contendo a palavra graphene, dados obtidos pelo portal web of Science (36).

Figura 6: Estrutura cristalina do grafeno: A) Há duas redes Bravais, indicadas pelas cores laranja e verde, onde $a_{1}$ e $a_{2}$ são vetores da rede recíproca. B) Rede recíproca da rede real em $\mathrm{A}$, onde a região hachurada é a primeira zona de Brillouin e $b_{1}$ e $b_{2}$ os vetores da rede recíproca.

Figura 7: A) Representação da dispersão de energias das bandas $\pi$ e $\pi *$, figura adaptada da referência (38), representação $2 \mathrm{D}$ da figura $\mathrm{A}$.

Figura 8: Estrutura do grafeno oxidado. A) Seus grupos funcionais. B) Estrutura tridimensional.

Figura 9: Processo de formação de um filme pela técnica ELBL 39

Figura 10: Diagrama do design de um sensor químico.

Figura 11: Diagrama de um MOSFET em A, e um ISFET em B.

Figura 12: Diagrama de um amplificador de instrumentação, figura adaptada da referência (92). .52

Figura 13: Diagrama de um filme automontado de PAMAM-G4/GO. .58

Figura 14: Diagrama do dispositivo potenciométrico.

Figura 15: Espectro de absorção de grafeno oxidado em marrom (GO), e um espectro de grafeno reduzido em preto (RGO).

Figura 16: Solução de grafeno esfoliado quimicamente sem tratamento em A. Solução de grafeno oxidado em diferentes concentrações em B. .66 
Figura 17: Microscopia ótica; A e B são de uma amostra sem tratamento após a esfoliação, A possui um aumento de 50x e B 100x. C e D são as amostras tratadas, C possui um aumento de 50x e D um aumento de 100x. Os círculos vermelhos indicam os bulks de grafite e os círculos verdes indicam a presença de grafeno oxidado de poucas camadas.

Figura 18: A) Amostra do grafeno oxidado, tratado e seu respectivo espectro EDS. B) amostra após a esfoliação. C) imagem do substrato.

Figura 19: Difratograma das amostras de grafeno oxidado sem tratamento, tratado e grafite utilizado na esfoliação...........................................................

Figura 20: Espectro de infravermelho de uma amostra de grafeno oxidado.........73

Figura 21: Mapa de intensidade Raman das seguintes bandas A) Banda 2D B) Banda D , C) Banda G referente a posição em torno de $1568 \mathrm{~cm}^{-1}$ D) Banda G referente a posição em torno de $1608 \mathrm{~cm}^{-1}$. .75

Figura 22: Espectro Raman de uma região central da folha de grafeno oxidado..76

Figura 23: Espectro da borda de uma folha de grafeno oxidado. Inset: Ajuste

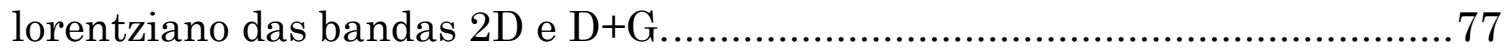

Figura 24: Estudo da posição das bandas G e D, e a razão I(D)/I(G) e a largura a meia altura de ambas as bandas em relação a um ponto referencial no centro do GO até a sua borda. .78

Figura 25: Comparações de imagens: A) Ótica. B) Raman (Banda D). C) AFM. ..79

Figura 26: Perfil de rugosidade em: A) folha de GO indicada na figura 25 como 1. B) folha de GO indicada na figura 25 como 2 .

Figura 27: Potencial-ろ de uma dispersão coloidal de GO, variando o pH de 2 a 12.

Figura 28: Crescimento de filmes automontados, absorbância por número de camadas em três tempos diferentes ( $20 \mathrm{~s}, 2$ min e $5 \mathrm{~min})$..............................8 82

Figura 29: Crescimento LBL para dois valores de $\mathrm{pH}$ diferentes (4 e 8)...............83

Figura 30: A) Crescimento de filme por LBL até 15 bicamadas. B) Acompanhamento do respectivo crescimento através um ponto em $230 \mathrm{~nm}$, correspondente ao pico de absorção do GO.

Figura 31: A) Espectro para diferentes bicamadas. B) Derivada em função do comprimento de onda.

Figura 32: Filmes automontados, variando o número de bicamadas de 2 a 10 bicamadas. 
Figura 33: Espectro FT-IR, das amostras de PAMAM-G4, filme de 10 bicamadas de PAMAM-G4/GO e GO.

Figura 34: Microscopia de força atômica de filmes PAMAM-G4/GO: A) filme de 1 bicamada $10 \times 10 \mu \mathrm{m} \mathrm{b}) 1$ bicamada área $3 \times 3 \mu \mathrm{m} \mathrm{C}$ ) filme de 3 bicamadas $10 \times 10 \mu \mathrm{m}$ D) 3 bicamadas área $3 \times 3 \mu \mathrm{m}$. 89

Figura 35: Histogramas: A) Número de pixels em função da altura, referente a figura 34.B. B) Distribuição de alturas de um conjunto de 50 folhas de GO presente na figura 34.A. C) Distribuição de comprimento no eixo X. D) Distribuição de comprimento no eixo y................................................... 90

Figura 36: Esquema da montagem do experimento de potenciometria. .92

Figura 37: A) Curvas de resposta do sistema em função do tempo. B) Sensibilidade do filme de GO em ITO.

Figura 38: Sensibilidade em função do tempo para ITO limpo e um filme de três bicamadas de PAMAM-G4/GO. .93

Figura 39: A) Curvas de resposta do sistema em função do tempo. B) Sensibilidade do filme para 5 bicamadas................................................ 94

Figura 40: Resposta da sensibilidade em função do número de bicamadas de PAMAM-G4/GO. .95

Figura 41: Comparação do modulo da sensibilidade ente um filme de duas bicamadas e cinco bicamadas ao longo do tempo. .96

Figura 42: Repetibilidade do sistema GO/PAMAM-G4, a variação e $\mathrm{pH}$ de um $\mathrm{pH}$ básico para um $\mathrm{pH}$ ácido e na direção de um $\mathrm{pH}$ ácido para um $\mathrm{pH}$ básico...97 



\section{LISTA DE TABELAS}

Tabela 1: Principais técnicas de fabricação de grafeno, adaptado da referência $(51)$ 36

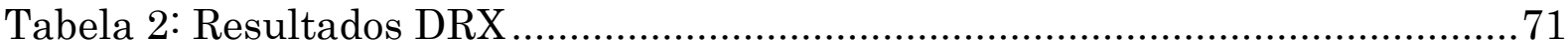

Tabela 3: Bandas presentes no grafeno oxidado........................................... 73

Tabela 4: Dados provenientes dos espectros Raman no centro do GO e em suas

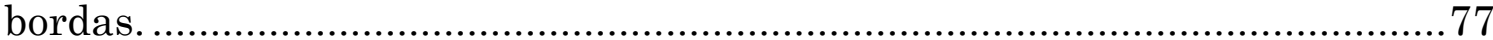

Tabela 5: Bandas referentes ao PAMAM-G4, filme PAMAM-G4/GO e GO.........88

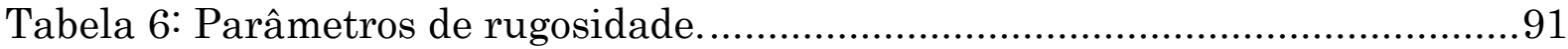





\section{LISTA DE ABREVEATURAS SIGLAS}

$\begin{array}{ll}\text { AFM } & \text { Atomic force microscopy } \\ \text { Ag/AgCl } & \text { Prata/Cloreto de Prata } \\ \text { CA } & \text { Corrente alternada } \\ \text { CC } & \text { Corrente continua } \\ \text { CdSe } & \text { Seleneto de Cádmio } \\ \text { CHEMFET } & \text { Chemical field-effect transistor } \\ \text { CMMR } & \text { Common mode rejection ratio } \\ \text { CVD } & \text { Chemical vapor deposition } \\ \text { DLC } & \text { Diamond Like Carbon } \\ \text { DRX } & \text { Difração de raios-x } \\ \text { EDQ } & \text { Eletrodinâmica Quântica } \\ \text { EDS } & \text { Espectroscopia de raios X por dispersão em energia } \\ \text { EGFET } & \text { Extended-Gate-Field-Effect-Transistor } \\ \text { ELbL } & \text { Electrostatic Layer-by-layer } \\ \text { EnFET } & \text { Enzymatic field-effect transistor } \\ \text { FT-IR } & \text { Fourier transform infrared spectroscopy } \\ \text { FWHM } & \text { Full Width Half Maximum } \\ \text { GO } & \text { Grafeno Oxidado } \\ \text { GO-ST } & \text { Grafeno Oxidado sem tratamento } \\ \text { GO-T } & \text { Grafeno Oxidado Tratado } \\ \text { GQR } & \text { Grafeno quimicamente reduzido } \\ \text { ISFET } & \text { Ion-Sensitive-Field-Effect-Transistor } \\ \text { ITO } & \text { Óxido de Índio dopado com Estanho } \\ \text { IUPAC } & \text { International Union of Pure and Applied Chemistry } \\ \text { MET } & \text { Microscopia eletrônica de tunelamento } \\ \text { MOSFET } & \text { Metal-oxide-semiconductor-FET } \\ \text { NMR } & \text { Ressonância magnética nuclear } \\ \text { OCP } & \text { Open Circuit Potential } \\ \text { PAMAM } & \text { Dendrímero poli(amidoamina) } \\ \text { pH } & \text { Potencial hidrogeniônico } \\ \text { pKa } & \text { Constante de dissociação ácida } \\ \text { q } & \text { Fator de crescimento } \\ \text { Ra } & \text { Rugosidade média } \\ & \end{array}$


Rg

$\mathrm{R}_{\mathrm{rms}}$

UV-vis

WSN
Resistor de ganho

Rugosidade média quadrática

Ultraviolet spectroscopy

Wireless Sensor Network 


\section{Sumário}

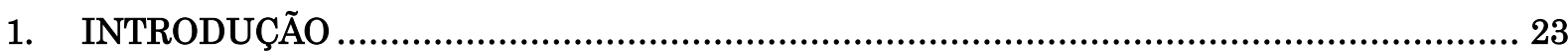

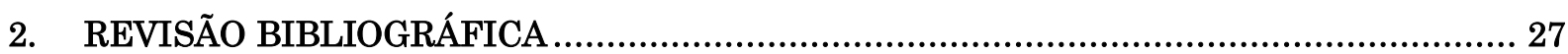

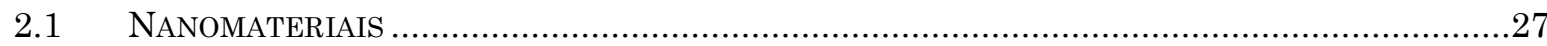

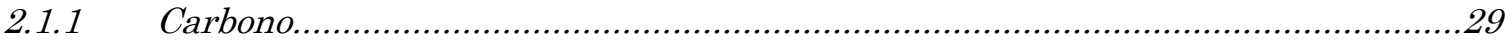

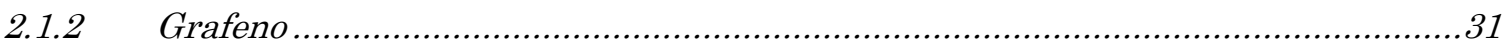

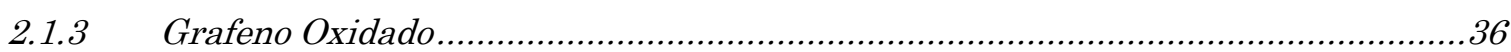

2.2 PROCESSAMENTO DE NANOMATERIAIS NA FORMA DE FILMES...........................................

2.2.1 Filmes automontados do tipo "Electrostatic Layer-by-layer " (ELBL) ....................38

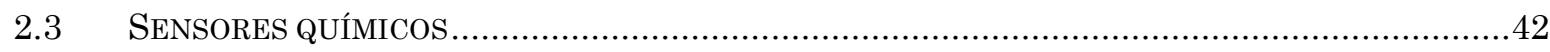

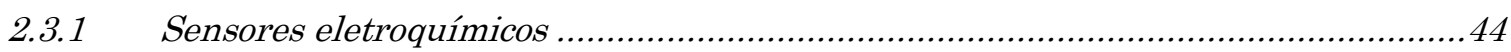

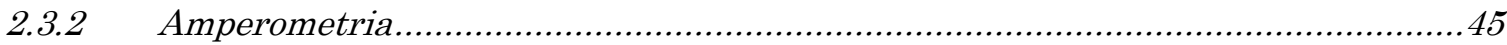

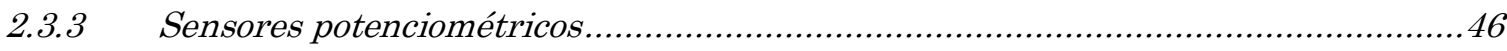

2.3.4 Transistor de efeito de campo sensível a íons........................................................48

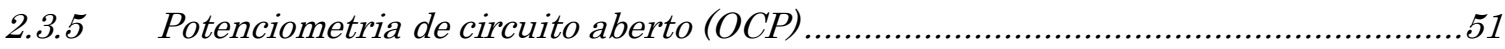

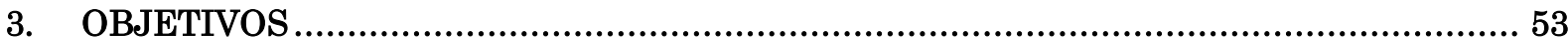

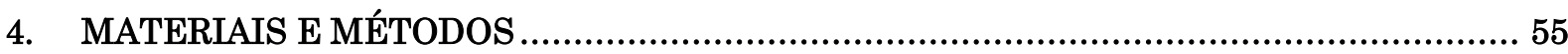

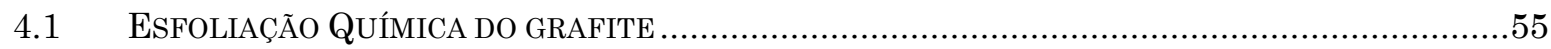

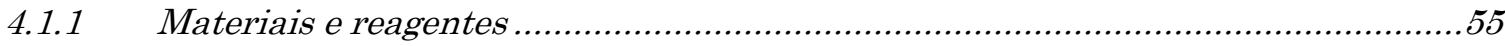

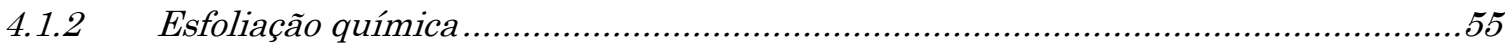

4.1.3 Preparação das amostras para caracterização e crescimento dos filmes...................56

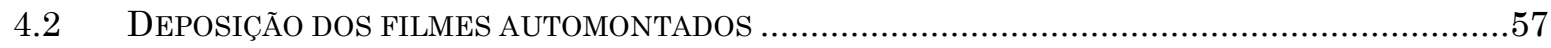

4.2.1 Materiais utilizados no crescimento dos filmes automontados ............................57

4.2.2 Processamento de filmes automontados........................................................57

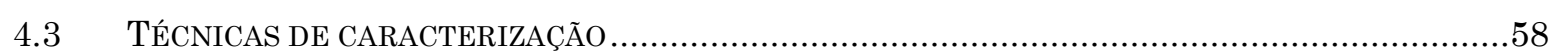

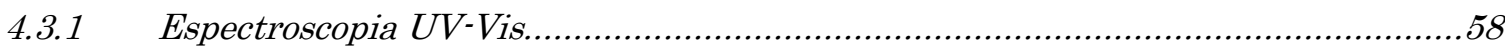

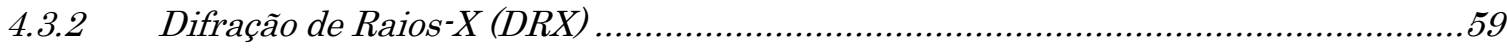

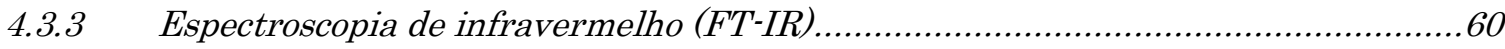

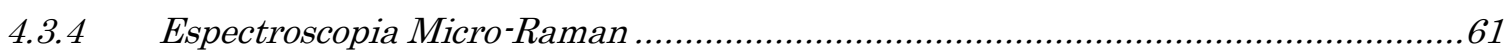

4.3.5 Energia dispersiva de espectroscopia de raios $X(E D S)$.......................................61

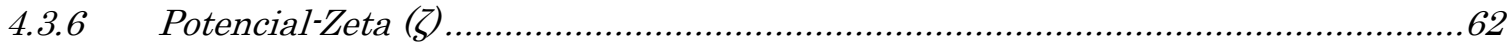

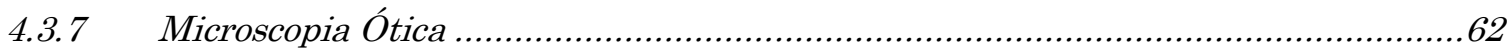

4.3.8 Microscopia de Força Atômica (AFM).................................................................... 63

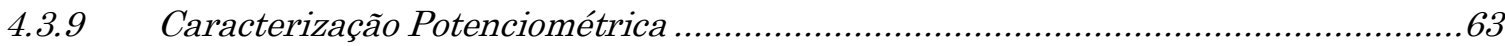

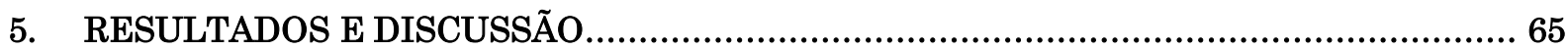

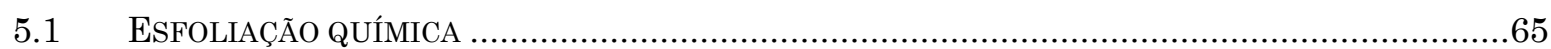




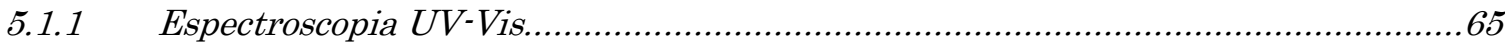

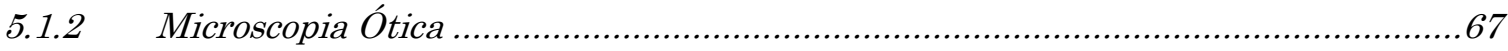

5.1.3 Espectroscopia de raios X por dispersão em energia (EDS) .................................68

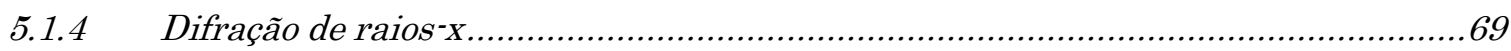

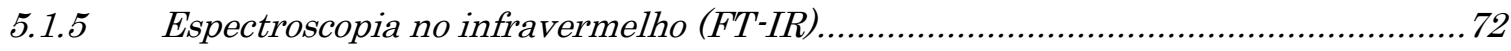

5.1.6 Espectroscopia Raman por mapeamento......................................................... 74

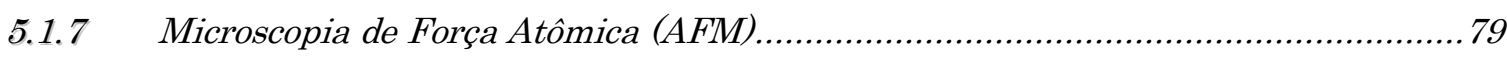

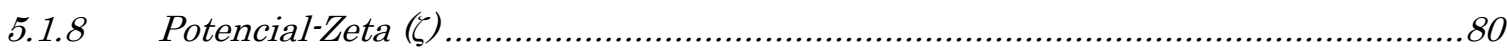

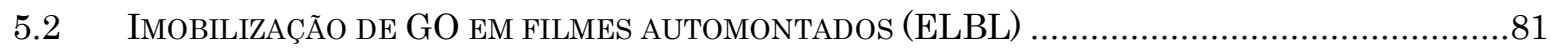

5.2.1 Monitoramento da adsorção de filmes automontados por $U V$-Vis ..........................81

5.2.2 Espectroscopia FT-IR dos filmes automontados................................................86

5.2.3 Microscopia de força atômica dos filmes automontados .........................................89

5.3 APLICAÇÃO DE FILMES AUTOMONTADOS DE PAMAM-G4/GO COMO SENSORES

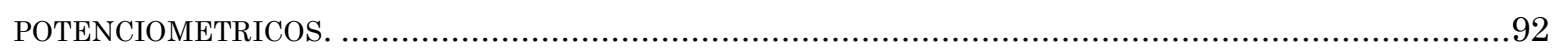

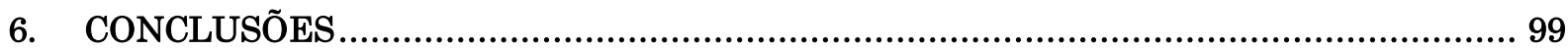

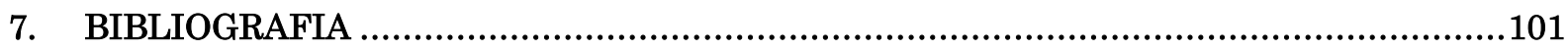




\section{Introdução}

Desde a famosa idéia de Richard Feymann, sobre a possibilidade de se escrever os vinte e quatro volumes da enciclopédia Britânica na cabeça de um

alfinete (1), pesquisas em nanociências e nanotecnologia tem se tornado o principal foco nas ultimas décadas. E o fruto desses trabalhos já se encontra inserido no nosso cotidiano, desde aparelhos eletrônicos, cosméticos, terá pêuticos, sensores e biossensores (2-7).

Além de estudos das propriedades de materiais já conhecidos, mas em escala nanométrica, como as nanopartículas metálicas (2). Houve também a descoberta de novos materiais e novas propriedades, como é o caso dos polímeros intrinsecamente condutores (8), e novas formas alotrópicas do carbono, como os fulerenos, nanotubos de carbono, e mais recentemente, o grafeno (9-11).

A capacidade de formar materiais estáveis, com hibridizações diferentes permite ao carbono formar compostos com inúmeras dimensionalidades, o que proporciona propriedades incríveis, superando todos os outros materiais, e que vêm sendo estudadas e aplicadas desde o final do século passado. Se o século XX foi a era do silício, esta será a idade do carbono, estando presentes em quase todas as áreas de conhecimento.

Dentre as formas alotrópicas do carbono, o grafeno merece destaque. Este material consiste de uma monocamada atômica de carbono $\mathrm{sp}^{2}$, disposta em uma rede bidimensional cristalina hexagonal, semelhante a um favo de mel. Esta é considerada a "mãe" de todas as formas do carbono, pois a partir de uma folha, é possível obter todas as outras formas (12). Com o grafeno foi possível compreender as propriedades de baixa dimensão, abrindo possibilidades na fabricação de dispositivos eletrônicos, e também mostrou à possibilidade de substituição de dispositivos a base de silício na eletrônica(13). Algumas propriedades fascinantes são encontradas nesse material, como o efeito Hall quântico inteiro em temperatura ambiente, aproximação adiabática BornOppenheimer, paradoxo de Klein e supercondutividade (12-16). Foi obtido pela primeira vez em 2004 por um grupo em Manchester, pelo método de microesfoliação mecânica (11). Os pesquisadores responsáveis pela descoberta 
foram agraciados com o prêmio Nobel em 2010, evidenciando o grande progresso na área.

Desde sua descoberta, vários esforços foram feitos para obtenção de grafeno, equilibrando sempre, a qualidade das amostras, com o custo operacional de obtenção. Uma dessas formas é a esfoliação química, que consiste da produção de grafeno a partir de grafite policristalino, em um ambiente altamente oxigenado, formando um produto intermediário, denominado grafeno oxidado (GO) (17). Por este método, gera-se um produto altamente estável e solúvel em água, podendo ser utilizado na obtenção de filmes ultrafinos, complexação com biomoléculas, super-capacitores, entre outras aplicações (18-20).

Uma das aplicações possíveis do grafeno oxidado é em sensoriamento. Este é um campo de pesquisa vasto, onde ainda é necessário o estudo de aplicações de novos materiais que viabilizem o sensoriamento rápido, preciso, seletivo e de baixo custo, principalmente os do tipo "point of care". O grafeno é um forte candidato, nessa área, devido a sua alta performace e seu baixo custo de processamento.

Com técnicas de adsorção de filmes ultrafinos, do tipo electrostatic layerby-layer (ELBL) é possível obter filmes nanoestruturados, de baixo custo, grande facilidade de construção e reprodutibilidade, e com a possibilidade de produção em escala industrial. Esta técnica utiliza o principio físico de interação entre dois eletrólitos de cargas opostas, uma solução catiônica e uma polianiônica (21). Diversos trabalhos já foram publicados sobre a construção de sensores e biossensores utilizando essa técnica, comprovando a sua eficiência e facilidade de uso.

Este trabalho consistiu da obtenção de grafeno oxidado pela esfoliação química do grafite e sua caracterização físico-química. A técnica ELBL foi utilizada na construção de filmes de grafeno oxidado, juntamente com o policátion dendritico poli(amidoamina) (PAMAM-G4) para aplicação como sensor de pH em uma plataforma potenciométrica. Um amplificador de instrumentação comercial, AD620, foi utilizado como transdutor na determinação da sensibilidade a mudanças de $\mathrm{pH}$ do dispositivo em estudo, mostrando que o sistema PAMAM- 
G4/GO, é altamente sensível, sendo possível a utilização em sensores do tipo "point of care" e plataformas de imobilização enzimáticas. 


\section{Revisão bibliográfica}

\subsection{Nanomateriais}

Nanomateriais são definidos pelas suas dimensões, onde pelo menos uma encontra-se em escala nanométrica. Segundo o documento da comissão europeia de 18 de outubro de 2010 (22), um nanomaterial consiste de “.. Por "nanomaterial», entende-se um material natural, incidental ou fabricado, que contém partículas num estado desagregado ou na forma de um agregado ou de um aglomerado, e em cuja distribuição, número, tamanho, 50 \% ou mais das partículas têm uma ou mais dimensões externas na gama de tamanhos compreendidos entre $1 \mathrm{~nm}$ e $100 \mathrm{~nm}$ ".

Dois principais fatores são os responsáveis pelas novas ou melhores propriedades dos materiais quando estes estão em escala nanométrica: efeitos de superfície e confinamento quântico (23). O primeiro, diz respeito à quantidade de átomos superficiais, onde a relação área/volume, aumenta à medida que o tamanho diminui, deixando um número maior de átomos expostos, tornando o mais reativo. Um exemplo deste fenômeno é a diminuição do ponto de fusão do ouro quando este material esta em nanoescala. Neste caso uma partícula de menor tamanho resulta em um número maior de átomos em sua superfície (23). Já os efeitos quânticos podem ser observados nos chamados "quantum dots", que são nanopartículas com alguns poucos nanômetros, que tem uma distribuição do par elétron-buraco ao longo das três dimensões. Estas nanopartículas se comportam como átomos individuais, ou seja, seus espectros de energia são quantizados e dependem do tamanho das partículas. Estes efeitos podem ser observados, por exemplo, em nanopartículas semicondutoras de Seleneto de Cádmio (CdSe), que exibem um espectro de fluorescência dependente do tamanho (24). 


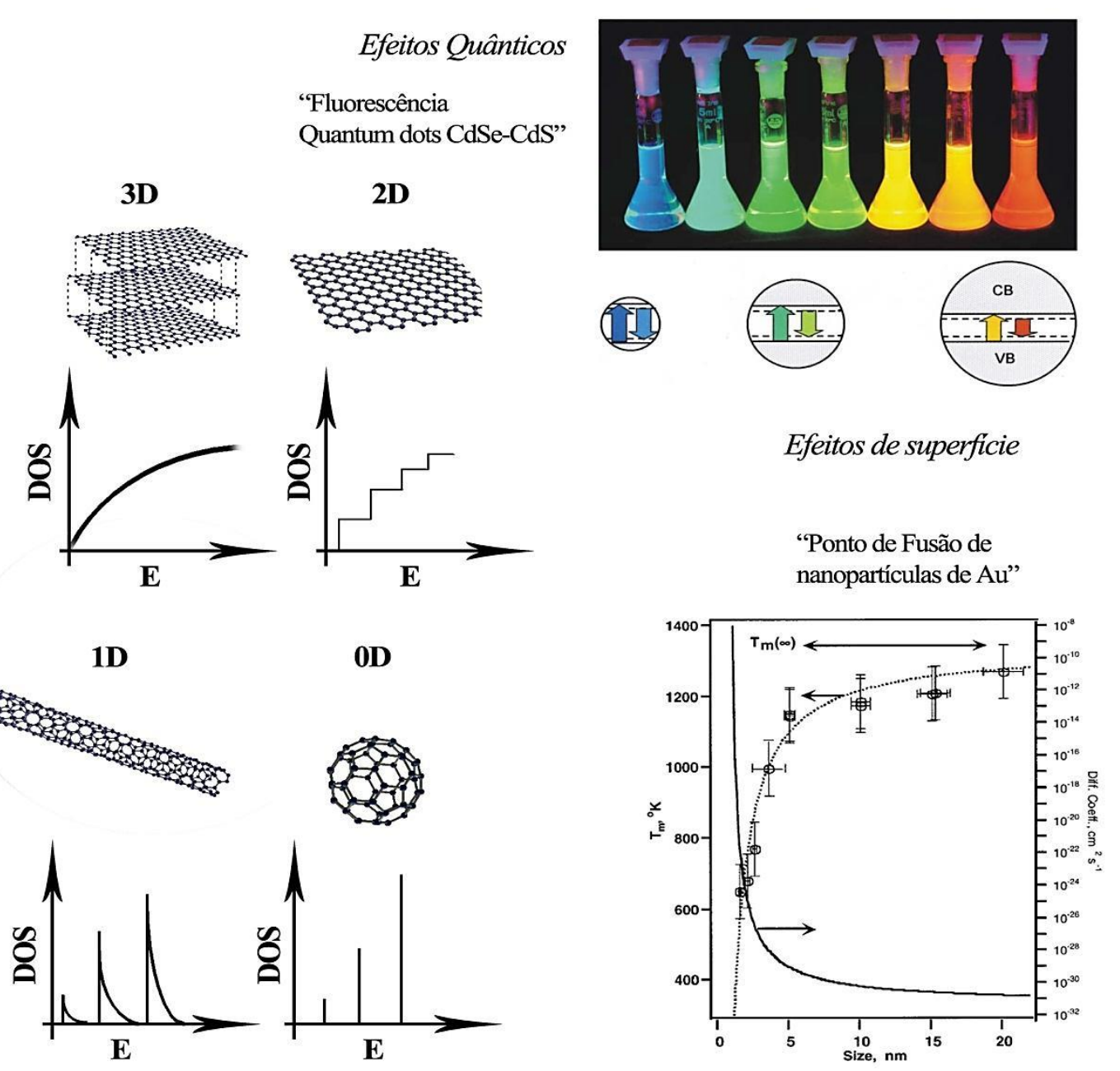

Figura 1: Exemplos de efeitos quânticos e superficiais de nanopartículas, dimensões possíveis, 0D, 1D, 2D e 3D, imagem adaptada das referências, [24-26]

A Figura 1 exibe alguns exemplos de nanomateriais e efeitos que ocorrem nesta escala. Também ilustra as densidades de estado em função da energia, segundo as dimensões em casos ideais, definindo-as como, zero dimensional (0D), unidimensional (1D), bidimensional (2D) e tridimensional (3D). 


\subsubsection{Carbono}

O carbono é um dos materiais de importância vital para todos os seres vivos e um dos mais abundantes na natureza, apresentando-se em diversas formas. O que dá a este material essa diversidade de estados é uma propriedade conhecida como alotropia, que consiste na formação de materiais do mesmo elemento, mas com configurações estruturais diferentes, devido à hibridização dos orbitais moleculares $\left(\mathrm{sp}^{1}, \mathrm{sp}^{2}, \mathrm{sp}^{3}\right)$.

No estado fundamental, o carbono apresenta seis elétrons ocupando os estados $1 \mathrm{~s}^{2}, 2 \mathrm{~s}^{2}, 2 \mathrm{p}^{2}$, onde o orbital $1 \mathrm{~s}$ tem os elétrons mais próximos do núcleo, apresentando uma forte ligação com o núcleo. Já os outros dois orbitais, $2 \mathrm{~s}^{2}$ e $2 \mathrm{p}^{2}$, contêm os elétrons de valência, tendo uma fraca ligação com o núcleo. Estes orbitais, $2 \mathrm{~s}$ e $2 \mathrm{p}$, conferem ao carbono a capacidade de hibridizar, ou seja, de formar diferentes tipos de ligações covalentes, chamadas de sp, $\mathrm{sp}^{2} \mathrm{e} \mathrm{sp}^{3}$.

$\mathrm{Na}$ hibridização $\mathrm{sp}^{3}$, o orbital $2 \mathrm{~s}$ funde-se aos três orbitais $2 \mathrm{p}$, originando quatro orbitais híbridos $\mathrm{sp}^{3}$ idênticos (ligações $\sigma$ ). Cada um dos orbitais se orienta segundo os vértices de um tetraedro regular, formando um ângulo entre ligações de $109^{\circ} 28^{\prime}$ s. Já a configuração $\mathrm{sp}^{2}$ é a combinação de um orbital $2 \mathrm{~s}$ com dois $2 \mathrm{p}$ resultando em três híbridos $\mathrm{sp}^{2}(1 \pi$ e $3 \sigma)$, que formam um ângulo de $120^{\circ}$ entre as ligações. Por fim, a hibridização sp é feita pela combinação do orbital $2 \mathrm{~s}$ e um $2 \mathrm{p}$, que forma dois híbridos $\mathrm{sp}$ e dois orbitais $2 \mathrm{p}(2 \pi$ e $2 \sigma)$. A Figura 2, ilustra a formação desses orbitais.
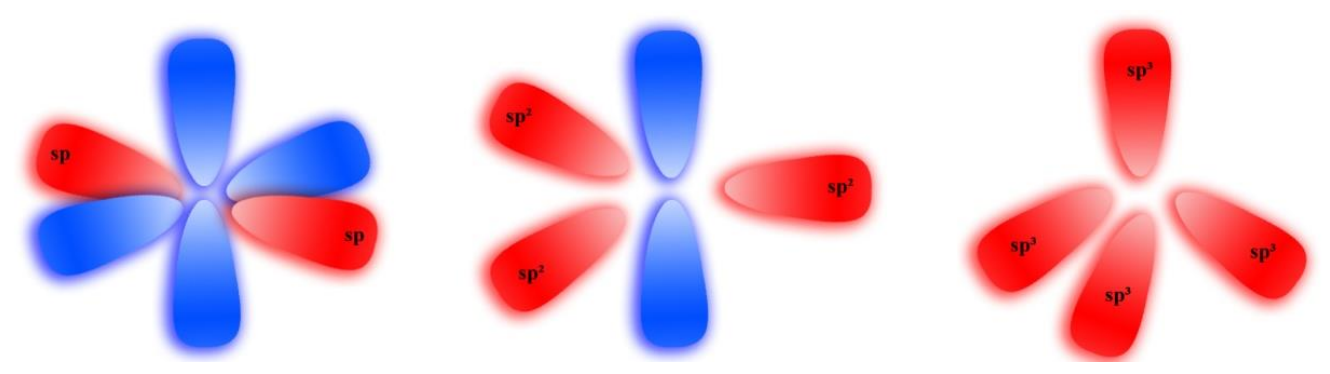

Figura 2: Tipos de hibridização possíveis para o carbono, a) hibridização sp, b) hibridização sp², c) hibridização $\mathrm{sp}^{3}$. 
Devido à capacidade do carbono de formar diferentes ligações, têm-se materiais constituídos do mesmo elemento, mas com propriedades totalmente diferentes. Esse é o caso do diamante, um material transparente, e o elemento mais duro encontrado na natureza, e o último elemento da escala de Mohs, além do seu uso em ornamentação. Já o grafite é um material escuro e muito macio, usado em lápis e também como lubrificante.

Quando se fala em materiais a base de carbono, estes citados acima são os mais comumente lembrados, mas nas últimas décadas, observou-se a descoberta de uma gama enorme de materiais em suas diferentes formas, mudando apenas a geometria e o tipo de ligação entre os carbonos. Os mais diferentes materiais foram encontrados e sintetizados, como os fulerenos, nanotubos de carbono e diamante amorfo (DLC, Diamond Like Carbon), todos com propriedades bem distintas $(9,10,25,26)$.

O nanotubo de carbono, em particular, foi um dos materiais mais estudados desde seu descobrimento, devido às suas propriedades antes nunca imaginadas para materiais convencionais, como a condutividade balística, excepcionais propriedades mecânicas e óticas, com aplicações nas mais diversas áreas do conhecimento. Publicações recentes mostram aplicações como efeito miragem (27), músculo artificial (28) e uma balança capaz de pesar um único próton, ou seja, um yoctograma $\left(10^{-24} \mathrm{~g}\right)(29)$.

Esses novos materiais vieram com a promessa de novas aplicações e novas tecnologias para os materiais a base de carbono. Muito se estudou e hoje já há muitas informações a respeito desses materiais, mas ainda restava a descoberta de um novo material, o que pode ser considerado o precursor de todas as formas dos materiais a base de carbono: o grafeno (12). 


\subsubsection{Grafeno}

Desde os anos de 1935 e 1937, com os trabalhos de Peierls e Landau (30, 31), sabia-se da impossibilidade de formação de materiais bidimensionais, uma vez que seriam termodinamicamente instáveis. Fradkin em 1986, ainda demonstrou estas instabilidades térmicas e determinou algumas de suas propriedades teoricamente, e declarou o "grafite" 2D como um material acadêmico, servindo somente para demonstrações teóricas (32, 33). Mas em 2004 o grupo de Geim e Novoselov conseguiu isolar uma monocamada atômica de carbono. Utilizando apenas fita adesiva, depositaram flocos de grafite em um Wafer de $\mathrm{SiO}_{2} / \mathrm{Si}$ e através de um microscópio ótico foi possível localizar camadas isoladas de grafeno (11). Assim ocorreu o primeiro estudo das propriedades do grafeno, as quais já haviam sido determinadas antes mesmo do seu isolamento. Na Figura 3 vemos as três formas que têm como origem uma folha de grafeno.

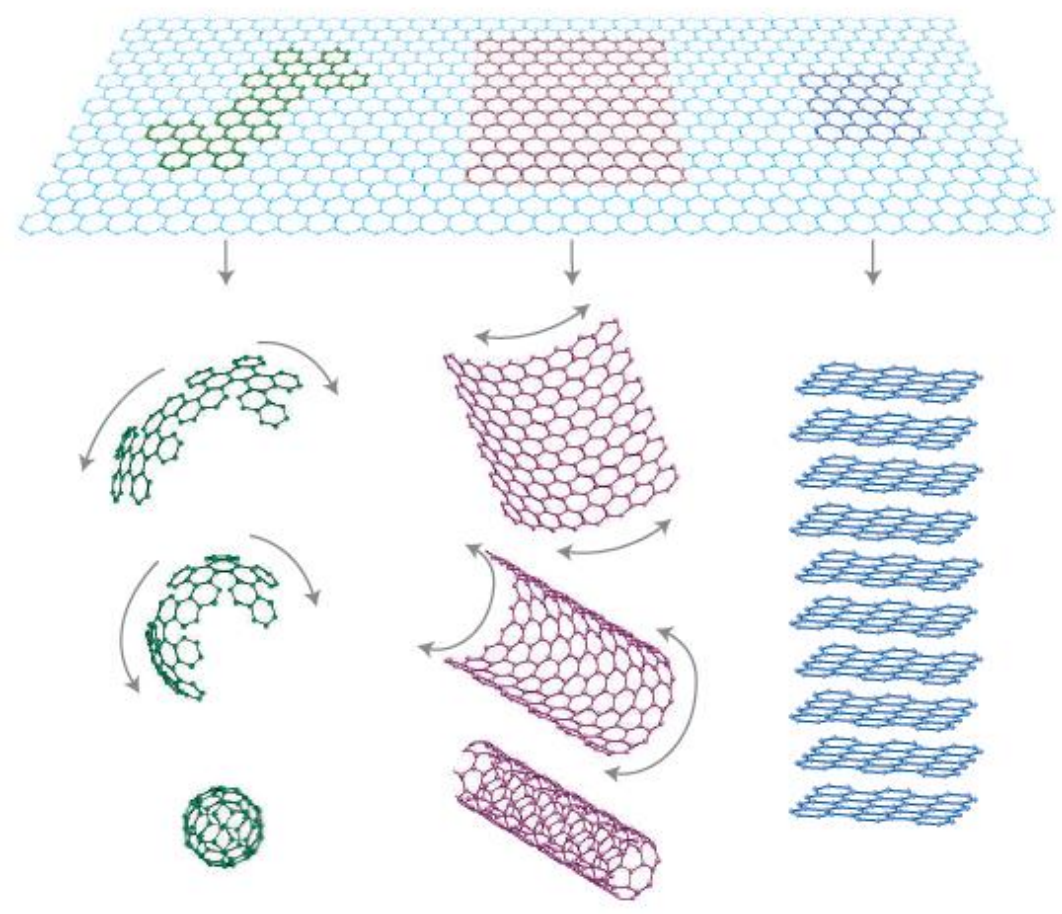

Figura 3: Grafeno, a mãe das formas grafíticas, onde temos a formação de fulerenos, nanotubos e grafite, figura retirada da referência (12).

O grafeno, como material bidimensional, apresenta algumas propriedades de grande interesse científico e de aplicações nanotecnológicas. Algumas dessas 
propriedades ultrapassam as de qualquer outro material conhecido, como uma de suas mais notáveis, o transporte balístico de cargas, cuja mobilidade consegue chegar próximo dos $200.000 \mathrm{~cm}^{2} / \mathrm{V} . \mathrm{s}$ (34). Também foi demonstrado que o grafeno pode atuar como um transistor, conseguindo operar em torno de $300 \mathrm{GHz}$. Os autores ainda afirmam a possibilidade de se elevar essa frequência de operação a casa dos $\mathrm{THz}$, levando־o a um possível candidato a suceder o silício na eletrônica (35). Na Figura 4, tem-se uma amostra de grafeno micro esfoliada no nosso grupo, onde é possível visualizar diferentes camadas por microscopia de força atômica.

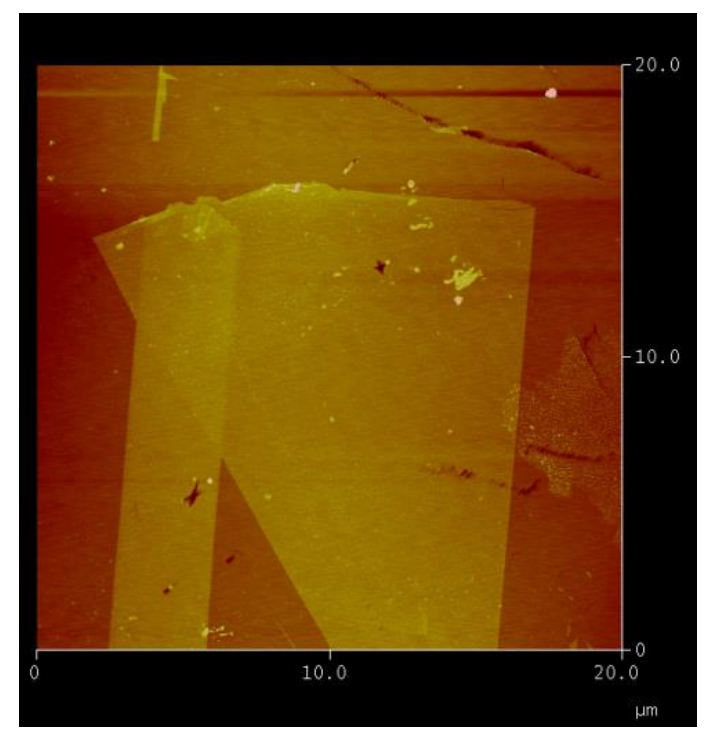

Figura 4: Grafeno esfoliado mecanicamente.

Outras aplicações já foram demonstradas e o seu uso está inserido em diversas áreas do conhecimento, incluindo a comprovação de muitos fenômenos físicos teorizados pela eletrodinâmica quântica (EDQ). Desde sua primeira publicação em 2004, o número de trabalhos envolvendo a palavra "graphene" aumentou exponencialmente (segundo web of Science (36)), evidenciando a grande importância que este material possui, na Figura 5. 


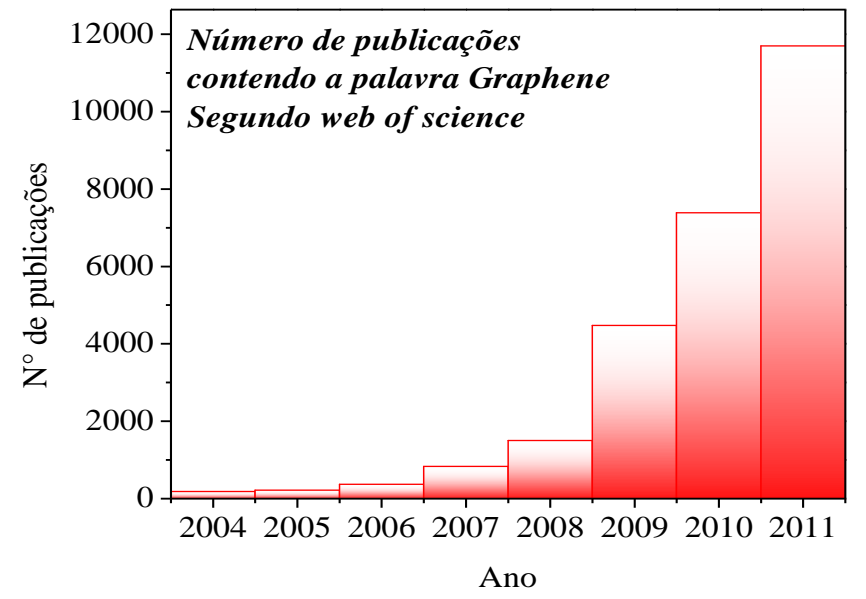

Figura 5: Número de publicações contendo a palavra graphene, dados obtidos pelo portal web of Science (36).

As propriedades do grafeno estão relacionadas à estrutura eletrônica, formada por uma rede bidimensional hexagonal de átomos de carbono $\mathrm{sp}^{2}$, semelhante a um favo de mel. Na Figura 6, tem-se a estrutura do grafeno formada por uma célula unitária com dois átomos (A e B), onde cada tipo forma uma sub-rede triangular (37).
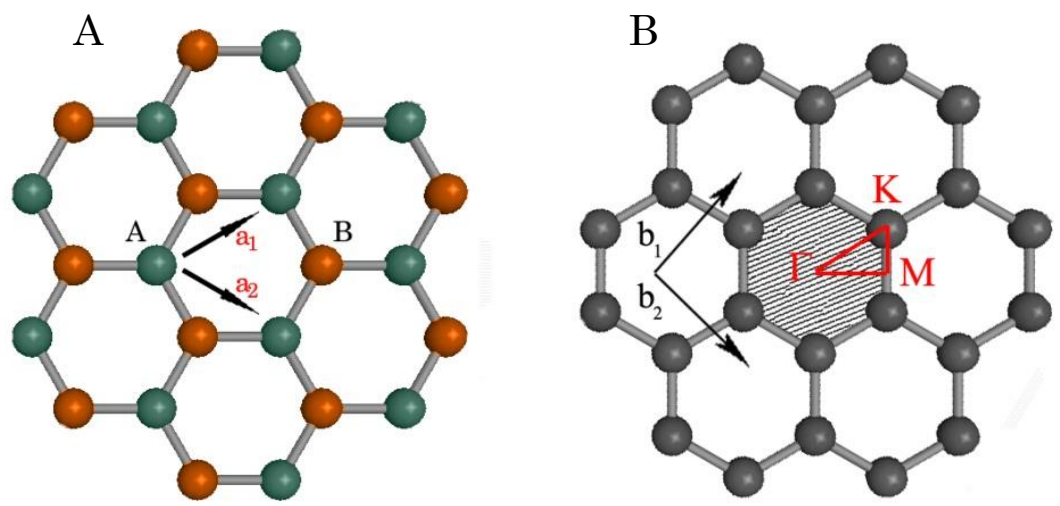

Figura 6: Estrutura cristalina do grafeno: A) Há duas redes Bravais, indicadas pelas cores laranja e verde, onde $\mathrm{a}_{1}$ e $\mathrm{a}_{2}$ são vetores da rede recíproca. $\mathrm{B}$ ) Rede recíproca da rede real em A, onde a região hachurada é a primeira zona de Brillouin e $b_{1}$ e $b_{2}$ os vetores da rede recíproca.

Os vetores unitários $\vec{a}_{1}, \vec{a}_{2}, \vec{b}_{1}, \vec{b}_{2}$ podem ser escritos da seguinte forma:

$$
\vec{a}_{1}=\frac{a_{0}}{2}\left(3, \sqrt{3)}, \vec{a}_{2}=\frac{a_{0}}{2}(3,-\sqrt{3)}\right.
$$




$$
\vec{b}_{1}=2 \pi\left(\frac{1}{\sqrt{3 a_{0}}}, \frac{1}{a_{0}}\right), \vec{b}_{2}=2 \pi\left(\frac{1}{\sqrt{3 a_{0}}},-\frac{1}{a_{0}}\right)
$$

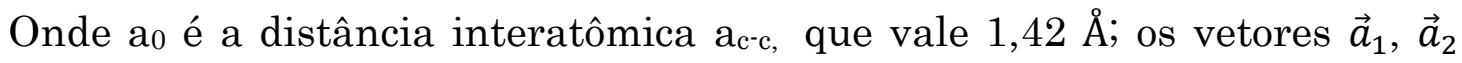
são os vetores do espaço real, enquanto os vetores $\vec{b}_{1}, \vec{b}_{2}$ são os vetores da rede recíproca.

Conhecer a estrutura eletrônica do grafeno é de fundamental necessidade para se entender suas propriedades. O grafeno possui seus orbitais $s, p_{\mathrm{x}}$ e $p_{\mathrm{y}}$ em hibridização $\mathrm{sp}^{2}$, os quais formam ligações $\boldsymbol{\sigma}$ extremamente fortes com o plano da folha de grafeno. Já os orbitais $\mathrm{p}_{z}$ formam as ligações do tipo $\pi$, sendo esse tipo de ligação que confere as propriedades eletrônicas excepcionais desse material. A partir da rede recíproca, com o triângulo $\Gamma \mathrm{MK}$, utilizando cálculos de tight-binding, obtém-se a dispersão de energias para os primeiros vizinhos, mostrado na Figura 7.
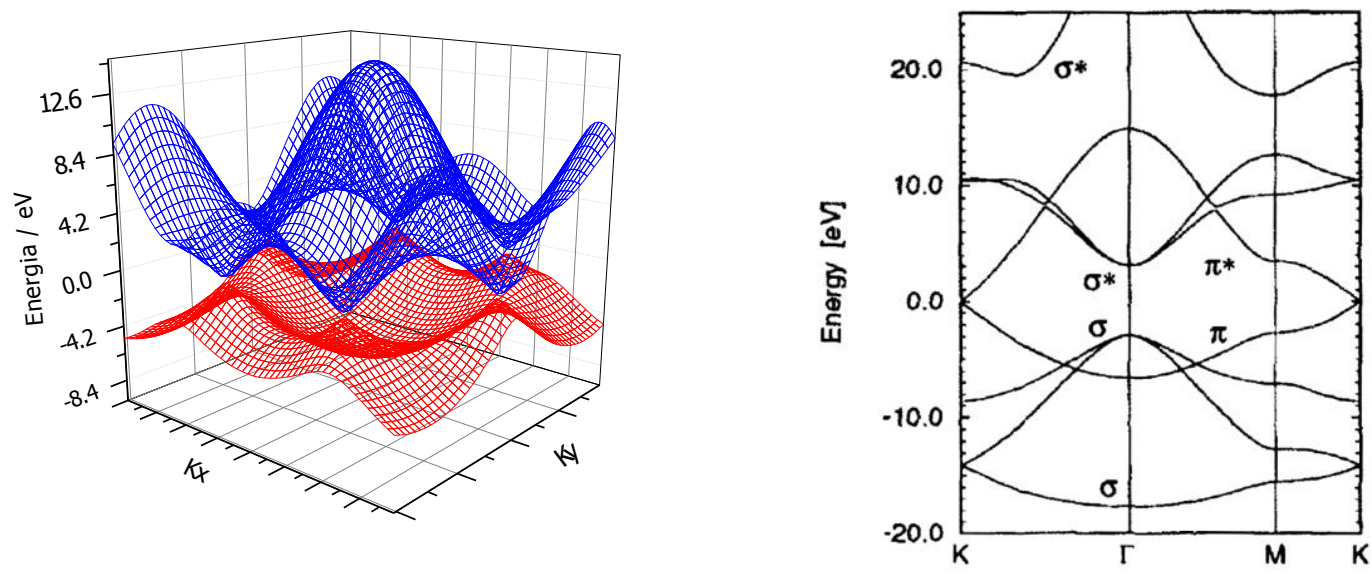

Figura 7: A) Representação da dispersão de energias das bandas $\pi$ e $\pi^{*}$, figura adaptada da referência (38), representação $2 \mathrm{D}$ da figura $\mathrm{A}$.

Na Figura 7 pode-se observar que as bandas $\boldsymbol{\pi} e \boldsymbol{\pi}^{*}$ tocam-se no ponto $\mathbf{K}$, e a existência de energia igual à zero neste ponto faz com que o grafeno seja um semimetal de bandgap zero (38).

As propriedades do grafeno também estão intimamente ligadas à cristalinidade de sua estrutura atômica e a interação com o substrato. $\mathrm{O}$ primeiro método utilizado na obtenção de folhas isoladas de grafeno foi o método de esfoliação micromecânica, utilizando uma fita adesiva (11), mas este método é 
pouco reprodutível, produzindo folhas de diferentes tamanhos e de espessura variável. É portanto, um método pouco eficiente para produção em larga escala e inviável em aplicações eletrônicas.

Novas técnicas foram criadas a fim de obter amostras em grande escala, reprodutíveis e de boa qualidade. E uma dessas técnicas foi o crescimento epitaxial em substrato de Carbeto de Silício (SiC). Dessa forma, foi possível obter alguns dispositivos, como transistores de alta velocidade e com capacidade de integração com a eletrônica (39-41).

Outra técnica largamente utilizada é o crescimento por deposição química a vapor em substratos metálicos. Alguns desses elementos são: Níquel (42), Rubídio (43), Irídio (44) e Cobre (45). Esta técnica possibilitou o crescimento de monocamadas de alta qualidade de até trinta polegadas, para aplicação em painéis sensíveis ao toque (46).

Já se sabia, desde o século XIX, que era possível oxidar o grafite na presença de ácidos fortes e oxidantes (47-49), cuja reação gera uma solução coloidal de folhas de grafeno oxidado, que já haviam sido identificadas em 1962 pelo alemão H. P. Boeh (50). No entanto, estudos das propriedades e aplicações não tinham sido exploradas até então. Somente em 2006 houve novamente interesse no grafite oxidado com potencial para produção de grafeno. Utilizando a redução do grafite oxidado na presença de um redutor forte, como Hidrazina (17), é possível obter monocamadas desse material.

Assim como nos outros métodos descritos, as propriedades do material estão ligadas ao seu método de fabricação. O grafeno quimicamente reduzido (GQR) possui propriedades eletrônicas inferiores aos obtidos por outros métodos, mas isso não o exclui de ter aplicações em nanotecnologia, uma vez que algumas de suas propriedades são de interesse em determinadas áreas.

Existem outras técnicas utilizadas na produção de grafeno, mas serão apresentadas na Tabela 1 as principais, e as que foram descritas anteriormente. 
Tabela 1: Principais técnicas de fabricação de grafeno, adaptado da referência (51).

\begin{tabular}{ccccc}
\hline Método & $\begin{array}{c}\text { Esfoliação } \\
\text { mecânica }\end{array}$ & $\begin{array}{c}\text { Redução } \\
\text { química }\end{array}$ & $\begin{array}{c}\text { Crescimento } \\
\text { epitaxial em SiC }\end{array}$ & $\begin{array}{c}\text { CVD em } \\
\text { Metais }\end{array}$ \\
\hline Tamanho & $10 \sim 100$ & $>6 ”$ & $<{ }^{\prime \prime}$ & Alta \\
\hline Mobilidade & Alta & Baixa & Alta & Sim \\
\hline Transferência & Sim & Sim & Não & Sim \\
\hline Aplicação & Não & Sim & Sim & \\
\hline $\begin{array}{c}\text { Produção em larga } \\
\text { escala }\end{array}$ & Não & Sim & & \\
\hline
\end{tabular}

\subsubsection{Grafeno Oxidado}

Como descrito no tópico anterior, o grafeno oxidado pode ser produzido através da oxidação do grafite. Suas propriedades são diferentes daquelas apresentadas para o grafeno cristalino, o que o torna um novo material. A primeira e mais evidente diferença entre os dois materiais é a condutividade: o grafeno na sua forma cristalina possui altíssima condutividade, enquanto o oxidado é um isolante (52). Essa característica se deve aos defeitos introduzidos na rede devido à oxidação, como ligações de ácidos carboxílicos, cetonas, hidroxilas, epóxidos e água adsorvida na estrutura do material. Esses defeitos introduzem ligações do tipo $\mathrm{sp}^{3}$, deixando a estrutura rugosa e com dobras, diminuindo assim a mobilidade eletrônica.

Como demonstrado na literatura, pela redução do grafeno na presença de um redutor forte, ou utilizando redução térmica, ou ainda a redução com esses dois processos simultaneamente, é possível restaurar parte de sua estrutura tornando־o condutor, mas ainda sem as qualidades de um grafeno mecanicamente esfoliado ou depositado por CVD (53).

Assim como o grafeno mecanicamente esfoliado, também é de vital importância entender e compreender a estrutura eletrônica do grafeno oxidado. 
$\mathrm{Na}$ literatura, alguns estudos usando NMR (54) e espectroscopia no infravermelho (55) já haviam determinado ligações de grupos funcionais contendo oxigênio e hidrogênio no grafite oxidado, e estas mesmas ligações podem ser estendidas para o grafeno oxidado.

Lerf e col. utilizando ressonância nuclear magnética determinaram a presença de grupos epóxidos em substituição às ligações $\mathrm{C}=\mathrm{C}$ e grupos hidroxilas ligados nos vértices dos anéis aromáticos formando quatro ligações $\mathrm{sp}^{3} \mathrm{e}$ em suas bordas, a formação de grupos de ácidos carboxílicos (56). Esses resultados foram comprovados por microscopia de tunelamento (STM), onde mostraram a presença de átomos de oxigênio ligados periodicamente no meio da estrutura do grafeno oxidado, formando uma rede periódica retangular (57).

$\mathrm{Na}$ Figura 8, verifica-se um modelo da estrutura química do grafeno oxidado, mostrando seus grupos funcionais e sua estrutura tridimensional.

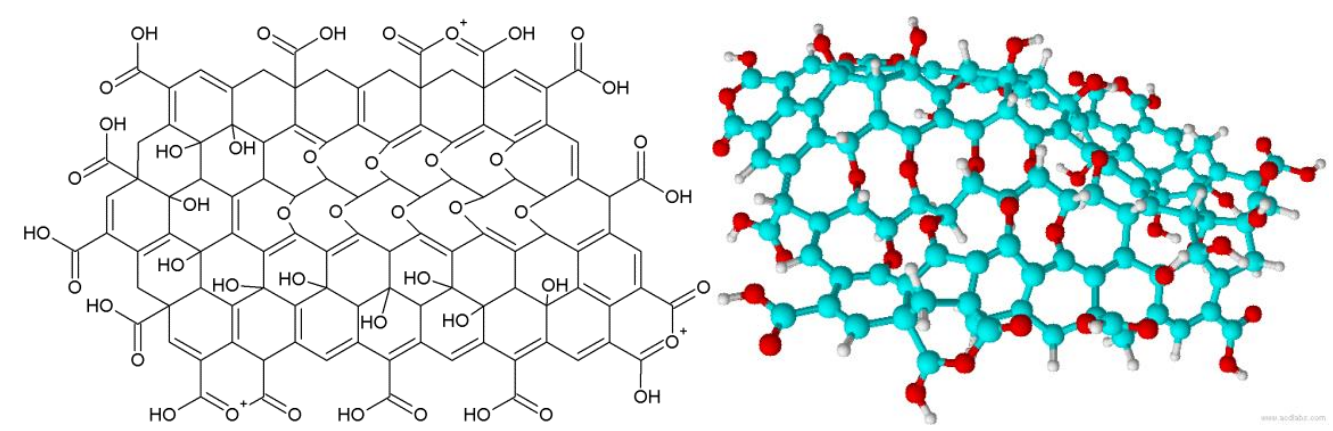

Figura 8: Estrutura do grafeno oxidado. A) Seus grupos funcionais. B) Estrutura tridimensional.

Esses aspectos do GO não o desqualificam como um material promissor em aplicações tecnológicas, pois diversos autores já relataram algumas aplicações, como em biossensores (58), super-capacitores (59), nanomembranas (20), e emissão de elétrons por campo (60).

\subsection{Processamento de nanomateriais na forma de filmes}


Pode-se processar nanomateriais das mais diversas formas e técnicas, incluindo técnicas: "Top-down" e "Botton-up". O primeiro, como o nome sugere, "de cima para baixo", é uma técnica muito difundida, principalmente na eletrônica, onde se obtém um controle preciso do tamanho das nanoestruturas. Por outro lado, as técnicas são de alto custo, como o caso da nanolitografia. Já o segundo tipo refere-se ao processamento de nanomateriais a partir do nível molecular, onde se utiliza átomos ou moléculas na construção de estruturas em três dimensões, e nos mais diferentes tamanhos e formas, com um baixo custo de produção (61).

Uma das possibilidades de se processar nanomateriais é na forma de filmes finos, e no próximo tópico será abordado um método eficiente de obtenção desses filmes utilizando o princípio de automontagem pela diferença de carga entre solução/substrato.

\subsubsection{Filmes automontados do tipo "Electrostatic Layer-by-layer" (ELBL)}

Quando se passa do universo macroscópico para o microscópico, em que a escala dos materiais e dispositivos está na ordem de bilionésimos de metros, a dificuldade de manipulação, processamento, reprodutibilidade, além do alto custo tecnológico envolvido no uso destes materiais em escala nanométrica fica claramente evidente. Além disso, não existe ainda uma compreensão completa sobre esse novo mundo das nanociências e estudos teórico-experimentais se fazem necessários para uma melhor compreensão. Portanto, a necessidade de uma boa qualidade de processamento de nanomateriais é um dos principais focos de estudos atualmente no mundo.

Decher e col. na última década do século XX propuseram uma alternativa que viabilizasse a manipulação desses nanomateriais, conhecida como automontagem Electrostatic layer-by-layer (ELBL) (62). Esta técnica permite a construção de dispositivos nanoestruturados com grande reprodutibilidade e controle de suas propriedades, além do baixo custo de processamento. Uma das 
grandes vantagens é a possibilidade de uso de diversos tipos de materiais orgânicos, inorgânicos, dispersões coloidais, além de materiais biológicos na montagem dos filmes $(5,21,63-66)$, possibilitando infinitas variedades de construção de diferentes tipos de dispositivos.

Esta técnica é simples e envolve o uso de um pequeno volume de soluções. Baseia-se na interação eletrostática de cargas opostas, em que o substrato é imerso alternadamente em uma solução policatiônica e outra polianiônica. Quando o substrato é imerso em uma solução onde a carga é positiva (A), o substrato também fica carregado positivamente com a formação de uma monocamada desse policátion, em seguida a solução é lavada para a retirada de excesso de material não adsorvido, podendo haver secagem à temperatura ambiente ou na presença de nitrogênio. Após esta etapa, o substrato agora com uma monocamada positiva, é imerso em uma solução carregada negativamente (B), e assim se forma a primeira bicamada. Este processo pode ser repetido $\boldsymbol{n}$ vezes, dependendo somente da aplicação e propriedade em que se deseja obter. $\mathrm{Na}$ Figura 9 tem-se a descrição do processo de automontagem ELBL.

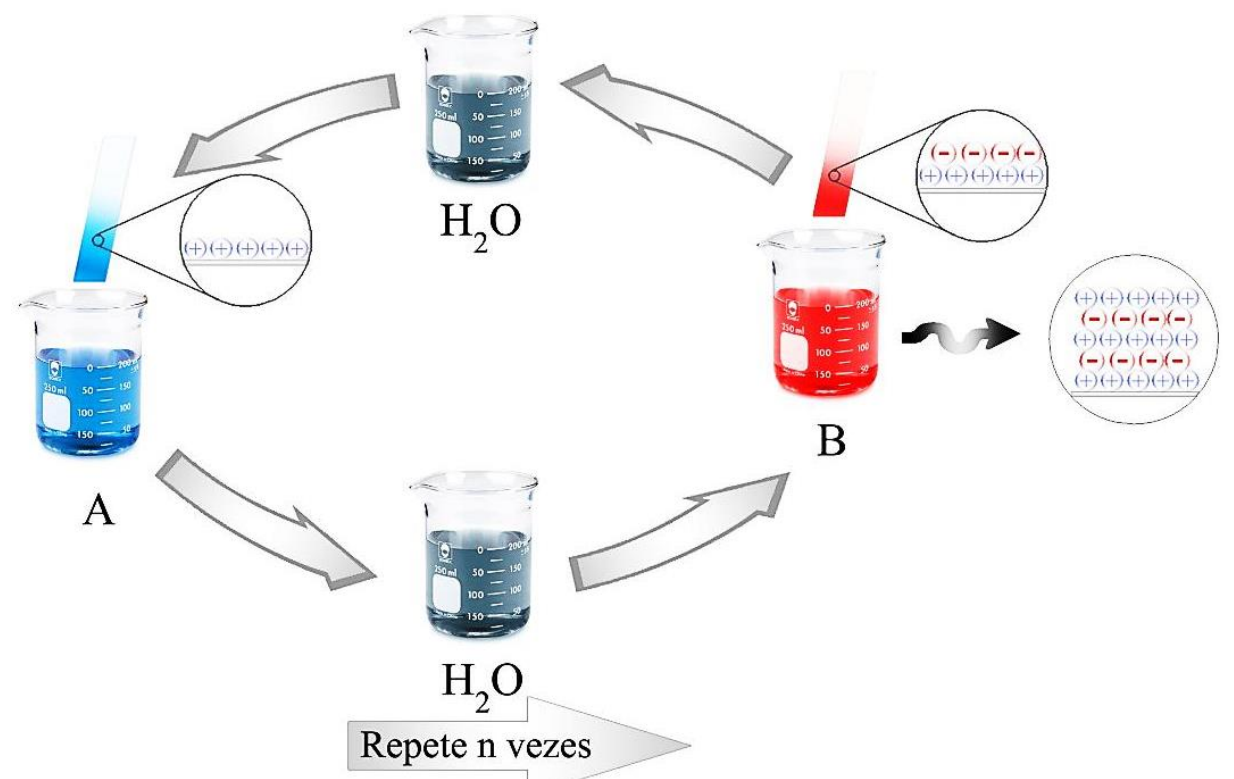

Figura 9: Processo de formação de um filme pela técnica ELBL

Entender os mecanismos que regem a adsorção de filmes automontados é de grande interesse, uma vez que o entendimento destes processos acarreta em 
melhor controle no crescimento dos filmes. Vários fatores influenciam na adsorção de polieletrólitos, como temperatura, pH, força iônica, concentração, tempo de imersão, tempo de enxague, solvente, densidade de carga e solubilidade. Desta forma observamos a complexidade do sistema e a real necessidade de se saber como se dá essa adsorção, e como otimizar o sistema para conseguir as características desejadas. A fim de estudar essas características descreveremos quatros mecanismos presentes na adsorção de filmes pela técnica ELBL, que se classificam da forma a seguir.

- Polieletrólitos fortemente carregados;

- Polieletrólitos parcialmente carregados;

- Interações secundarias;

- Interações especificas;

O primeiro e de maior ocorrência na fabricação de filmes ELBL, é pelo uso de polieletrólitos fortes, sendo este proposto primeiramente por Decher e col. (62). O principio desta adsorção consiste das interações iônicas que ocorrem entre as camadas, onde a interação eletrostática entre os polieletrólitos com o substrato levam à adsorção. Este tipo de interação é muito forte e fornece filmes bem homogêneos e com espessura de cada camada na ordem de $1 \mathrm{~nm}$. Este mecanismo é somente limitado às forças de interação filme/solução, quando estes entram em equilíbrio eletrostático a adsorção se encerra. Experimentos de potencial- $\zeta$ mostram claramente a sobreposição de cargas quando se adsorve um determinado eletrólito, fazendo com que essa camada fique com a carga liquida da solução. Outras características influenciam nessa adsorção, como a mudança de $\mathrm{pH}$, que pode deixar o polieletrólito mais ou menos carregado. A lavagem dos mesmos após a imersão nas soluções também está relacionada à estabilidade e espessura dos filmes (67). Outro fator importante na adsorção neste tipo de filmes está na relação da força iônica dos polieletrólitos com a espessura das camadas. Lvov e Decher mostraram que a espessura de uma camada varia com a raiz quadrada da força iônica (68). Utilizando reflectometria de neutros, Lösche e col. mostraram também que existe uma interpenetração das camadas de policátion e 
poliânion, aumentando a rugosidade do filme, o que aumenta a quantidade de sítios disponíveis para a adsorção das camadas adjacentes (69).

O segundo tipo de filmes automontados, refere-se a polieletrólitos fracamente carregados. Nestes filmes prevalecem as interações eletrostáticas, e como no caso anterior, as condições experimentais também influenciam no crescimento dos filmes. Neste caso, a espessura dos filmes é maior que nos polieletrólitos fortemente carregados, podendo variar até uma ordem de grandeza dependendo do pH. Este tipo de camada é denominado de "supermonolayer". Estes polieletrólitos formam segmentos do tipo "loop" e caudas, o que aumenta a espessura da camada. Shiratori e Rubner conseguiram crescer filmes com espessuras variando de 5 a $80 \AA$, apenas controlando o número de grupos ionizados de ácidos carboxílicos contidos no polieletrólito (70). Essa transição entre camadas mais finas e espessas pode ocorrer em um intervalo muito pequeno de $\mathrm{pH}$, ou seja, alterações na carga de superfície causam uma grande modificação nas propriedades de adsorção. Rubner e col. mostraram também que o controle da porosidade pode ser feito com uso de polieletrólitos fracos, onde demonstraram que apenas uma mudança de pH em torno de 2,3 a 2,5 foi suficiente para um aumento de 200\% na espessura dos filmes, com a formação de poros que variam de 100 a $500 \mathrm{~nm}$ com uma redução de um terço da densidade inicial (71).

O terceiro tipo de filme automontado baseia-se em ligações secundárias, como ponte de hidrogênio, ligação de Van der Waals e interações hidrofóbicas. Ainda podemos subdividir este tipo de filme em dois subgrupos: um em que ocorrem somente interações secundárias, e outro em que estas ocorrem conjuntamente com interações eletrostáticas. Stockton e Rubner sugeriram que para o crescimento de filmes por ligação de hidrogênio, é necessário que o material possua forte capacidade de formar ligações de hidrogênio, como a Polianilina (72). No segundo tipo de interações secundárias, uma de suas propriedades mais notáveis é a adsorção autolimitada, que consiste da adsorção fora do equilíbrio, onde a quantidade de material adsorvido é sempre maior que a de material dessorvido, este fato só pode ser explicado pelas interações de hidrogênio, onde materiais poliméricos com essas características adsorvem sobre 
si mesmos. Esta propriedade é de grande aplicabilidade na fabricação e dispositivos, pois torna-se possível obter um controle eficaz da espessura do filme em comparação com outras técnicas como "drop casting” e "spin-coating" (73).

O quarto mecanismo de adsorção é através de interações altamente específicas como no caso da avidina e biotina, onde uma poliamina é marcada com biotina. Mesmo com os dois polieletrólitos estando carregado positivamente, é possível ocorrer adsorção e isso se deve à afinidade da avidina com a biotina . Shimazaki e col. mostraram que este tipo de interação se deve ao caráter doador de elétrons ou aceitador de elétrons em seus grupos laterais das cadeias poliméricas (74)

\subsection{Sensores químicos}

Desde tempos remotos, o homem sempre teve a necessidade de utilizar sensores, pois era necessário saber quando haveria chuva ou se haveria período de seca. Já em nossa época, o uso de sensores está inserido em todos os segmentos da sociedade, desde um simples termômetro de mercúrio para verificação da temperatura corporal, até as modernas redes de sensoriamento do tipo (WSN), utilizadas em aplicações militares.

Um sensor consiste basicamente da saída de uma resposta a uma medida especifica (75). Desta forma podemos ter sensores onde a resposta ao que se mede pode ser um sinal químico ou físico. Classificando-os pelo método de sinal recebido, podem ser: mecânicos, térmicos, elétricos, magnéticos, radiantes e químicos.

Os sensores químicos são amplamente utilizados em todos os setores produtivos, na indústria, comércio, pesquisa e desenvolvimento, alimentos e militar.

Pela definição da IUPAC, um sensor químico consiste de, "Um dispositivo que transforma uma informação química, variando a concentração de uma amostra específica, em um sinal analítico mensurável”. Este sistema contém duas componentes, um elemento de reconhecimento (receptor), que transforma uma 
informação química em energia e um transdutor físico-químico que irá transformar essa forma de energia em um sinal analítico mensurável (76).

O receptor pode ser dividido em três tipos, de acordo com a resposta:

- Físico: Não envolve uma reação química, mas ocorre uma resposta física característica do elemento analisado;

- Químico: Ocorre uma reação química, entre o receptor e o analito;

- Bioquímico: O receptor é uma biomolécula, que interage com o analito, gerando um sinal analítico;

O receptor pode ou não ser seletivo, isto dependerá somente de como é feita a preparação do receptor no dispositivo e da técnica utilizada. Já o transdutor não apresenta seletividade, apenas convertendo uma energia em outra.

Podemos também classificar os sensores químicos de acordo com o método de transdução envolvido, que consiste da transformação de um sinal químico em outro sinal mensurável. Estes métodos podem ser térmicos, gravimétricos, eletroquímicos e óticos. Esses métodos ainda se dividem em outros subgrupos (75, 77). Na Figura 10, temos um diagrama do "design" de um sensor químico mostrando seus principais componentes, dividido por método de transdução e seus subgrupos. 


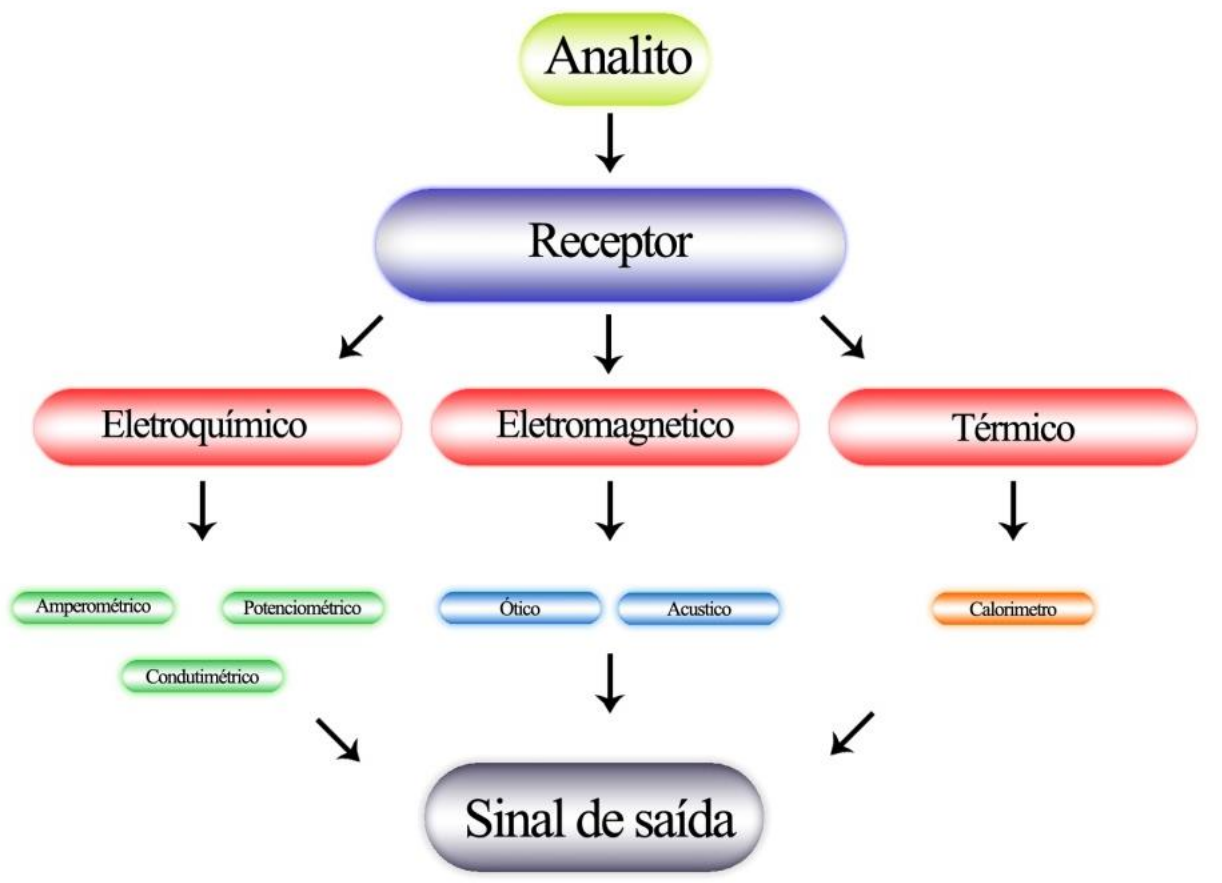

Figura 10: Diagrama do design de um sensor químico.

Para não deixarmos o enfoque desta dissertação, serão apenas apresentados os métodos de transdução eletroquímicos.

\subsubsection{Sensores eletroquímicos}

Sensores eletroquímicos são os dispositivos mais empregados e com grande diversidade no uso de diferentes técnicas, como amperometria, condutimetria, potenciometria, impedanciometria, além da possibilidade de integração com outras técnicas não-eletroquímicas, como uma fonte de potenciostato acoplado com uma microbalança de quartzo.

Essas técnicas são de custo relativamente baixo, montagem experimental simples, resposta rápida e com boa sensibilidade, seletividade e aplicação em diversas áreas, como biossensores, detecção de pesticidas, estudos de corrosão, phmetros, entre outras. Estas técnicas medem a concentração e atividade de íons e espécies neutras em soluções, sólidos e gases (78).

Os sensores eletroquímicos podem ser divididos em duas grandes classes. A primeira envolve técnicas que medem a condutividade e mudanças na constante 
dielétrica dos materiais na presença de um campo elétrico alternado (CA) ou continuo (CC). A resposta do sensor ocorre por alterações superficiais ou de volume da impedância, quando o eletrodo interage com o analito e ou o ambiente. A outra grande classe de sensores eletroquímicos envolve reações químicas na interface dos eletrodos, onde o sinal gerado pode ser um potencial dependente do tempo, corrente iônicas e eletrônicas, em que o sinal é proporcional à concentração ou atividade das espécies químicas envolvidas. Vários fatores afetam a resposta destes sensores, como a termodinâmica das reações químicas, cinética, força iônica, $\mathrm{pH}$ e temperatura (78). Dentro deste grupo ainda aparecem mais duas categorias, baseada no principio de funcionamento, as células galvânicas, e as células eletrolíticas.

Uma célula galvânica consiste da conversão da energia química em energia elétrica quando uma reação de oxidação/redução ocorre espontaneamente. Esta energia elétrica é medida como uma força eletromotriz entre dois eletrodos, onde um deles é um eletrodo de referência. Este tipo de célula é comumente utilizado em potenciometria. O outro tipo de célula é a eletrolítica, na qual ocorre o inverso da célula galvânica: Têm-se a conversão de energia elétrica em energia química, através de uma reação química de oxidação/redução na superfície de um eletrodo.

Devido ao grande número de técnicas disponíveis, vamos nos concentrar

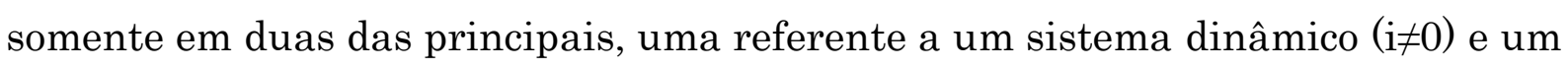
sistema estático $(\mathrm{i}=0)$.

\subsubsection{Amperometria}

Sensores amperométricos envolvem a medida de fluxo de corrente, e desta forma diversas técnicas estão inseridas neste tipo de transdução. Uma delas é a cronoamperometria, que consiste da aplicação de um potencial constante dependente do tempo, podendo haver somente um ou mais potenciais aplicados com tempos pré-definidos. Normalmente aplica-se um potencial de circuito aberto que irá criar um potencial de dupla camada, e em seguida o potencial de redução ou oxidação da espécie química que se deseja mensurar. Através da equação de 
Cottrell, podemos obter uma relação entre a corrente com a concentração dessas espécies, mostrada na equação 3.

$$
i_{(t)}=\frac{n F A D_{0}^{1 / 2} C_{0}}{\pi^{1 / 2} t^{1 / 2}}
$$

Onde $i_{(t)}$ é a corrente em função do tempo, $n$, o número de elétron, $F$, a constante de Faraday, $A$, a área do eletrodo, $C_{0}$, a concentração das espécies oxidadas e $D_{0}$, o coeficiente de difusão. A equação (3) aparece em sua forma resumida, sendo válida somente para eletrodos planos e desprezando os efeitos de bordas (79).

\subsubsection{Sensores potenciométricos}

$\mathrm{Na}$ indústria, em pesquisa, ou nos laboratórios de ensino, um dos equipamentos imprescindíveis é o phmetro. Este equipamento se baseia em uma das técnicas mais antigas utilizadas em detecção de espécies iônicas: a potenciometria, sendo utilizada na detecção de mais de sessenta tipos diferentes de analitos $(80,81)$.

Potenciometria, por definição, consiste na medida de uma força eletromotriz ou um potencial proporcional ao logaritmo da atividade de um íon de interesse, através de uma membrana íon-seletivo, de acordo com a equação de Nernst (82). Na equação (4) tem-se a equação Nernst, onde $\boldsymbol{E}$, é o potencial do eletrodo versus o eletrodo de referência $\boldsymbol{E}_{\boldsymbol{c}}^{\mathbf{0}}, \boldsymbol{R}$, a constante universal dos gases $\left(8,314 \mathrm{Jmol}^{-1} \mathrm{~K}^{-1}\right), \boldsymbol{T}$, a temperatura absoluta e $\boldsymbol{F}$, a constante de Faraday $(9,648 \mathrm{x}$ $10^{4} \mathrm{C}$ ). Os termos $\boldsymbol{a}_{\text {oxi }}, \boldsymbol{a}_{\text {red }}$, correspondem à atividade dos íons, oxidado e reduzido, e $\boldsymbol{n}$, é o número de elétrons que participa da reação de oxidação/redução, de acordo a equação (5). 


$$
\begin{aligned}
& E=E_{c}^{0}+\frac{R T}{n F} \ln \frac{a_{\text {oxi }}}{a_{\text {red }}} \\
& a_{\text {oxi }}+n e^{-} \rightleftharpoons a_{r e d}
\end{aligned}
$$

Este sistema possui um eletrodo de referência e um eletrodo de trabalho, íons seletivos. Ambos os eletrodos são imersos em uma solução contendo o analito a ser mensurado, sendo representado abaixo como:

\section{Eletrodo de referência | Ponte salina | Solução do analito | Eletrodo indicador}

O potencial de uma célula eletroquímica pode ser determinado por:

$$
E_{\text {célula }}=E_{\text {indicador }}-E_{\text {referência }}+E_{\text {pon.salina }}
$$

Sensores potenciometricos podem ser fabricados com diferentes configurações: eletrodos de vidros, eletrodos metálicos, ou membranas, além dos ISFETs (do inglês Ion-Sensitive-Field-Effect-Transistor) (83). Esse último possibilitou uma nova abordagem na área de sensoriamento, possibilitando a miniaturização e integração com a eletrônica. Desta forma é possível separar o eletrodo indicador em (84):

- Eletrodo metálico - tipo 1: Este tipo de eletrodo é um metal puro em equilíbrio com seu cátion em uma solução, onde ocorre a reação:

$$
\mathrm{M}^{n+1}(\mathrm{aq})+n e^{-} \rightleftharpoons \mathrm{M}(s)
$$

Este tipo de eletrodo não é muito utilizado, principalmente devido à sua não-seletividade, fazendo com que o metal possa responder não somente ao seu cátion, mas também a outros cátions mais facilmente redutíveis. Outro fator limitante deste eletrodo é sua baixa resistência à oxidação.

- Eletrodo metálico - tipo 2: É um eletrodo metálico (M) que tem resposta à atividade de um ânion (A), no qual seu cátion forma um complexo estável e ocorre a seguinte reação: 


$$
\mathrm{MA}^{\mathrm{n}-}(s)+n e^{-} \rightleftharpoons \mathrm{M}(s)+\mathrm{A}^{-}(\mathrm{aq})
$$

- Eletrodos metálicos - tipo 3: São eletrodos inertes usados em sistemas de oxidação/redução, atuando como fonte de elétrons para este sistema. Por exemplo: Platina, Ouro.

- Eletrodo de vidro: É um tipo de eletrodo de membrana: Neste caso uma fina camada de vidro é preenchida com uma solução de $\mathrm{HCl}$ saturado com $\mathrm{AgCl}$, podendo, em alguns casos, ser um tampão. Nesta solução está inserido um eletrodo de referência de $\mathrm{Ag} / \mathrm{AgCl}$, conectado a um dos terminais do dispositivo. Diferentemente dos eletrodos metálicos, o potencial medido de um eletrodo de membrana de vidro deve-se a um potencial na junção da membrana que separa a solução contendo o analito a ser medido da solução interna do eletrodo.

- Eletrodo modificado: Classe de eletrodos seletivos, em que a camada sensível pode ser produzida de varias maneiras: Membrana de polímero, polímero condutor, superfícies metálicas funcionalizadas, eletrodos modificados com enzimas, entre outros materiais e métodos (85-88).

O estabelecimento de um potencial de eletrodo é causado pela separação de cargas na superfície deste eletrodo, onde ocorre a quimissorção do íon primário da solução para a interface do eletrodo.

\subsubsection{Transistor de efeito de campo sensível a íons}

Transistor de efeito de campo (da sigla inglesa, FET) é um pequeno dispositivo de estado sólido, feito de material semicondutor. O FET apresenta uma porta ou "gate", feito de um metal-óxido, o que dá o nome a este dispositivo, MOSFET (metal-oxide-semiconductor-FET). Estes dispositivos são amplamente utilizados na indústria eletrônica, como chaves eletrônicas e amplificadores. Um dos problemas enfrentados pelos pesquisadores na fabricação desses dispositivos 
referia-se a sua sensibilidade na presença de íons, o que causava instabilidade nesses dispositivos.

Aproveitando a característica dos FET's de serem sensíveis a íons, Bergveld, desenvolveu em 1970 o primeiro ISFET. Este dispositivo corresponde exatamente a um MOSFET utilizado em eletrônica. A diferença se encontra na porta do transistor, que no caso do ISFET, é retirado o metal, deixando a superfície do óxido exposta a uma solução, como mostra a Figura 11.

A

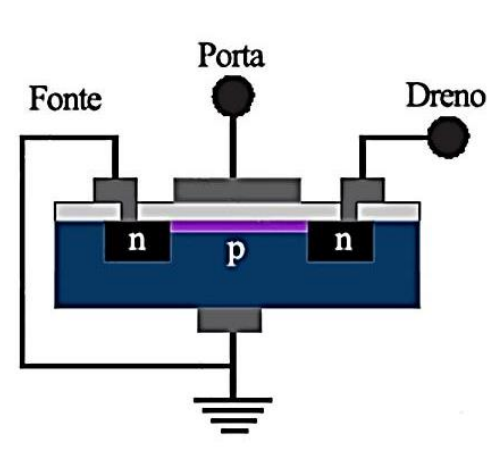

B Eletrodo de referência

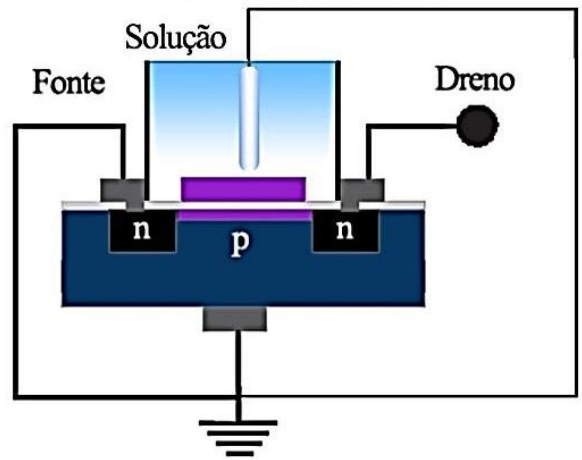

Figura 11: Diagrama de um MOSFET em A, e um ISFET em B.

Diversos materiais têm sido utilizados como membrana seletiva. Os óxidos mais utilizados são os $\mathrm{SiO}_{2}, \mathrm{Si}_{3} \mathrm{~N}_{4}, \mathrm{Al}_{2} \mathrm{O}_{3}, \mathrm{Ta}_{2} \mathrm{O}_{5}$. O óxido de silício foi o primeiro a ser empregado e o mais relatado na literatura (89).

O principio de funcionamento de um ISFET é exatamente o mesmo de um MOSFET, mudando-se a forma de modulação do potencial na porta do transistor. No caso de um ISFET, a modulação ocorre pelos íons na superfície do óxido. A descrição teórica desenvolvida para o ISFET parte da formulação do MOSFET. Temos que a corrente de dreno em um transistor de efeito de campo é dada pelas equações (9) e (10).

$$
\begin{aligned}
& I_{d}=\mu C_{o x i} \frac{W}{L}\left[\left(V_{g s}-V_{t h}\right) V_{d s}-\frac{1}{2} V_{d s}^{2}\right] \\
& V_{t h}=\frac{\Phi_{M}-\Phi_{S i}}{q}-\frac{Q_{o x i}+Q_{s s}+Q_{B}}{C_{o x i}}+2 \phi_{f}
\end{aligned}
$$

Onde W e $\mathbf{L}$ são a largura e o comprimento do canal, $\boldsymbol{C}_{\boldsymbol{o x}}$, a capacitância do oxido por unidade de área e $\boldsymbol{\mu}$, a mobilidade do elétron, $\boldsymbol{V}_{\boldsymbol{t h}}$ é a tensão limiar, 
$\boldsymbol{V}_{\boldsymbol{g} \boldsymbol{s}}, \boldsymbol{V}_{\boldsymbol{d} \boldsymbol{s}}$, são a tensão da porta/fonte e dreno/fonte, respectivamente. Esta equação só é valida quando o transistor esta na região de tríodo (linear), ou seja, $V_{g s}>V_{t h}$ e $V_{d s}<V_{g s}-V_{t h}$. Observa-se que somente o potencial de porta modula a corrente de dreno. Já na equação (10), o primeiro termo se refere à diferença da função trabalho do silício e do metal da porta. Esta parte da expressão, para um ISFET, é modificada pelos potenciais de interface do óxido/solução e do potencial do eletrodo de referência.

A sensibilidade do dispositivo é determinada por uma expressão desenvolvida por Van Hal e Eijkel, onde uma constante é determinante na sensibilidade do sistema, chamado de parâmetro $\alpha$. Quando $\alpha<1$, temos um sensor do tipo subnernstiano, $\alpha=1$, um sistema nernstiano e para $\alpha>1$, temos um sensor do tipo supernernstiano, esse parâmetro é visto na equação (11).

$$
\Delta \Psi=-2,3 \alpha \frac{R T}{F} \Delta p H
$$

Onde $\alpha$, pode ser escrita como de função de:

$$
\alpha=\left(\left(\frac{2,3 k T C_{s}}{q^{2} \beta_{s}}\right)+1\right)^{-1}
$$

Onde $\boldsymbol{\beta}_{\boldsymbol{s}}$ significa a capacidade de a superfície adsorver ou liberar prótons, $\boldsymbol{C}_{\boldsymbol{s}}$, a capacitância de dupla camada $\boldsymbol{k}, \boldsymbol{T}, \boldsymbol{q}$, são as constantes de Boltzmann, temperatura absoluta e a carga elementar, respectivamente $(89,90)$.

Os experimentos de Bergveld abriram as portas para o desenvolvimento de novos materiais e metodologias na área de sensoriamento químico e bioquímico. Com os ISFET, diversos dispositivos foram desenvolvidos para melhorar esse sistema e diversas variações ao ISFET foram criadas, como o CHEMFET, ENFET, EGFET. Este último possibilitou uma nova abordagem no uso dos transístores de efeito de campo, onde não se utiliza a superfície exposta do ISFET, o que traz algumas desvantagens, como o custo de fabricação. Neste sentido, o EGFET (Extended-Gate-Field-Effect-Transistor), se torna uma 
alternativa de baixíssimo custo, utilizando um transistor de efeito de campo comercial, onde a porta é ligada a uma membrana sensível a íons. Desta forma o sistema pode ser reutilizado infinitas vezes, trocando apenas a membrana seletiva.

\subsubsection{Potenciometria de circuito aberto (OCP)}

Em potenciometria é possível à utilização de um simples voltímetro para a medição do potencial. Este não é o método mais indicado em caso de medidas de precisão, pois as correntes envolvidas são extremamente baixas, na ordem de $10^{-9}$ a 10-12 A. A resistência interna do multímetro é aproximadamente da mesma ordem da resistência do sistema potenciométrico que se está medindo, assim o próprio sistema de medida causa interferência, chegando a resultados errôneos e instáveis (84). Uma solução para minimizar este problema é o uso de amplificadores operacionais, disponíveis em diversos equipamentos.

Estes dispositivos são largamente utilizados na eletrônica, sendo os primeiros a se tornar em circuitos integrados (91). O nome "amplificador operacional" é devido aos primeiros anos de utilização desse dispositivo em computadores analógicos, no uso de operações matemáticas.

Devido à sua grande diversidade de aplicações, os fabricantes desenvolveram diversas variações deste dispositivo, e uma dessas é a junção de três amplificadores operacionais e sete resistências, formando um amplificador de instrumentação. Estes dispositivos amplificam a diferença entre as duas entradas, mantendo uma grande impedância de entrada e alta rejeição de sinais de modo comum (da sigla inglesa CMMR) e com ganho variável. Estes dispositivos apresentam um baixo custo, viabilizando a fácil integração com outros dispositivos eletrônicos e a produção em larga escala, tornando-os de grande aplicabilidade em instrumentação de alta precisão. Na Figura 12, tem-se o circuito de uma montagem típica de um amplificador de instrumentação, em que A1, A2 são amplificadores de entra e A3 é o amplificador diferencial. É neste estágio que ocorre a rejeição de modo comum. 


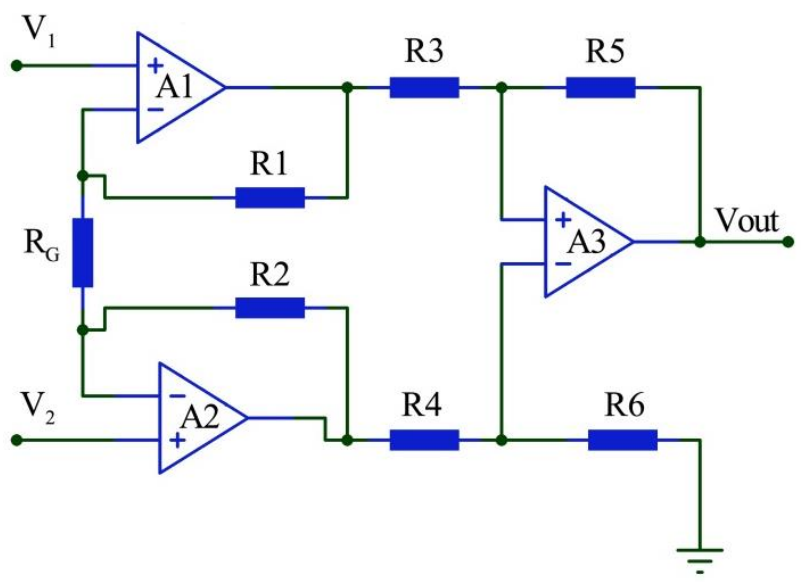

Figura 12: Diagrama de um amplificador de instrumentação, figura adaptada da referência (92).

A tensão de saída diferencial do amplificador de instrumentação pode ser descrita pela equação (13):

$$
V_{\text {OUT }}=\left(1+\frac{2 R_{1}}{R_{G}}\right) \cdot\left(V_{2}-V_{1}\right)
$$

Onde $R_{G}$ é o resistor de ganho, e $V_{1}, V_{2}$, as entradas do amplificador de instrumentação. Neste caso a amplificação fica sujeita apenas a variações do resistor $R_{G}$.

Um destes dispositivos amplamente utilizados em diversas aplicações é o AD620. Esse amplificador de instrumentação apresenta todas as características mostradas acima, sendo que algumas aplicações em potenciometria já têm sido relatadas na literatura $(93,94)$.

Amplificadores operacionais ou de instrumentação são bastante empregados em experimentos de OCP (Open Circuit Pontential), onde há necessidade de medir o potencial de uma solução usando um circuito aberto, ou seja, o potencial da própria solução, sem a presença de um campo externo.

O potencial de circuito aberto depende de muitos fatores, como a carga superficial do eletrodo ou da membrana, a limpeza dos substratos, capacitâncias parasitas e a forma como são preparadas as membranas seletivas (95). 


\section{Objetivos}

O presente trabalho teve como objetivo o processamento de grafeno oxidado na forma de filmes ultrafinos imobilizados sobre plataformas adequadas, e estudo de sua aplicação como sensores potenciométricos.

Os objetivos específicos foram:

1.) Obtenção: Esfoliar quimicamente o grafite policristalino e a partir deste obter o grafeno na sua forma oxidada. Preparar as amostras para crescimento de filmes e eliminar possíveis impurezas e obter GO com um menor número possível de camadas.

2.) Caracterização das amostras: Caracterizar as amostras quimicamente esfoliadas, avaliar a qualidade da esfoliação, tamanho das folhas, número de camadas, grupos funcionais, cristalinidade e impurezas.

3.) Processamento na forma de filmes finos e caracterização: Caracterização dos filmes automontados de grafeno oxidado e poli(amidoamina) geração quatro (PAMAM-G4), em substrato de ouro e óxido de Índio dopado com estanho (ITO), em uma plataforma potenciométrica, utilizando AD620. Aplicação dos eletrodos como sensor de $\mathrm{pH}$. 


\section{Materiais e Métodos}

\subsection{Esfoliação Química do grafite}

\subsubsection{Materiais e reagentes}

Os materiais utilizados na esfoliação química do grafite para obtenção de grafeno oxidado e crescimento de filmes automontados de GO/PAMAM-G4 são descritos neste capítulo. Todos os reagentes utilizados foram de grau analítico.

\section{Síntese:}

- Grafite obtido pela Nacional de Grafite $<200 \mu \mathrm{m}$

- Persulfato de potássio $\left(\mathrm{K}_{2} \mathrm{~S}_{2} \mathrm{O}_{8}\right)$

- Pentóxido de fósforo $\left(\mathrm{P}_{2} \mathrm{O}_{5}\right)$

- Ácido Sulfúrico $\left(\mathrm{H}_{2} \mathrm{SO}_{4}\right)$

- Permanganato de Potássio $\left(\mathrm{KMnO}_{4}\right)$

- Peróxido de Hidrogênio $\left(\mathrm{H}_{2} \mathrm{O}_{2}\right)$

- Ácido Hidrocloridrico (HCl)

- Água Mili-q $18 \mathrm{M} \Omega$

\subsubsection{Esfoliação química}

Existem diversas rotas de esfoliação para obter o grafeno quimicamente (53). Optamos por seguir uma rota em que fosse possível obter folhas da ordem de alguns micrometros. Escolhemos a rota utilizada por (Kaner e colaboradores), que consiste em uma modificação do método Hummer's, proposto em 1957 (49, 96).

$\mathrm{O}$ grafite foi pré-tratado com a adição de $12 \mathrm{ml}$ de $\mathrm{H}_{2} \mathrm{SO}_{4}$ concentrado e aquecido até $90{ }^{\circ} \mathrm{C}$, e 2,5 g de $\mathrm{K}_{2} \mathrm{~S}_{2} \mathrm{O}_{8}$ e $\mathrm{P}_{2} \mathrm{O}_{5}$, adicionados logo em seguida, em agitação, até a completa dissolução dos reagentes. Esfriou-se a mistura até $80{ }^{\circ} \mathrm{C}$ 
e adicionou-se $3 \mathrm{~g}$ de grafite, sendo a dispersão mantida nesta temperatura por 4,5 horas. Em seguida, a solução foi diluída em $500 \mathrm{~mL}$ de água deionizada e permaneceu overnight. Posteriormente, a solução foi colocada em uma centrifuga a $5000 \mathrm{rpm}$ por 2 horas. O sobrenadante foi retirado para neutralizar a acidez da amostra. Este processo foi repetido três vezes.

Para a etapa de oxidação, foram adicionados $100 \mathrm{ml}$ de $\mathrm{H}_{2} \mathrm{SO}_{4}$ em um erlenmeyer, mantido a $0{ }^{\circ} \mathrm{C}$. Em seguida, foram adicionados $15 \mathrm{~g}$ de $\mathrm{KMnO}_{4}$, e a temperatura monitorada constantemente para não ultrapassar os $10{ }^{\circ} \mathrm{C}$. Subsequentemente foram adicionados $230 \mathrm{ml}$ de água deionizada, sempre mantendo a temperatura a $10^{\circ} \mathrm{C}$. O volume final da solução foi de $700 \mathrm{~mL}$, ao se adicionar, nessa etapa, $12 \mathrm{~mL}$ de $\mathrm{H}_{2} \mathrm{O}_{2} 30 \%$ v/v. A solução foi então lavada com água e $\mathrm{HCl}(10 \%)$, e em seguida centrifugada novamente a $5000 \mathrm{rpm}$ por 2 horas até a retirada do ácido. Em seguida o material foi adicionado em uma membrana de diálise por uma semana, para retirada de metais provenientes da síntese, e por fim a solução estoque é mantida refrigerada a $8^{\circ} \mathrm{C}$.

\subsubsection{Preparação das amostras para caracterização e crescimento dos filmes.}

Logo após a esfoliação foi necessário purificar as amostras, devido à presença de grafite não-esfoliado e não-oxidado. Com intuito de eliminar esses resíduos, as seguintes etapas foram realizadas.

Uma hora em banho de ultrassom $(80 \mathrm{~W})$, para dispersar as partículas, em seguida colocado em um ultrassom de ponta $(450 \mathrm{~W})$ por 30 minutos em amplitude de $25 \%$ e pulsos de 15 segundos. Posteriormente as amostras foram centrifugadas a 4000 rpm por 1 hora e o sobrenadante separado. Por fim, uma alíquota da amostra foi separada para determinar a concentração de grafeno oxidado, no qual a amostra foi secada por 24 horas em uma estufa a $50{ }^{\circ} \mathrm{C}$ e em seguida pesada em uma balança analítica. 


\subsection{Deposição dos filmes automontados}

\subsubsection{Materiais utilizados no crescimento dos filmes automontados}

- Polieletrólito PAMAM-G4, obtido da Dendritech ${ }^{\circledR}$.

- Água Mili-q $18 \mathrm{M} \Omega$.

- Grafeno oxidado.

- Ácido Clorídrico ( $\mathrm{HCl})$.

- Hidróxido de Sódio ( $\mathrm{NaOH})$.

\subsubsection{Processamento de filmes automontados}

Para imobilização de GO em camadas alternadas com PAMAM-G4, foram utilizadas amostras da solução de grafeno oxidado na concentração de $0,5 \mathrm{~g} \mathrm{~L}^{-1} \mathrm{e}$ pH 4. A solução de PAMAM-G4 foi preparada na concentração de $1 \mathrm{~g} \mathrm{~L}^{-1}$, e pH 8.

Para monitorar o crescimento dos filmes foram utilizadas lâminas de quartzo e o crescimento foi monitorado pela variação da absorbância no UV-Vis, em função do número de camadas adsorvidas no substrato. A adsorção dos polieletrólitos no substrato foi realizada pela imersão alternada em uma solução de PAMAM-G4 (Solução catiônica) e GO (Solução aniônica). O tempo de imersão para o PAMAM-G4, foi de 5 minutos (97), e $20 \mathrm{~s}$ para o GO. Este tempo foi determinado experimentalmente neste trabalho. Após cada etapa, foram imersos em água Mili-q por 1 minuto, para retirar o excesso de material não adsorvido e seco em nitrogênio. A Figura 13 ilustra a arquitetura de um filme automontado. 


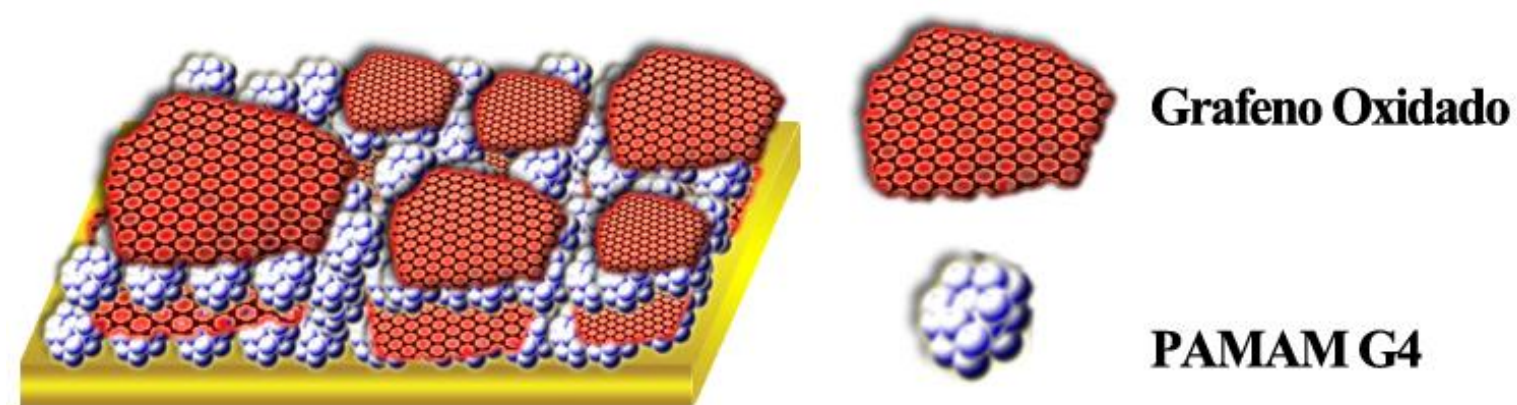

Figura 13: Diagrama de um filme automontado de PAMAM-G4/GO.

Para análise por FT-IR, foi utilizado um substrato de Silício (Si); e, para as demais caracterizações elétricas foram utilizados substratos de ouro ( $\mathrm{Au})$ depositados em vidro BK-7, com a espessura de $100 \mathrm{~nm}$ (produzidos no grupo de polímeros Bernard Gross), por meio da deposição a vapor.

\subsection{Técnicas de caracterização}

Várias técnicas foram utilizadas com o objetivo de caracterizar o grafeno oxidado e os filmes automontados. Todas as técnicas utilizadas serão descritas neste tópico, resumindo suas principais características físicas, sua importância e a função desempenhada nesta dissertação.

\subsubsection{Espectroscopia UV-Vis}

A espectroscopia no ultravioleta-visível consiste de uma técnica física amplamente utilizada no estudo das transições eletrônicas de moléculas (84). Está técnica também é utilizada no estudo de soluções coloidais e moléculas biológicas, como proteínas, aminoácidos, peptídeos e ácidos nucléicos (98, 99). É utilizada também na análise quantitativa de concentração de espécies absorventes diluídas, utilizando a Lei de Lambert-Beer (84).

$$
\boldsymbol{A}=\boldsymbol{\varepsilon} \boldsymbol{c l}
$$


Além disso, esta técnica é utilizada no monitoramento da adsorção de moléculas, biomoléculas e coloides em filmes automontados, que relaciona a intensidade de absorção com o número de bicamadas adsorvidas $(62,100)$, sendo essa relação linear em muitos casos.

Neste trabalho, a técnica de UV-Vis foi utilizada para caracterizar o grafeno esfoliado quimicamente, identificando, através do seu pico de absorção característico, que a esfoliação ocorreu de maneira adequada, utilizando uma solução diluída em uma cubeta de quartzo de $10 \mathrm{~mm}$ de caminho ótico.

A cinética de crescimento dos filmes automontados e o crescimento variando-se o número de bicamadas dos polieletrólitos PAMAM-G4/GO, foram analisadas utilizando lâminas de quartzo. Para realização destes experimentos foi utilizado o espectrofotômetro HITACHI U-2900 pertencente ao Laboratório de Nanomedicina e Nanotoxicologia.

\subsubsection{Difração de Raios-X (DRX)}

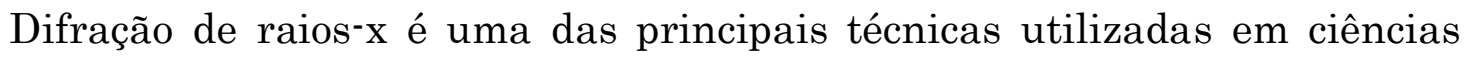
dos materiais, engenharias, geociências, química e biologia estrutural, na caracterização microestrutural de materiais. Quando uma onda eletromagnética encontra obstáculos igualmente espaçados e de magnitude comparável ao comprimento de onda incidente, tem-se o fenômeno de difração. A difração de raios $^{-} \mathrm{x}$ foi verificada experimentalmente pela primeira vez pelo alemão Von Laue em 1912. Os irmãos Bragg desenvolveram a Lei de Bragg, que relaciona o ângulo de incidência de um feixe de raios $^{-x}$ com a distância interatômica do material, a qual é dada pela equação (15):

$$
\frac{2 \operatorname{sen} \theta}{\lambda}=\frac{n}{d}
$$

Onde $\boldsymbol{\theta}$ é o ângulo de difração, $\lambda$ o comprimento de onda e $\boldsymbol{d}$ a distância interatômica. Utilizando este principio, é possivel obter para diferentes ângulos, diferentes planos cristalográficos (101). 


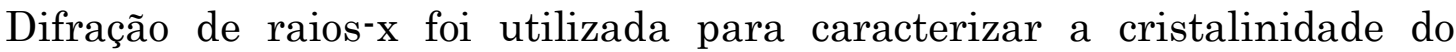
grafeno oxidado e a possível presença de grafite não oxidado nas amostras. Outra informação possivel de se obter é a quantificação do número de camadas das amostras de grafeno oxidado.

Para realizar este experimento foi necessário o pré-tratamento das amostras na forma de pó. Estas foram secas em uma estufa a $50{ }^{\circ} \mathrm{C}$, a fim de se eliminar toda a água presente, formando um filme espesso e escuro. Este filme foi raspado e o pó foi submetido à análise DRX. Foram preparadas três amostras: i) grafeno oxidado após o tratamento descrito no tópico anterior. ii) o produto da esfoliação sem tratamento, e como referência, iii) uma amostra do grafite, utilizado na esfoliação química. Estes experimentos foram realizados em um difratômetro Rigaku Rotaflex, modelo RU200B do grupo de cristalografia do instituto de Física de São Carlos (IFSC-USP), com comprimento de onda de CuKa $(1,5406 \AA ̊$ ) .

\subsubsection{Espectroscopia de infravermelho (FT-IR)}

Espectroscopia de infravermelho explora o fato de que as moléculas absorvem energia em frequências específicas, que são características de sua estrutura. Essas absorções são frequências ressonantes, ou seja, a frequência da radiação absorvida corresponde à frequência da ligação ou do grupo que vibra. As energias são determinadas pela forma do poço de potencial molecular, as massas dos átomos e o acoplamento associado a essas vibrações. Essas vibrações, também chamadas de modos de vibração, podem ser: translacional, rotacional e vibração; e a cada tipo está associado um grau de liberdade (102).

Foi usado um espectrofotômetro Nicolet ${ }^{\circledR}$ 6700, do grupo de Biotecnologia Molecular (IFSC-USP), com resolução de $4 \mathrm{~cm}^{-1}$, espectros obtidos de 400 a 4000 $\mathrm{cm}^{-1}$, com 200 scans em amostras de GO, PAMAM-G4 e filmes PAMAM-G4/GO em substrato de silício. Todas as amostras foram secas em dessecador a vácuo por 24 horas, antes da realização do experimento. 


\subsubsection{Espectroscopia Micro-Raman}

Quando a matéria interage com uma determinada radiação, observam-se vários fenômenos, sendo possível ocorrer reflexão, absorção, transmissão e espalhamento dos fótons. A técnica Raman mede o espalhamento inelástico da luz, quando essa interage com a matéria, onde o fóton espalhado tem uma energia diferente do fóton incidente, também chamado de espalhamento RamanStokes e espalhamento Raman-AntiStokes. Estes se diferem pelos estados de energia final do fóton que foi incidido na amostra (103). Devido às melhorias que a técnica experimentou ao longo dos anos, principalmente com o advento do detector CCD (charge-coupled device), é possível a criação de equipamentos mais robustos e sensíveis, possibilitando a criação de imagens a partir de vários espectros obtidos em uma área definida na amostra (104).

Utilizando esta técnica, foi possível obter imagens espectroscópicas de folhas de grafeno oxidado individuais para caracterizar sua estrutura e defeitos na rede cristalina. Neste estudo foi utilizado um microscópio confocal acoplado com Raman-AFM da Witec ${ }^{\circledR}$, modelo alpha 500, excitação em $532 \mathrm{~nm}$ pertencente ao Instituto de Pesquisas Tecnológica (IPT). Cada imagem foi obtida através de 5625 pixels, em que cada pixel corresponde a um espectro, o tempo de integração foi de $62 \mathrm{~ms}$.

\subsubsection{Energia dispersiva de espectroscopia de raios-X (EDS)}

Espectroscopia de energia dispersiva de raios-X (EDS) é uma técnica analítica utilizada para análise elementar química. Esta técnica se baseia no fato de que cada elemento possui uma estrutura atômica única. Um detector EDS é acoplado a um microscópio eletrônico de varredura (MEV). Os elétrons emitidos do canhão do microscópio incidem na amostra, interagindo com esta e liberando elétrons retroespalhados, elétrons secundários, fótons de raios-x e, menos frequentemente, elétrons Auger. Como os fótons emitidos são provenientes das 
camadas mais internas do átomo e cada um possui uma configuração única, podese utilizar este principio para a análise elementar química (105).

Neste trabalho, essa técnica foi utilizada com o intuito de determinar a presença de contaminantes oriundos da esfoliação química, utilizando o microscópio JEOL $^{\circledR}$ acoplado com EDS JSM-6510, pertencente a EMBRAPA Instrumentação.

\subsubsection{Potencial-Zeta (飞)}

O estudo das cargas superficiais de uma partícula em uma solução é de grande importância no estudo do crescimento de filmes. É devido a essas cargas superficiais que a interação eletrostática entre ânions e cátions ocorre (106). Uma dada partícula dissolvida em uma solução apresenta uma camada elétrica chamada de camada de Stern, que é fortemente ligada à superfície da partícula, e uma camada externa difusa, formando o que se chama de potencial de dupla camada. Nesta, quando ocorre um deslocamento hidrodinâmico na presença de um campo elétrico, surge um potencial, que é chamado de potencial-̧. Quando este potencial é maior que $\pm 30 \mathrm{mV}$, temos uma solução coloidal estável. No desenvolvimento deste estudo foi utilizado o equipamento Malvern Instruments ${ }^{\circledR}$, modelo Zetasizer Nano ZS90 acoplado com titulador automático.

\subsubsection{Microscopia Ótica}

Nesta dissertação foi utilizado um microscópio óptico OLYMPUS ${ }^{\circledR}$ modelo BX51-JR, no modo reflectância, com o objetivo de visualizar as amostras depois da síntese, a fim de verificar a presença de grafeno oxidado em diferentes camadas. A deposição foi feita por "drop casting" em um substrato de oxido de silício $\left(\mathrm{SiO}_{2} / \mathrm{Si}\right)$. 


\subsubsection{Microscopia de Força Atômica (AFM)}

Para este experimento foi utilizado o AFM acoplado com Raman da Witec ${ }^{\circledR}$, modelo alpha 500, usando uma ponta de não contato do Instituto de Pesquisas Tecnológica (IPT).

\subsubsection{Caracterização Potenciométrica}

As medidas potenciométricas foram realizadas com o objetivo de investigar o material em estudo, como plataforma sensorial. Utilizando uma fonte/multímetro de tensão continua Keithley ${ }^{\circledR} 2612 \mathrm{~A}$, foram realizadas medidas alimentando um circuito integrado amplificador de instrumentação AD620 da Analog Devices ${ }^{\circledR}$ (92). Como tensão de referência, foi utilizado um eletrodo saturado de calomelano. As medidas foram realizadas em diferentes $\mathrm{pH}$, usando soluções padrões, usadas em calibração de phmetro $(2,4,7,10,12)$ em uma célula eletroquímica de $10 \mathrm{~mL}$. A aquisição dos dados foi realizada usando o software TSPExpress, via cabo de rede. Na Figura 14, mostramos um diagrama da configuração utilizada para realização deste experimento.

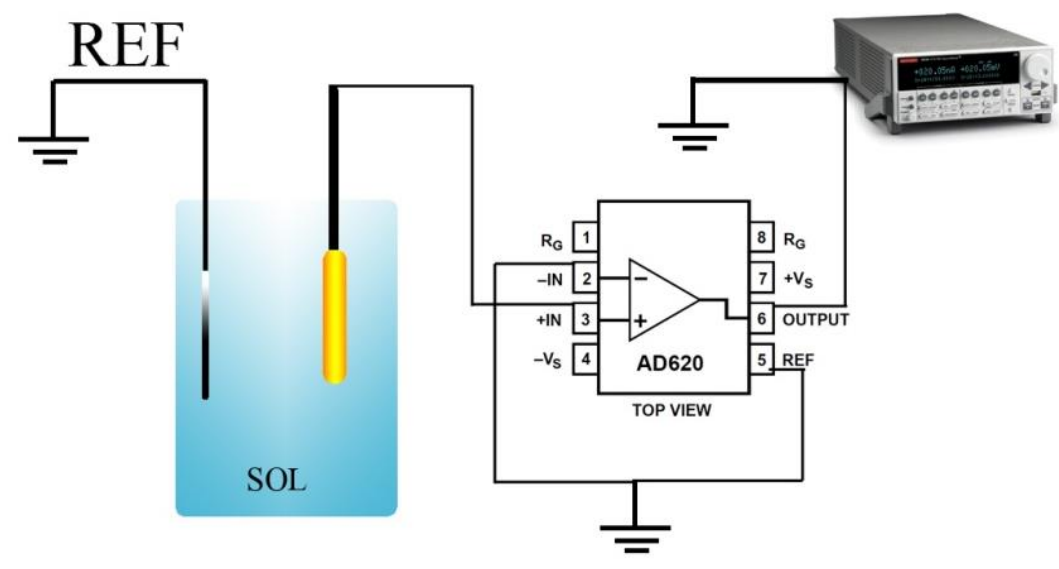

Figura 14: Diagrama do dispositivo potenciométrico. 
A escolha deste dispositivo levou em conta diversos fatores:

- Baixo custo

- Precisão

- Facilidade de operação

- Possível de implementar uma eletrônica simples com o objetivo de miniaturizar o dispositivo.

- Para amplificar um sinal é necessário somente um resistor externo, com ganho de 1 a 10.000 vezes.

- Alta impedância de entrada

- Baixo consumo (1,3 mA), útil em aplicações portáteis. 


\section{Resultados e discussão}

\subsection{Esfoliação química}

\subsubsection{Espectroscopia UV-Vis}

A verificação da presença de grafeno oxidado foi inicialmente realizada por espectroscopia UV-Vis, uma das principais técnicas de absorção utilizada na caracterização do grafeno oxidado $(52,107,108)$. Este material apresenta absorção em $230 \mathrm{~nm}$. Esta absorção corresponde às transições $\pi \rightarrow \pi^{*}$ das ligações dos anéis aromáticos $\mathrm{C}=\mathrm{C}$. Ocorre também a presença de um ombro em $300 \mathrm{~nm}$, que pode ser atribuído a transições do tipo $n \rightarrow \pi^{*}$, atribuídas a ligações do tipo $\mathrm{C}=0$. O pico em $230 \mathrm{~nm}$ tem um deslocamento batocrômico quando é submetido a uma redução, deslocando para comprimentos próximos a $270 \mathrm{~nm}$. Isto indica que a estrutura cristalina do grafeno oxidado foi parcialmente reconstituída. O desaparecimento do ombro em $300 \mathrm{~nm}$ isto indica que houve uma desoxigenação do grafeno. Na Figura 15 são mostrados os espectros de absorção do grafeno oxidado esfoliado quimicamente.

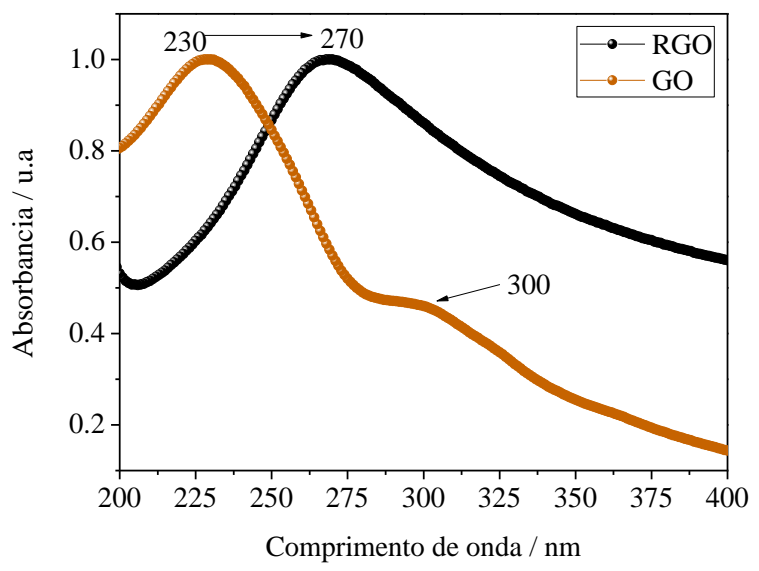

Figura 15: Espectro de absorção de grafeno oxidado em marrom (GO), e um espectro de grafeno reduzido em preto (RGO). 
A titulo de ilustração é mostrado também na Figura 15 um espectro de absorção de uma amostra de grafeno reduzido na presença de borohidreto de sódio $\left(\mathrm{NaBH}_{4}\right)$, onde observamos o pico em $270 \mathrm{~nm}$, mostrando que a rede cristalina foi parcialmente restaurada, e sem o ombro em $300 \mathrm{~nm}$, indicando que houve uma desoxigenação do grafeno oxidado.

O produto da esfoliação química gera uma dispersão viscosa e escura, quando diluído em água. Devido a problemas com precipitação, houve a necessidade de um pré-tratamento das amostras, como foi descrito no capitulo anterior. Assim obtivemos uma dispersão coloidal altamente estável em água. A Figura 16 ilustra uma amostra sem tratamento e as soluções pós-tratamento em diferentes concentrações $\left(0,05 \mathrm{gL}^{-1}, 0,1 \mathrm{gL}^{-1}, 0,5 \mathrm{gL}^{-1}, 1 \mathrm{gL}^{-1}\right)$.

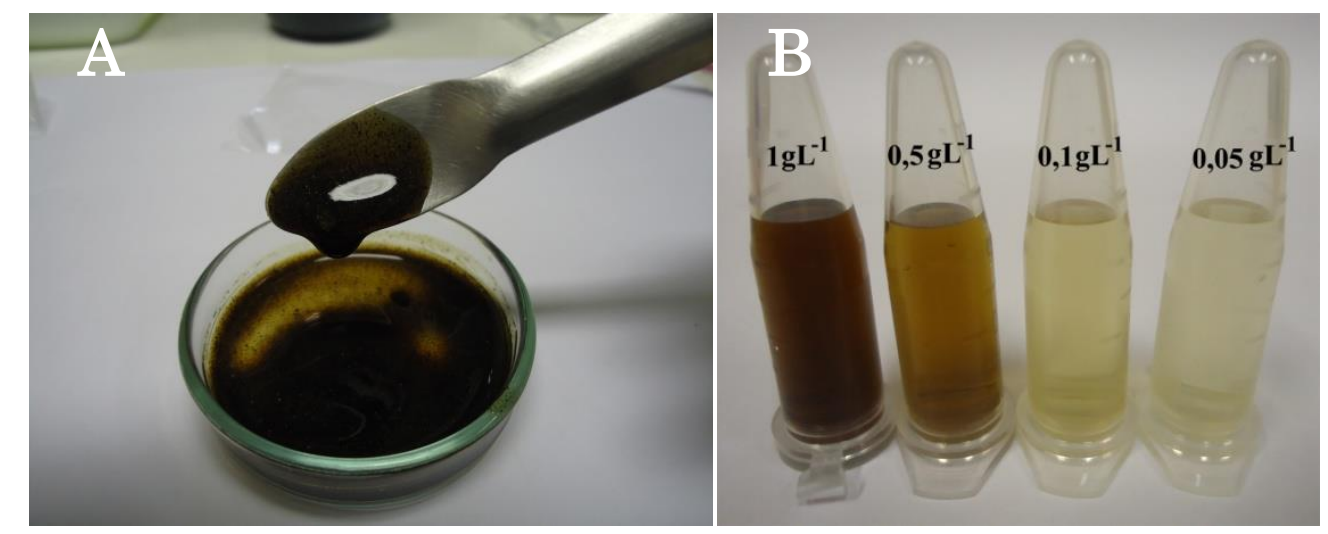

Figura 16: Solução de grafeno esfoliado quimicamente sem tratamento em A. Solução de grafeno oxidado em diferentes concentrações em B.

$\mathrm{Na}$ literatura há poucos trabalhos referentes a tratamentos do grafeno oxidado. Alguns utilizam ultracentrifugação para separar as folhas de diferentes camadas $(109,110)$. O tratamento realizado neste trabalho após a esfoliação teve por objetivo separar o grafite que não foi oxidado do grafeno oxidado. 


\subsubsection{Microscopia Ótica}

Após a esfoliação química, a microscopia ótica foi usada para avaliar qualitativamente a presença de grafeno de poucas camadas. Quando este é depositado em um substrato de óxido de silício $\left(\mathrm{SiO}_{2} / \mathrm{Si}\right)$, gera um contraste com o substrato, possibilitando sua visualização $(11,111,112)$. Desta forma, foram obtidas as seguintes imagens mostras na Figura 17, de uma amostra sem tratamento e outra tratada, com os métodos descritos na seção anterior.
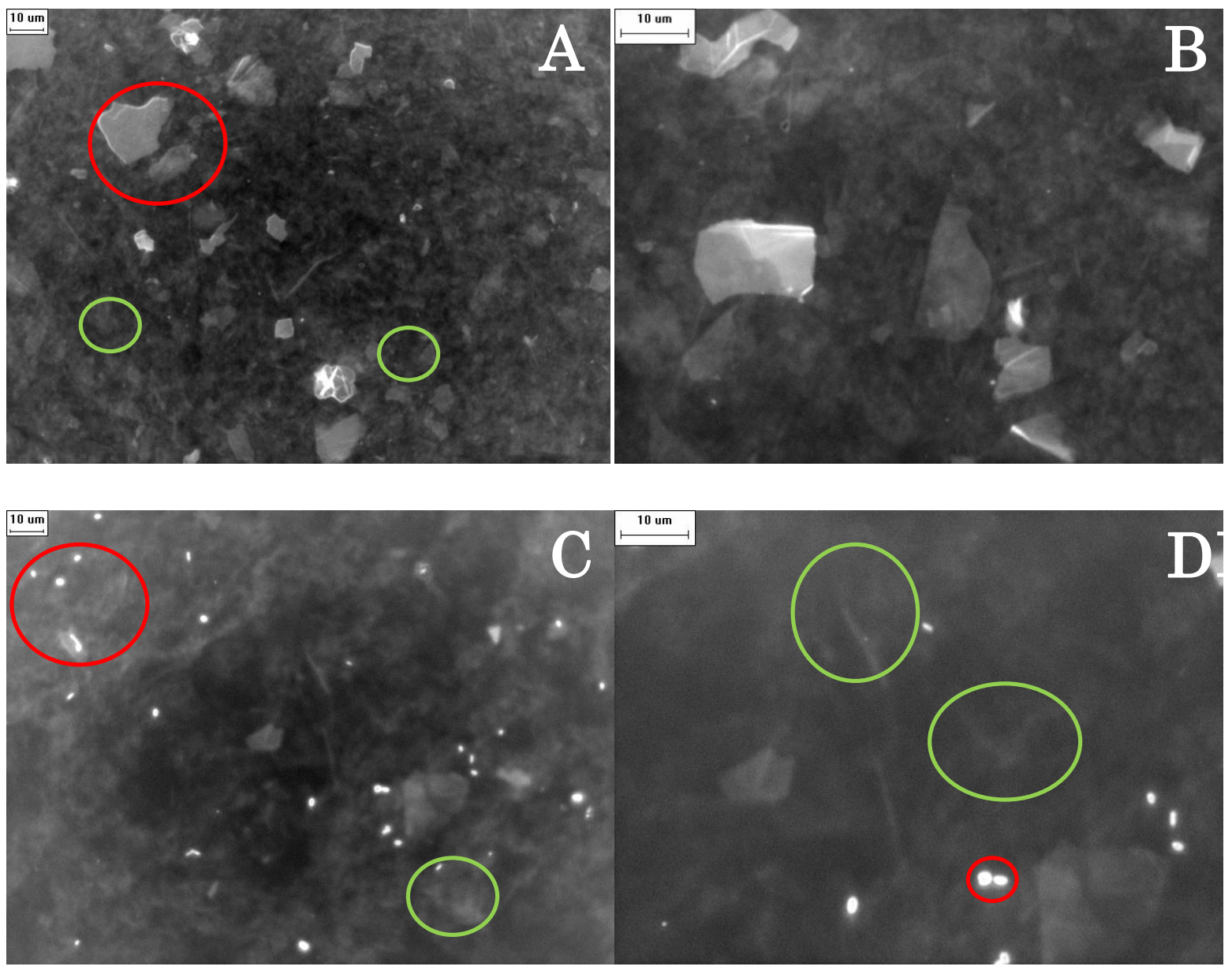

Figura 17: Microscopia ótica; A e B são de uma amostra sem tratamento após a esfoliação, A possui um aumento de 50x e B 100x. C e D são as amostras tratadas, C possui um aumento de 50x e D um aumento de 100x. Os círculos vermelhos indicam os bulks de grafite e os círculos verdes indicam a presença de grafeno oxidado de poucas camadas. 
Devido ao fato da câmera do microscópio tirar fotos somente em preto e branco, um tratamento nas imagens foi necessário pra melhor visualizar as folhas de grafeno oxidado. Fazendo um negativo na imagem original foi possível obter uma imagem com mais informações. Como é visto acima, uma amostra sem tratamento adequado apresenta uma quantidade muito maior de aglomerados de grafite. Estes precipitam poucas horas depois de preparada a solução. Com o ultrassom de ponta, estes aglomerados se quebram, formando folhas menores como é mostrado em C e D da Figura 17.

\subsubsection{Espectroscopia de raios X por dispersão em energia (EDS)}

As medidas de EDS tiveram por objetivo a análise química elementar das amostras de GO, a fim de determinar a presença ou não de contaminantes. Foram realizadas medidas de uma amostra sem tratamento e outra após o tratamento descrito no capitulo 4. Na Figura 18 mostramos essas duas amostras. Em A, temos a amostra tratada e em B, uma amostra não tratada e seus respectivos espectros.
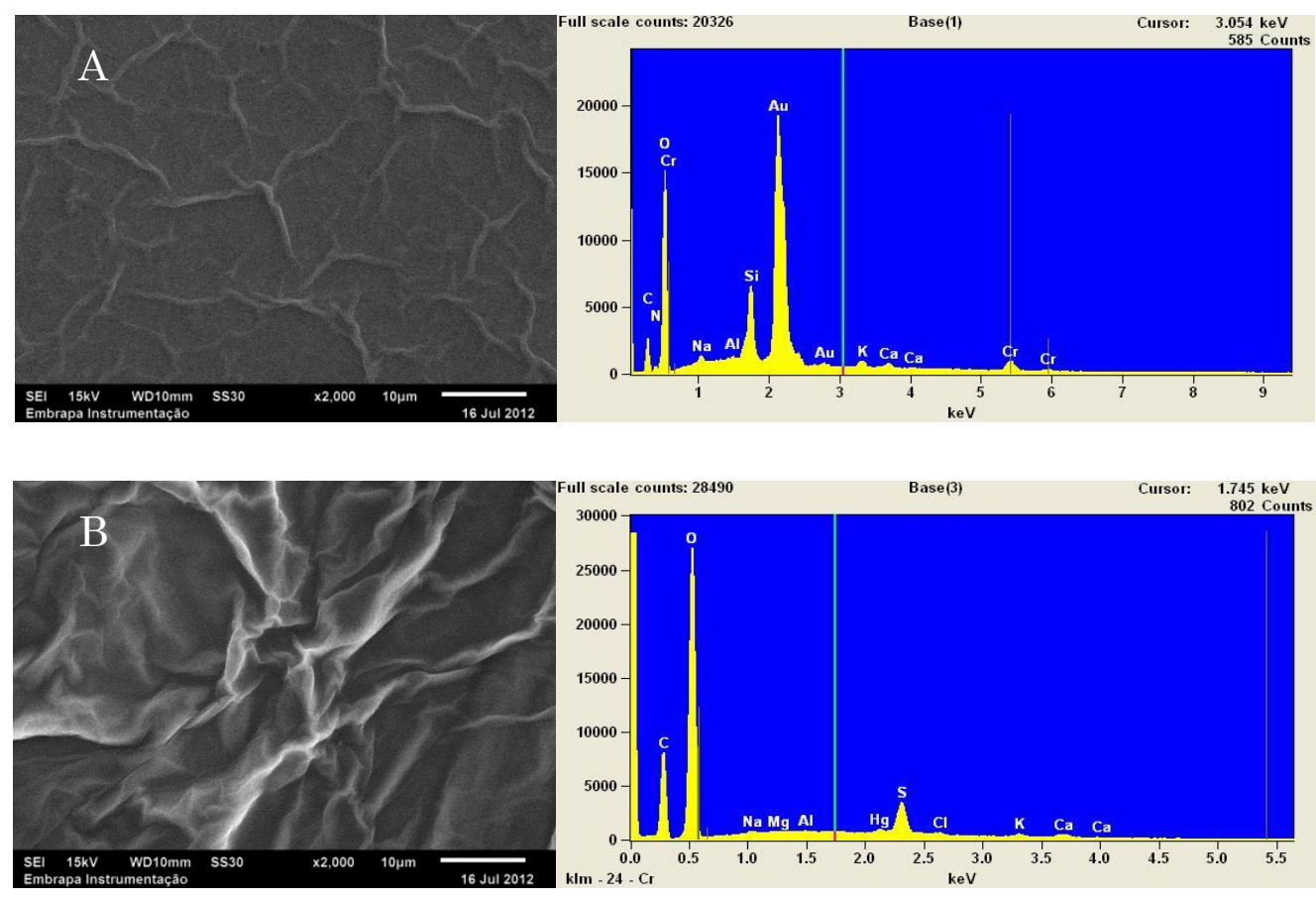


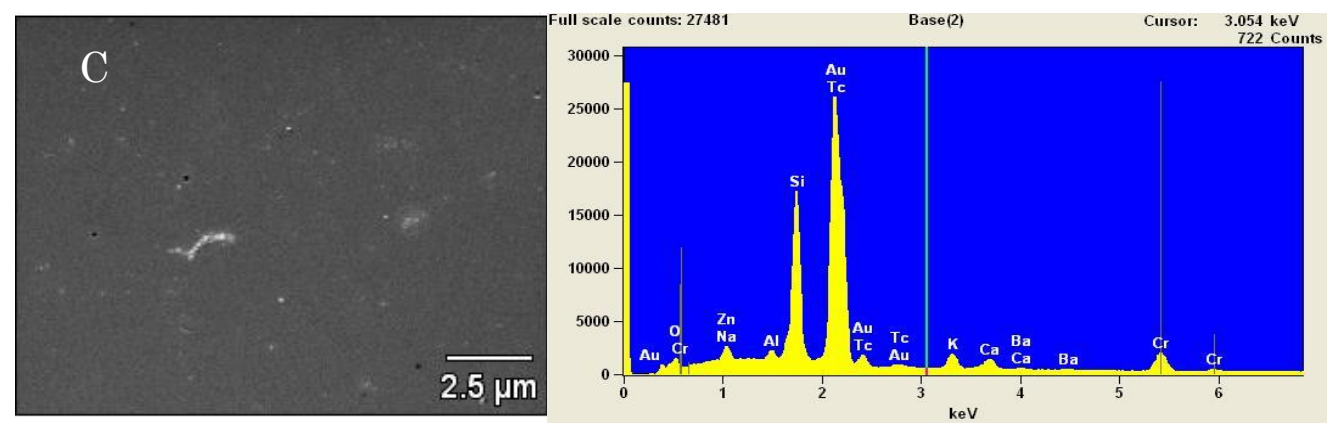

Figura 18: A) Amostra do grafeno oxidado, tratado e seu respectivo espectro EDS. B) amostra após a esfoliação. C) imagem do substrato.

A partir desses espectros, observamos que o grafeno oxidado tratado não apresenta nenhum contaminante. Baseando-se no espectro do substrato, pode-se concluir que as bandas apresentadas em A e B na Figura 18 são somente devidas ao substrato, que apresenta uma espessura de aproximadamente $100 \mathrm{~nm}$ de ouro e mais uma fina camada de cromo. Devido à espessura da amostra também ser bastante fina, pode-se concluir que a intensidade do feixe de elétrons interage com o substrato, emitindo os raios-x característicos de cada elemento. Já para a amostra sem nenhum tratamento prévio, constata-se a presença de enxofre, que é proveniente da esfoliação química, provavelmente algum resíduo de ácido utilizado. Uma análise quantitativa da composição de cada elemento não pode ser feita, devido ao equipamento possuir um erro qualitativo inerente à medida, impossibilitando a obtenção de valores corretos.

\subsubsection{Difração de raios-x}

Pela técnica de difração de raios $^{-x}$ foi possível determinar, semi quantitativamente, o número médio de camadas de GO presentes na solução esfoliada, além de determinar a distância interatômica do plano das folhas de GO.

Neste experimento foram comparados difratogramas de três amostras: grafite utilizado na esfoliação, grafeno esfoliado quimicamente sem tratamento, e 
grafeno oxidado após o tratamento. Na Figura 19, mostramos os difratogramas para as três amostras, grafeno oxidado tratado (GO-T), grafeno oxidado sem tratamento (GO-ST) e grafite.

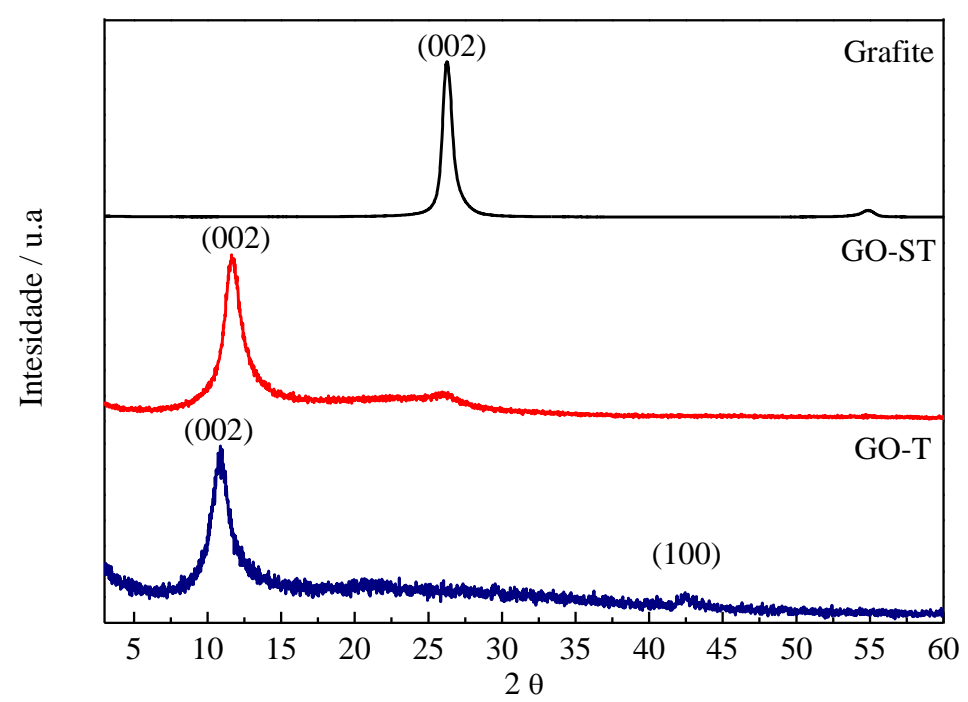

Figura 19: Difratograma das amostras de grafeno oxidado sem tratamento, tratado e grafite utilizado na esfoliação.

A partir dos dados apresentados na Figura 19 obtemos as distâncias das camadas de grafeno oxidado e o número de camadas, usando a lei de Bragg e a equação Sherrer.

Usando a equação de Bragg, onde $\theta$ é o ângulo de difração e $\lambda \quad 0$ comprimento de onda do feixe incidente, a distância interplanar pode ser descrita por:

$$
d_{(002)}=\frac{\lambda}{2 \operatorname{sen}(\theta)}
$$

A partir da equação de Sherrer podemos obter o tamanho do cristalito na direção de um plano cristalográfico. Na equação $16, \mathbf{k}$ é uma constante dependente da forma do cristalito, que vale $0,89, \beta$ é a intensidade do pico de difração a meia altura e $\theta$ o ângulo de difração.

$$
D_{(002)}=\frac{k \lambda}{\beta \cos \theta}
$$


Dividindo a equação (16) por (15), temos um número estimado médio de camadas do grafeno oxidado.

$$
\frac{D_{(002)}}{d_{(002)}} \approx N\left(\mathrm{n}^{\circ} \text { de camadas }\right)
$$

Os resultados estão descrito na tabela 2:

Tabela 2: Resultados DRX

\begin{tabular}{cccccccc}
\hline & $\begin{array}{c}\text { Largura do } \\
\text { pico }\end{array}$ & $\mathbf{2 \theta}$ & $\boldsymbol{\lambda}$ & $\mathbf{k}$ & $\mathrm{D}(002)$ & $\mathrm{d}(002)$ & $\begin{array}{c}\mathrm{N} \\
\text { (Camadas) }\end{array}$ \\
\hline GO-T & 1,45 & 10,88 & 1,5406 & 0,89 & 54,11 & 8,13 & $\approx 6$ e 7 \\
\hline $\begin{array}{c}\text { GO- } \\
\text { ST }\end{array}$ & 1,37 & 11,72 & 1,5406 & 0,89 & 57,31 & 7,54 & $\approx 7$ e 8 \\
\hline
\end{tabular}

Estes resultados são apenas uma estimativa. Experimentalmente é verificado um número maior de diferentes camadas, pois alguns fatores interferem nesses resultados, como a técnica de preparação das amostras e as limitações da equação de Sherrer. Contudo, algumas conclusões podem ser inferidas a partir dos difratogramas, como a diminuição do número de camadas, induzidas pelo ultrassom de ponta. Este também aumenta o número de defeitos na estrutura do grafeno e a intercalação de $\mathrm{H}_{2} \mathrm{O}$, aumentando a distância entre os planos cristalinos. Hun. e col. afirmam sobre a presença dessas moléculas de água entre as camadas, sendo o principal fator para o aumento das distâncias interatômicas do GO, seguido dos defeitos estruturais e a presença de grupos funcionais (113). A presença de água também foi confirmada com espectroscopia do infravermelho. Outra constatação é a presença de carbono amorfo, em ambas as amostras, revelado pelo deslocamento da linha de base dos difratogramas. Através de outras técnicas como micro espectroscopia Raman, também foi verificado a presença de carbono amorfo. Na amostra GO-ST, é verificada também a presença de grafite não oxidado, pelo aparecimento de um pico em $26,26^{\circ}$, indicando que a oxidação do grafeno não foi completa. A oxidação pode não ter ocorrido completamente, devido ao tamanho do grafite utilizado: quanto maior o cristal, menor é a superfície reativa, o que gera um menor rendimento na separação das folhas. Mas como foi verificado, a separação da parte não oxidada 
da oxidada foi realizada satisfatoriamente, não interferindo nas outras caracterizações e aplicações.

\subsubsection{Espectroscopia no infravermelho (FT-IR)}

Foram obtidos espectros vibracionais de FT-IR das amostras, para verificar a presença de grupos funcionais no grafeno oxidado. A Figura 20, ilustra um espectro de FT-IR obtido por transmissão, de $500 \mathrm{~cm}^{-1}$ a $4000 \mathrm{~cm}^{-1}$, da amostra sem tratamento (GO-ST) e de uma amostra de grafeno oxidado após o tratamento (GO-T).

As bandas na região de $2800 \mathrm{~cm}^{-1}$ a $4000 \mathrm{~cm}^{-1}$ correspondem à sobreposição das bandas $\mathrm{O}-\mathrm{H}, \mathrm{H}_{2} \mathrm{O}$ e $\mathrm{COOH}(114,115)$. A água presente na amostra se encontra intercalada nas camadas de $\mathrm{GO}$, como foi descrito no experimento de difração de raios`x. Já a banda em $1735 \mathrm{~cm}^{-1}$ pertence à vibração de estiramento da carbonila do ácido carboxílico. Quanto à banda em $1623 \mathrm{~cm}^{-1}$, ainda existem algumas divergências na determinação de sua real correspondência. Alguns autores atribuem essa banda a grupos contendo oxigênio, tais como éster, ou à presença de $\mathrm{H}_{2} \mathrm{O}$ adsorvida ou ainda a domínios não oxidados, correspondendo às ligações $\mathrm{C}=\mathrm{C}$ dos anéis benzênicos não oxidados (116-118). Nota-se uma maior intensidade dessa banda em GO-ST, o que pode ser uma evidência da presença de $\mathrm{H}_{2} \mathrm{O}$ entre as folhas, já confirmado por outras técnicas utilizadas nesse trabalho. Além disso, é interessante notar também a presença de uma nova banda em 1574 $\mathrm{cm}^{-1}$ para o GO-T. Esta banda, segundo Chabal e colaboradores, corresponde à dupla ligação $\mathrm{C}=\mathrm{C}$ da vibração no plano das folhas (115). A presença dessa banda também se encontra no grafeno quimicamente reduzido, o que reforça essa teoria.

A banda em $1420 \mathrm{~cm}^{-1}$ corresponde ao estiramento O-H (119), já o dublete 1278 e $1238 \mathrm{~cm}^{-1}$ e a banda em $835 \mathrm{~cm}^{-1}$ estão associados ao grupo epóxido. A banda em $1070 \mathrm{~cm}^{-1}$ corresponde ao estiramento $\mathrm{C}-\mathrm{O}$ (115). 


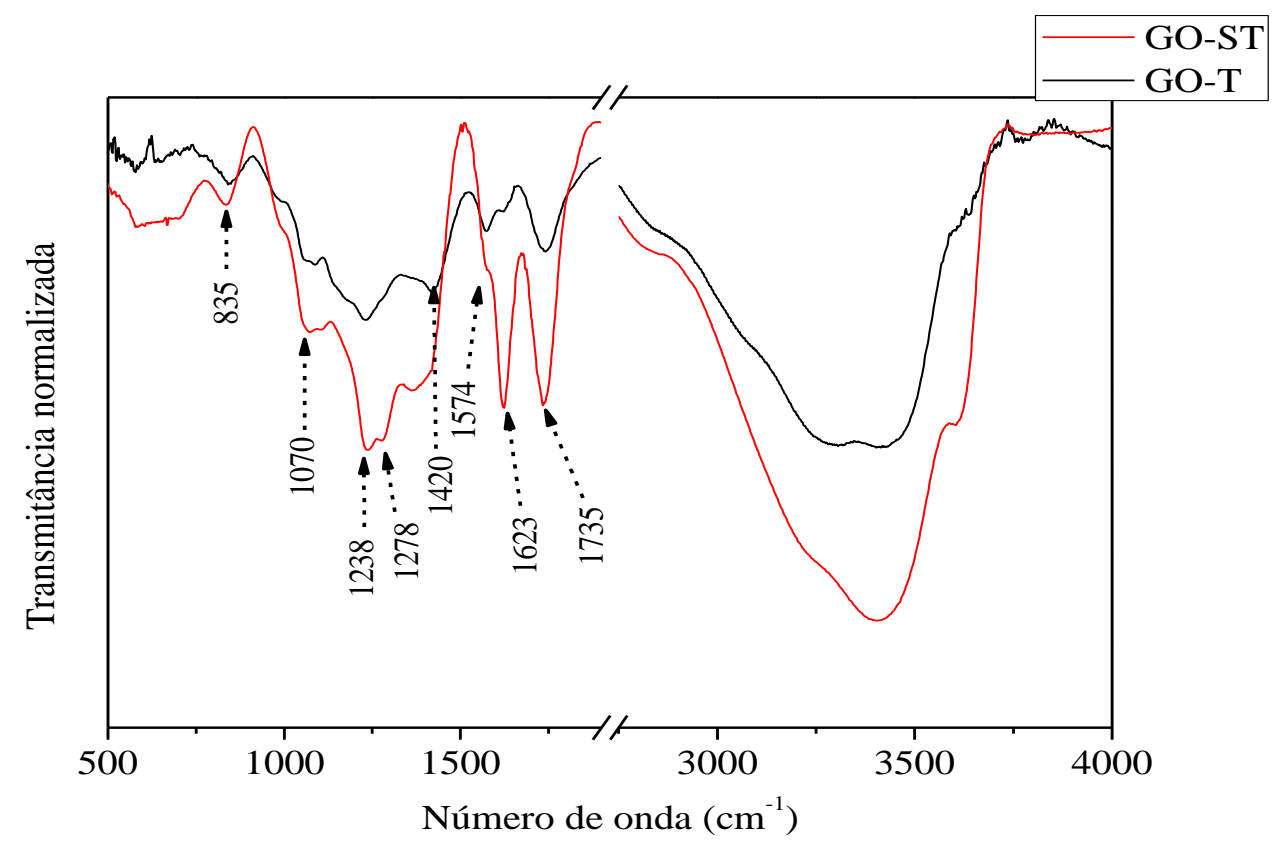

Figura 20: Espectro de infravermelho de uma amostra de grafeno oxidado.

A partir do espectro da Figura 20, temos as energias de vibração dos grupos funcionais compilados na Tabela 3.

Tabela 3: Bandas presentes no grafeno oxidado.

\begin{tabular}{c|c}
\hline Banda $\left(\mathrm{cm}^{-1}\right)$ & Grupo funcional e tipo de vibração \\
\hline 2800 à 4000 & $\mathrm{C}-\mathrm{OH}, \mathrm{H} 2 \mathrm{O}, \mathrm{O}-\mathrm{H}$; bandas sobrepostas, onde $\mathrm{H}_{2} \mathrm{O}$ corresponde água \\
& $\begin{array}{r}\text { intercalada entre as camadas do GO } \\
1735\end{array}$ \\
1623 & $\mathrm{C}=\mathrm{O}$; vibração de estiramento carbonila de grupos carboxílicos \\
1574 & $\mathrm{H}=\mathrm{C}$ : Vibrações de regiões não oxidadas. \\
1278,1238 & $\mathrm{C}-\mathrm{O}-\mathrm{C} ;$ Dublete relacionado ao grupo epóxido \\
1070 & $\mathrm{C}-\mathrm{O}$; vibração de estiramento \\
835 & $\mathrm{C}-\mathrm{O}-\mathrm{C} ;$ estiramento assimétrico \\
\hline
\end{tabular}

O conhecimento dos grupos funcionais presentes no GO é de grande importância no estudo de adsorção de filmes automontados, e na imobilização de biomoléculas, pois sabendo-se quais grupos funcionais estão presentes no material, tornou-se possível aperfeiçoar o processo de imobilização. 


\subsubsection{Espectroscopia Raman por mapeamento}

Espectroscopia Raman é uma das principais técnicas de caracterização do grafeno em suas diversas formas. Espectros de espalhamento podem ser facilmente obtidos com as técnicas atuais, sendo possível criar mapas de intensidade de uma banda especifica, criando assim uma imagem química do material analisado (120). Este experimento teve o objetivo de avaliar por micro espectroscopia Raman a qualidade das amostras esfoliadas quimicamente. O espectro Raman do grafeno é simples, com a presença de poucas bandas, mas é possível obter diversas informações sobre o material, como a estimativa do número de camadas de carbono, quantificação de defeitos e tamanho de cristalitos (121-123).

As bandas do espectro Raman do grafeno oxidado são ligeiramente diferentes do grafeno cristalino. Uma dessas diferenças é a presença de uma banda intensa de defeitos chamada de banda $\mathbf{D}$, que corresponde aos modos de respiração dos seis carbonos dos anéis aromáticos do grafeno, este modo só é ativado na presença de um defeito na rede. Como já mostrado por DRX e por FTIR, estes defeitos são devido à presença de água intercalada nas camadas de carbono, defeitos na rede, e à presença de grupos funcionais, além de um certo grau de amorfização. Uma maneira de quantificar esses defeitos é através da razão entre a intensidade da banda $\mathbf{D}$ e a banda $\mathbf{G}$ correspondente ao fônon $\mathrm{E}_{2 \mathrm{~g}}$ da zona de Brillouin. A razão $I(D) /(G)$ pode ser expressa em função das intensidades, ou da largura a meia altura (do inglês, FWHM-Full Width Half Maximum). A primeira fornece informação sobre a distorção da rede: quanto maior essa relação maior a quantidade de defeitos. A segunda abordagem fornece a informação sobre anéis com mais de seis carbonos, e formação de ligação sp³ . Quanto mais larga a banda, maiores são as quantidades desses defeitos (124). A Figura 21 ilustra uma imagem de uma folha de grafeno oxidado, onde são

representados as bandas D, G e $2 \mathrm{D}$ também denominado de (G'). Esta última é uma ressonância de segunda ordem da banda $\mathbf{D}$ fortemente dispersiva, ou seja, 
depende da energia de excitação. Essa banda esta sempre presente em grafeno e demais materiais a base de carbono.
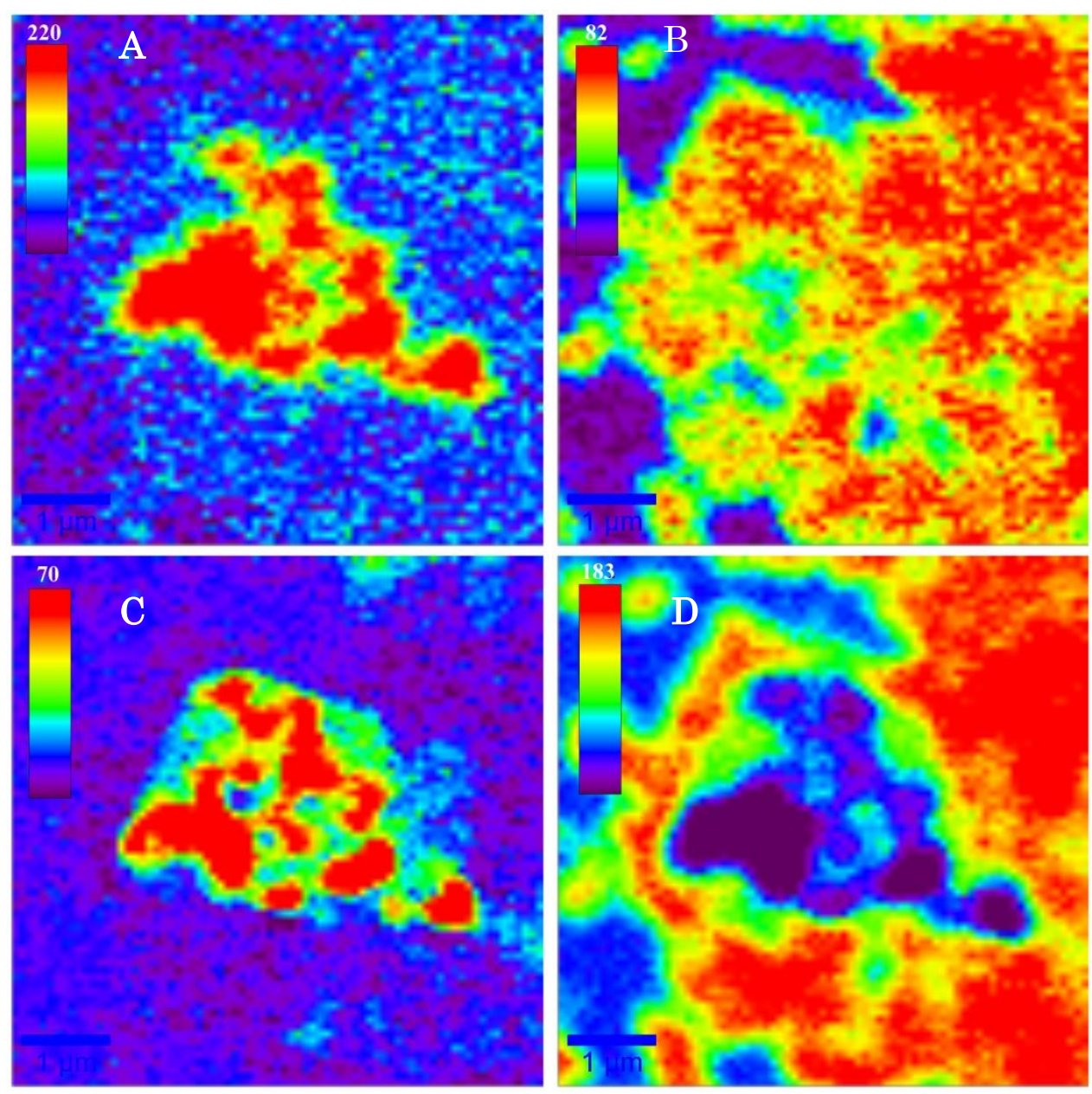

Figura 21: Mapa de intensidade Raman das seguintes bandas A) Banda 2D B) Banda D, C) Banda G referente a posição em torno de $1568 \mathrm{~cm}^{-1}$ D) Banda $G$ referente a posição em torno de $1608 \mathrm{~cm}^{-1}$.

$\mathrm{Na}$ Figura 21 as regiões em vermelho indicam a maior intensidade da respectiva banda como informado na legenda. Na Figura 21.A, é monitorada a banda 2D, onde vemos maior intensidade em uma região delimitada em vermelho. Esta região apresenta um número maior de camadas, e uma maior cristalinidade, diferentemente das regiões em azul claro, onde há uma predominância maior de defeitos. A Figura 21.B, mostra a localização da banda de defeitos, que se estende a praticamente toda a imagem, sendo mais intensa nos arredores do grafeno. Isto indica a presença de folhas de grafeno menores e mais desorganizadas, devido ao processo de oxidação e do esfoliamento induzido com o ultrassom de ponta. 
As Figura 21.C e 23.D são referentes a mesma banda G. A Figura 21.C representa onde a banda $\mathrm{G}$ está mais próxima de $1568 \mathrm{~cm}^{-1}$, e a Figura 21.D representa esta banda em torno de $1608 \mathrm{~cm}^{-1}$, podendo ser diferenciada pela localização das intensidades nas duas figuras.

A partir das imagens de espectroscopia Raman foi possível observar duas regiões distintas da amostra: uma região ao centro, e outra na borda do GO, sendo possível observar a predominância maior de defeitos nas bordas, como esperado para uma folha de grafeno esfoliado mecanicamente (121). Na Figura 22 , temos um espectro da região no centro do GO e outro espectro da borda na Figura 23, onde observa-se uma banda em $2659 \mathrm{~cm}^{-1}$ (banda 2D). No espectro Raman da região das bordas, aparecem as bandas em $2656 \mathrm{~cm}^{-1}$ (2D) e $2913 \mathrm{~cm}^{-1}$ (D+G). Nesta região foi aplicado um ajuste usando uma função lorentziana.

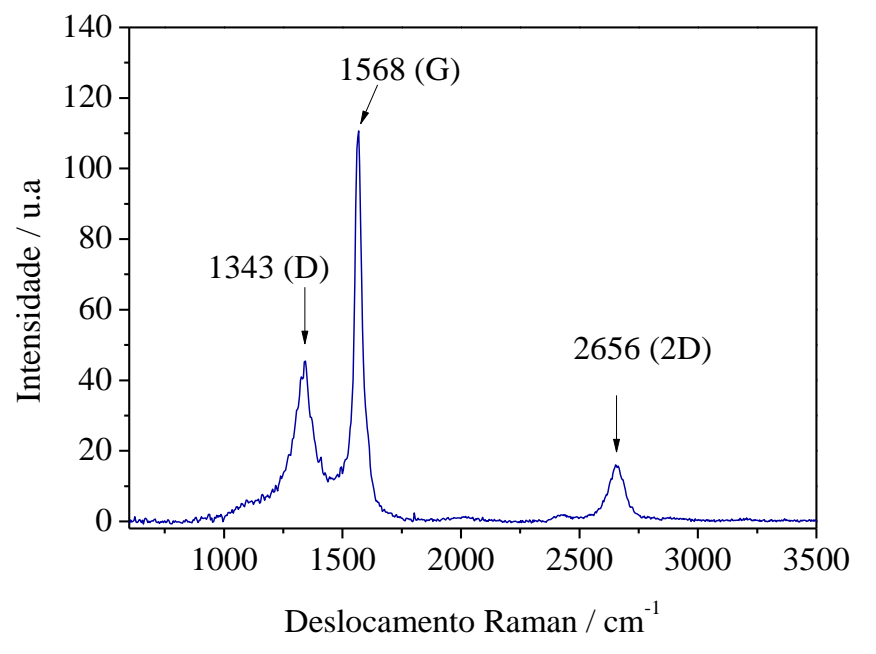

Figura 22: Espectro Raman de uma região central da folha de grafeno oxidado.

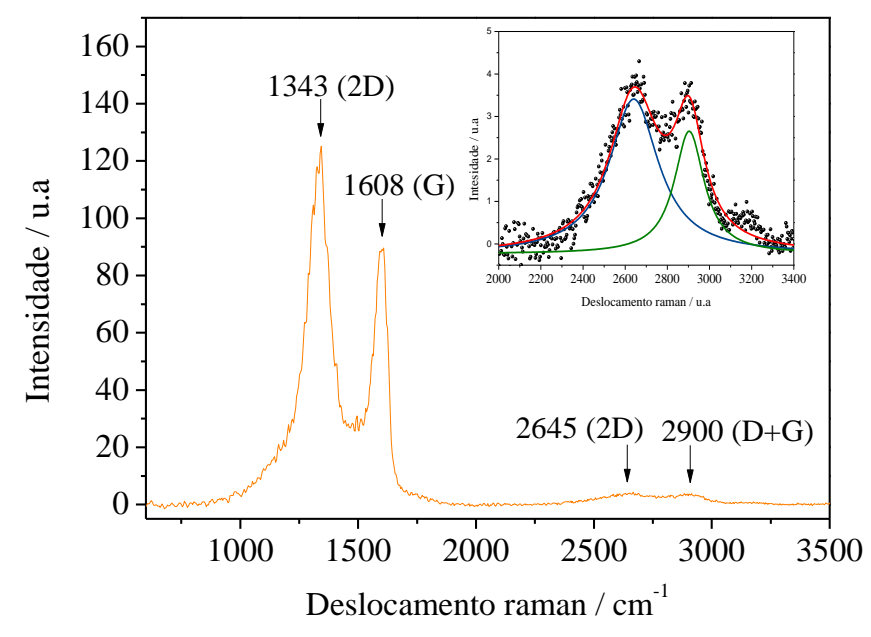


Figura 23: Espectro da borda de uma folha de grafeno oxidado. Inset: Ajuste lorentziano das bandas 2D e D+G.

A Tabela 4 mostra os valores das intensidades e posições das duas regiões da folha de GO, além dos cálculos realizados para largura a meia altura e intensidade relativa em ambos os espectros.

Tabela 4: Dados provenientes dos espectros Raman no centro do GO e em suas bordas.

\begin{tabular}{c|cccc}
\hline \multicolumn{2}{c}{ Centro } & \multicolumn{3}{c}{ Borda } \\
\hline Banda & Intensidade & $\begin{array}{c}\text { Posição } \\
\left(\mathbf{c m}^{-1}\right)\end{array}$ & Intensidade & $\begin{array}{c}\text { Posição } \\
\left(\mathbf{c m}^{-1}\right)\end{array}$ \\
\hline D & 39 & 1336 & 117 & 1332 \\
G & 109 & 1567 & 89 & 1595 \\
2D & 16 & 2656 & 3,7 & 2645 \\
D+G & & & 3 & 2900 \\
I(D)/I(G) & 0,36 & & 1,32 & \\
\hline
\end{tabular}

Da Tabela 4 observamos que os valores $\mathrm{I}(\mathrm{D}) / \mathrm{I}(\mathrm{G})$ aumentam do centro para a borda. Desta forma, podemos concluir que existe uma menor quantidade de defeitos no centro do GO, pois essa relação é diretamente proporcional a I(D)/I(G), aumentando de 0,36 para 1,32 para as bordas. Mas este resultado não é conclusivo, pois temos que considerar a posição da banda D e G. Nos dois casos a banda $\mathbf{D}$ permanece praticamente constante, enquanto que para a banda $\mathbf{G}$, temse um deslocamento significativo. Este deslocamento corresponde a uma desordem topológica, onde se tem uma relação crescente com a quantidade e a forma das ligações $\mathrm{sp}^{2}$. Já a largura a meia altura da banda $\mathbf{G}$ pode nos dizer sobre a desordem estrutural que surge devido a diferentes ângulos de ligação e distorções nos comprimentos das ligações. Um maior comprimento de ligação leva a uma maior desordem e uma maior largura a meia altura (125). Na Figura 24 temos a variação da largura a meia altura para banda $\mathbf{G}$ e $\mathbf{D}$, a razão $\mathbf{I}(\mathbf{D}) / \mathbf{I}(\mathbf{G})$, e a posição do pico da banda $\mathbf{D}$ e $\mathbf{G}$, todos em relação a um ponto no centro do grafeno oxidado da Figura 21. 


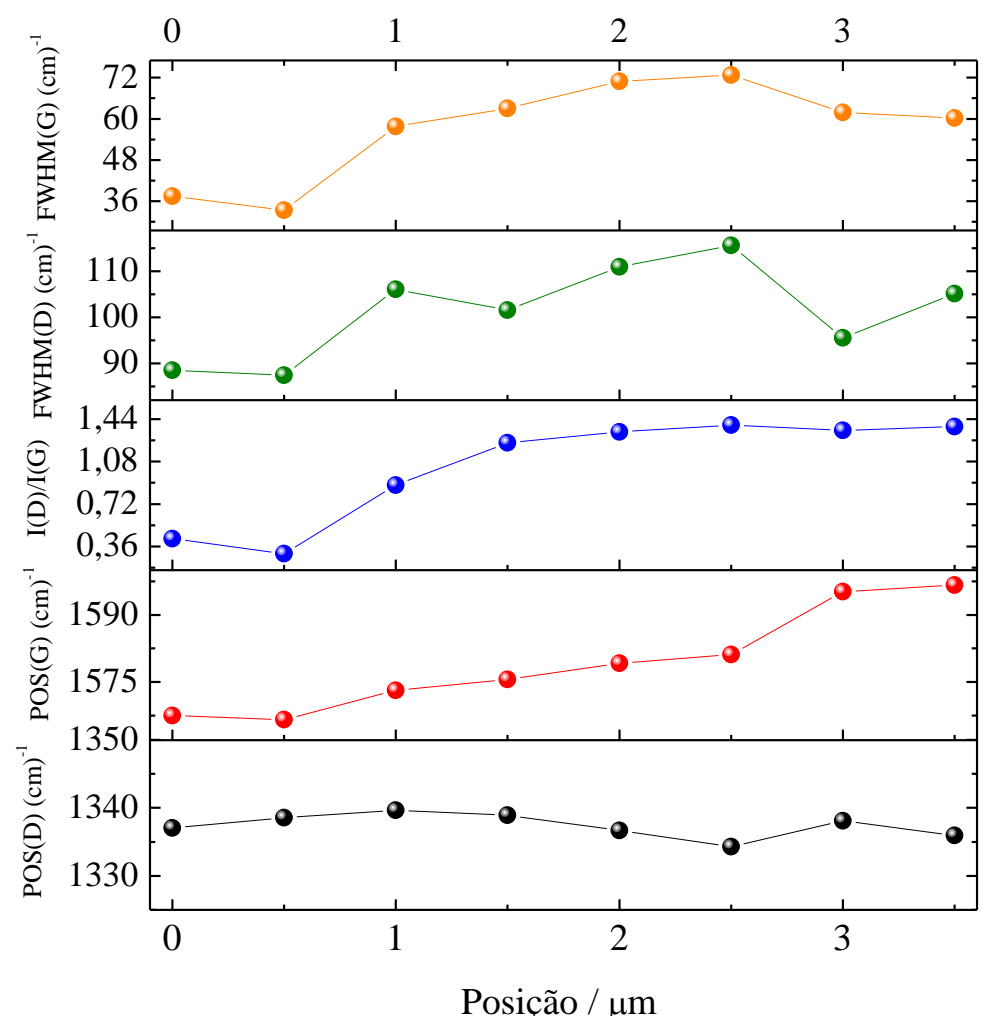

Figura 24: Estudo da posição das bandas $\mathrm{G}$ e D, e a razão $\mathrm{I}(\mathrm{D}) / \mathrm{I}(\mathrm{G})$ e a largura a meia altura de ambas as bandas em relação a um ponto referencial no centro do GO até a sua borda.

Pela Figura 24 observamos que a banda D não apresenta nenhum deslocamento, mas há aumento da largura a meia altura, o que sugere a formação de aglomerados de defeitos nas bordas, comprovado pelo aumento da relação $\mathbf{I}(\mathbf{D}) / \mathbf{I}(G)$, que corresponde ao grau de amorfização da amostra. Já o deslocamento da banda $\mathbf{G}$ sugere a formação de anéis aromáticos distorcidos e a presença de no máximo $20 \%$ de ligações do tipo $\mathrm{sp}^{3}$ no centro do GO (124). A medida que se desloca para borda, há um aumento significativo da presença de ligações do tipo $\mathrm{sp}^{3}$ que é demonstrado pela intensidade a meia altura da banda $\mathbf{G}$ (FWHM(G)), que sugere um maior comprimento das ligações (125). 


\subsubsection{Microscopia de Força Atômica (AFM)}

Por microscopia de força atômica foi estudada a morfologia e a distribuição de número de camadas das amostras. Na Figura 25 temos três imagens referentes à mesma folha de GO, obtidas por: microscopia ótica (A), microespectroscopia Raman (B) e por AFM (C).
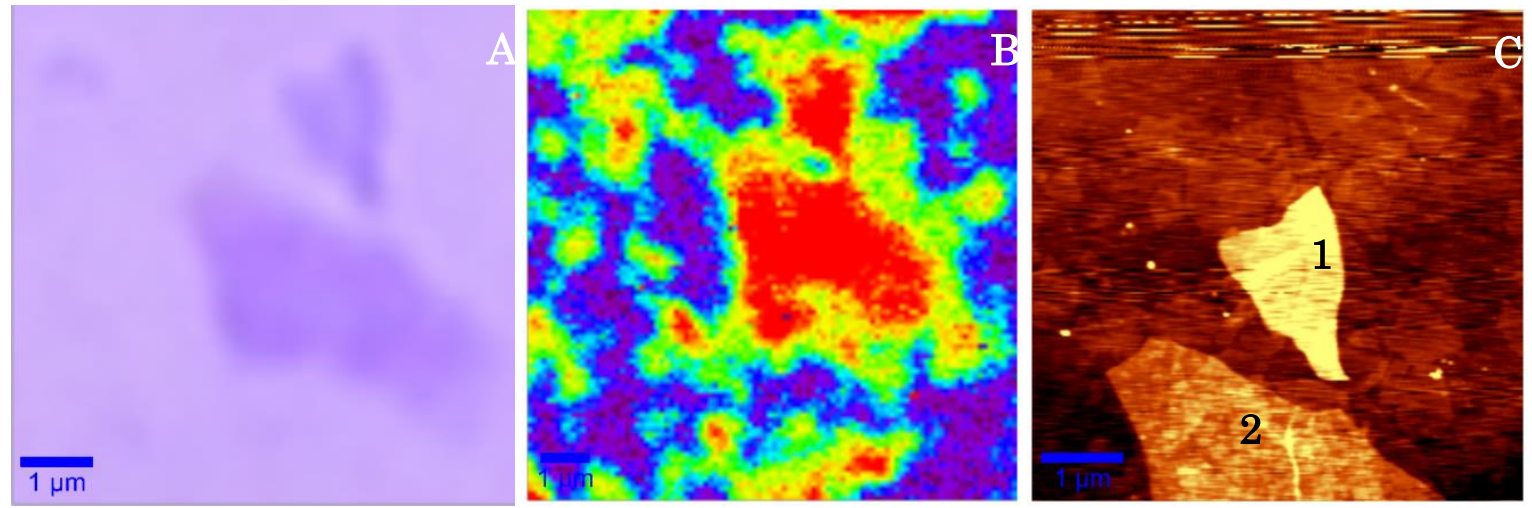

Figura 25: Comparações de imagens: A) Ótica. B) Raman (Banda D). C) AFM.

Usando a imagem ótica podemos encontrar a folha de grafeno devido ao contraste que esta faz com o substrato de $\mathrm{SiO}_{2} / \mathrm{Si}$. Já a Figura 25.B mostra um mapeamento Raman referente a banda de defeitos. Na imagem AFM, podemos observar o número de camadas e morfologia.

Da Figura 25 observamos a presença de folhas de GO de diferentes tamanhos e alturas, onde o contraste é proporcional ao número de camadas de GO. Desta imagem foi retirado um perfil de rugosidade para as duas folhas maiores, em destaque, indicadas pelos números 1 e 2, mostradas na Figura 26. 

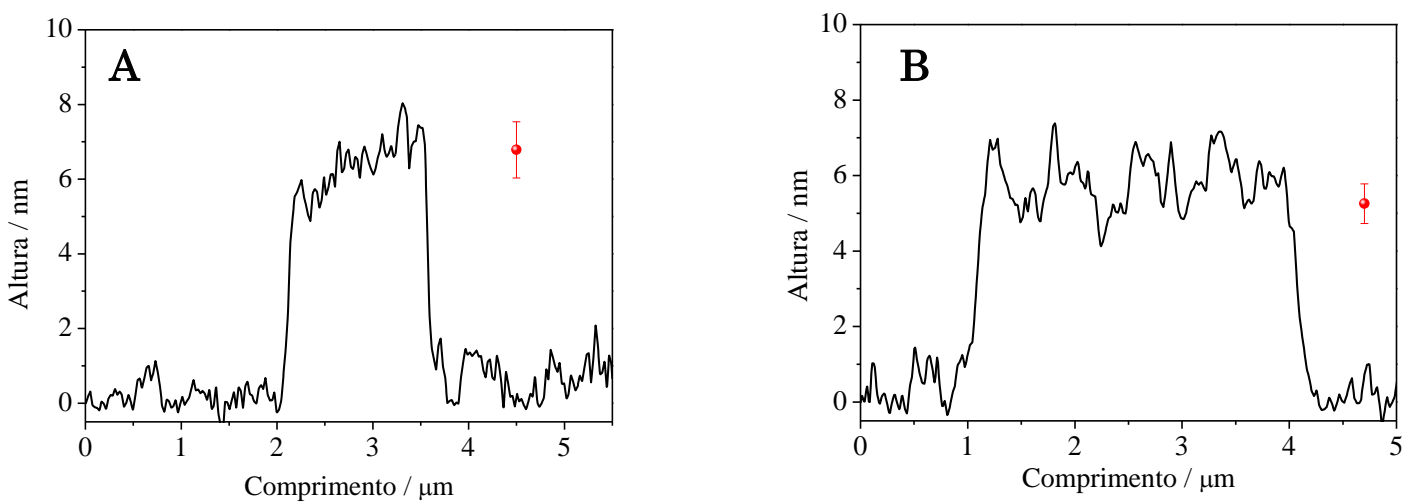

Figura 26: Perfil de rugosidade em: A) folha de GO indicada na figura 25 como 1. B) folha de GO indicada na figura 25 como 2.

Dividindo-se a altura das folhas de GO indicadas na Figura 26 pelo valor da distância interatômica obtida por difração de raiosx, para a região 1, aproximadamente oito camadas, enquanto para a região 2 , temos aproximadamente seis camadas de GO. Essa amostra também apresenta folhas de menores tamanhos e menores alturas.

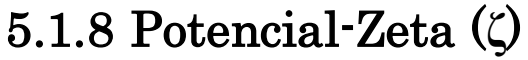

Para otimizar o processo de adsorção de filmes automontados, há a necessidade de conhecer qual a carga do eletrólito e sua estabilidade. Desta forma, foram realizadas medidas de potencial $-\zeta$, e obtivemos a magnitude e o sinal do potencial da superfície das folhas de GO, variando-se o pH de 2 a 12 . Cada ponto representa a média de três medidas e seu respectivo desvio padrão como mostrado na Figura 27. 


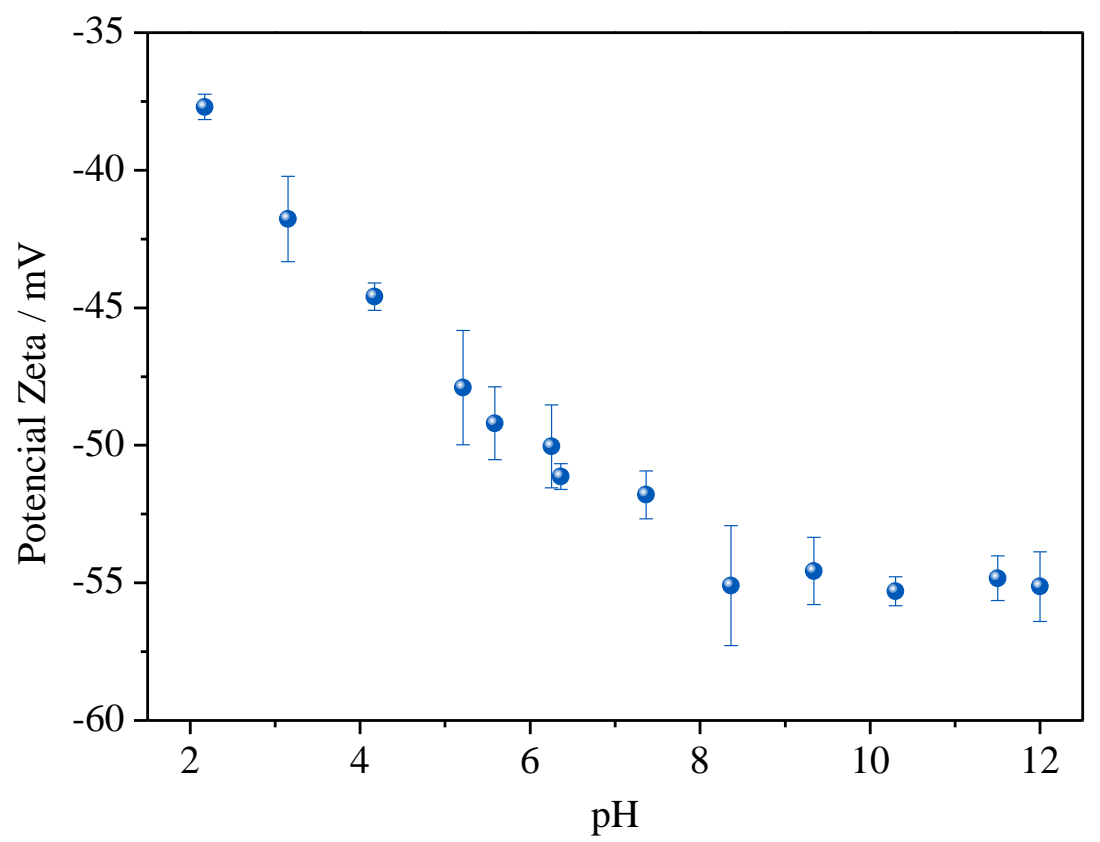

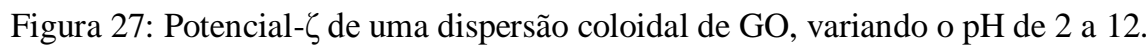

Observamos que a solução de GO é bastante estável, pois o valor de $\zeta$ é maior que $-30 \mathrm{mV}$, para toda a faixa de variação de $\mathrm{pH}$, sendo que este valor aumenta para $\mathrm{pH}$ básicos, com um máximo de $-55 \mathrm{mV}$, para $\mathrm{pH} 12$. Nesta região há uma maior repulsão entre as folhas, o que confere a sua estabilidade. Esta característica se deve principalmente à presença de grupos carboxílicos (126).

\subsection{Imobilização de GO em filmes automontados (ELBL)}

\subsubsection{Monitoramento da adsorção de filmes automontados por UV-Vis}

A fabricação de filmes automontados por ELBL requer, se possível, à análise prévia da cinética de adsorção, que geralmente é realizada através de medidas de espectroscopia UV-Vis em função do tempo, para cada camada depositada. A Figura 28 mostra a adsorção de GO sobre uma camada prévia de 
PAMAM-G4, utilizando-se 3 tempos de imersão para o grafeno $(20 \mathrm{~s}, 2$ min e 5 min), para o PAMAM-G4 o tempo foi fixado em 5 min. Cada ponto representa a média de três filmes diferentes, e em cada filme foram realizadas quatro análises. Pode-se observar a rápida adsorção do grafeno oxidado sobre as camadas de PAMAM-G4, as linhas tracejadas representam ajustes numéricos.

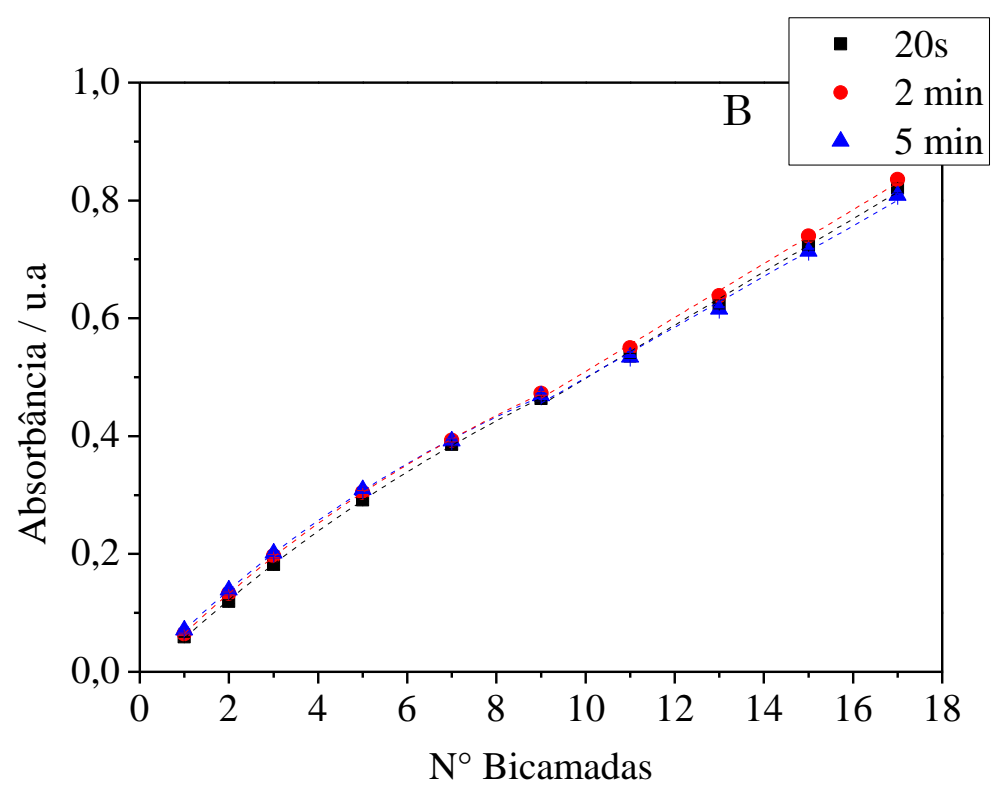

Figura 28: Crescimento de filmes automontados, absorbância por número de camadas em três tempos diferentes (20 s, 2 min e $5 \mathrm{~min})$.

No processamento camada por camada de polieletrólitos em filmes automontados é necessário controlar alguns parâmetros, como o pH da solução e a força iónica. É possível montar em escala molecular, filmes com diferentes espessuras e obter diferentes propriedades para um mesmo tipo de filme (127). Com este intuito foram analisados filmes automontados em $\mathrm{pHs}$ diferentes, e determinada a melhor solução, visando otimizar a deposição de GO. A Figura 29 ilustra a adsorção de um filme onde foram utilizados dois diferentes pHs (4 e 8). As medidas são a média de quatros pontos para cada filme depositado sobre uma lâmina de quartzo, e o pH do PAMAM-G4 foi fixado em 8. 


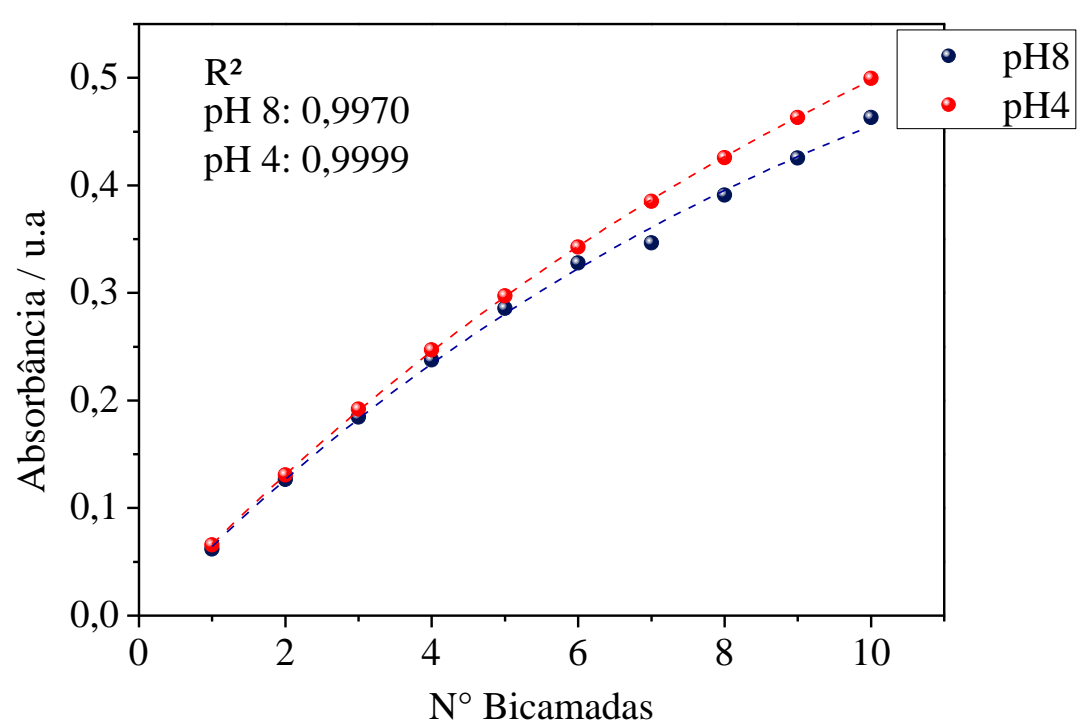

Figura 29: Crescimento LBL para dois valores de $\mathrm{pH}$ diferentes (4 e 8).

Observa-se que houve pouca influência do $\mathrm{pH}$ no crescimento dos filmes automontados, o que se deve principalmente à ionização dos grupos funcionais do GO, que apresentam três distribuições de pKas. O grupo que confere a maior estabilidade em soluções aquosas é o grupo carboxílico, e assim sendo, quando o GO está em uma solução de pH mais alto, ocorre a ionização desses grupos, fazendo com que ocorram pontes de hidrogênio intramoleculares. Este fato diminui a exposição desses grupos durante a automontagem, diminuindo assim a quantidade de espécies adsorvidas ao longo do tempo. As análises de espectroscopia UV-Vis foram realizadas com o GO solubilizado em água, onde o $\mathrm{pH}$ da solução básica foi ajustado utilizando-se $\mathrm{NaOH}$, e no ajuste do $\mathrm{pH}$ da solução ácida foi utilizado $\mathrm{HCl}$.

Com esses parâmetros definidos, foram obtidos filmes automontados com até 15 bicamadas de PAMAM-G4/GO, em três substratos diferentes. A Figura 30.A mostra um espectro UV-Vis de um filme automontado, onde se pode ver que o filme apresenta um alargamento na sua banda de absorção deslocando-se para comprimento de onda menor, comportamento esse diferente do GO em solução. E na Figura 30.B temos o monitoramento do crescimento a partir da banda de absorção em $230 \mathrm{~nm}$. 
A)

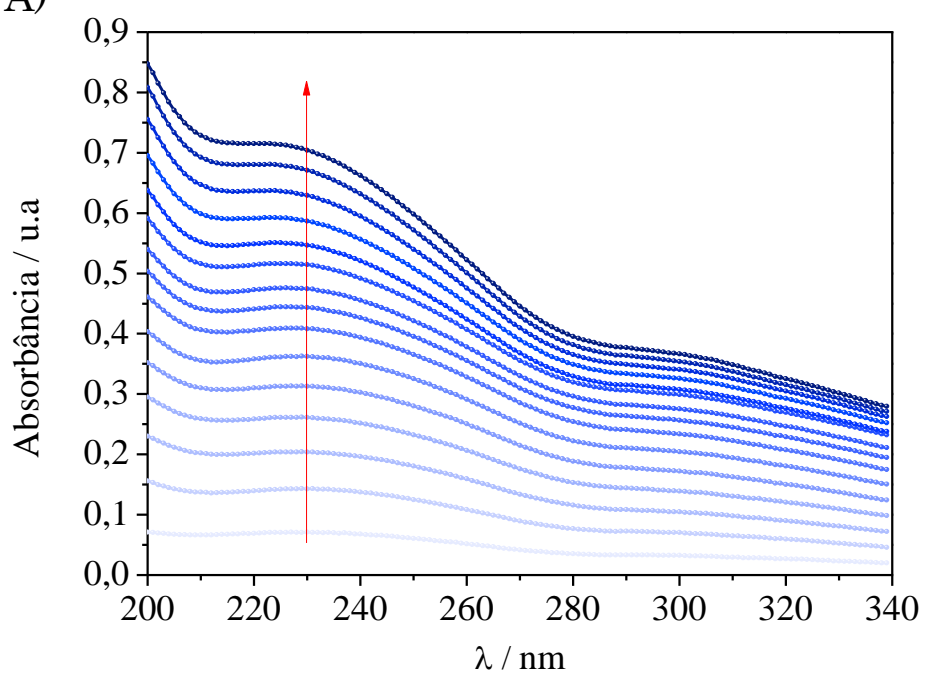

B)

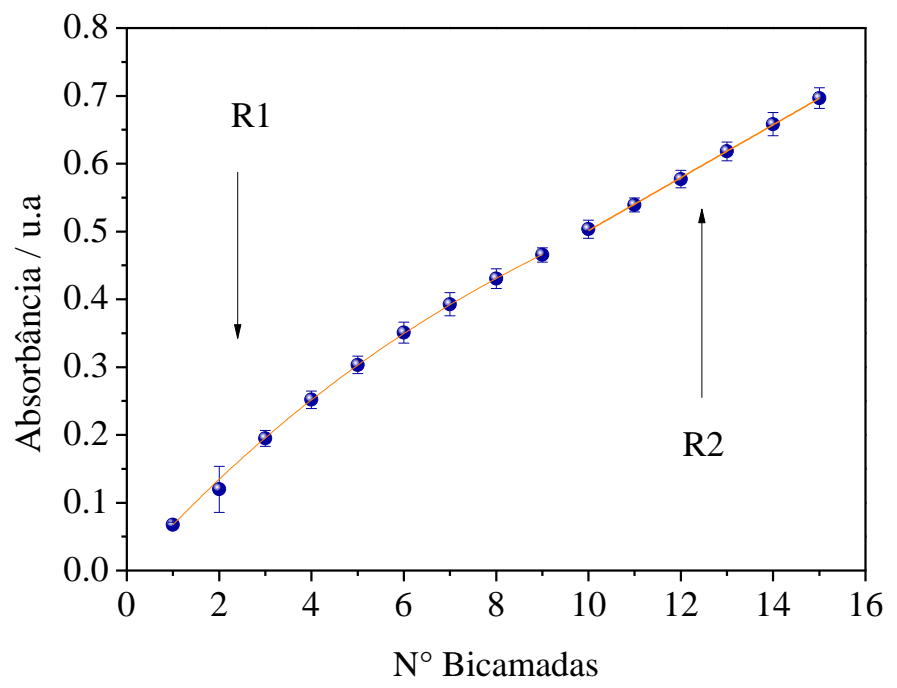

Figura 30: A) Crescimento de filme por LBL até 15 bicamadas. B) Acompanhamento do respectivo crescimento através um ponto em $230 \mathrm{~nm}$, correspondente ao pico de absorção do GO.

Através da Figura 30.B, podemos ver que o crescimento do filme é nãolinear até nove bicamadas, e a partir deste ponto se torna linear. Jiang. e col., propuseram um modelo matemático para explicar o crescimento de filmes automontados, em que eles inserem um parâmetro "q", chamado de fator de crescimento (128). Para valores de q menores que 1, o crescimento é logarítmico, para valores de q iguais a 1 , o crescimento é linear e para q maior que 1 , temse crescimento exponencial. Estes valores são derivados da equação 18: 


$$
S=\sum_{i=1}^{n} m q^{i-1}=m \times \frac{q^{n}-1}{q-1}
$$

Para a região na Figura 30.B indicada por R1, temos um valor de $q$, correspondente a 0,91 com $\mathrm{R}^{2}$ igual a 0,99987, o que indica o correto ajuste ao modelo. Já a região indicada por $\mathrm{R} 2$, temos que a equação linear para o crescimento a partir de dez bicamadas é $y=0,039 * n+0,111$. Assim, temos para cada bicamada um aumento de 0,039 unidades de absorção, onde $\mathrm{R}^{2}$ é igual a 0,99948, também mostrando o correto ajuste da equação. Este efeito é devido à mudança de morfologia que ocorre no filme com o aumento do número de camadas, por microscopia de força atômica, será visto como ocorre essa mudança.

Observando a Figura 30.A, nota-se um alargamento da banda em $230 \mathrm{~nm}$, formando um ombro.
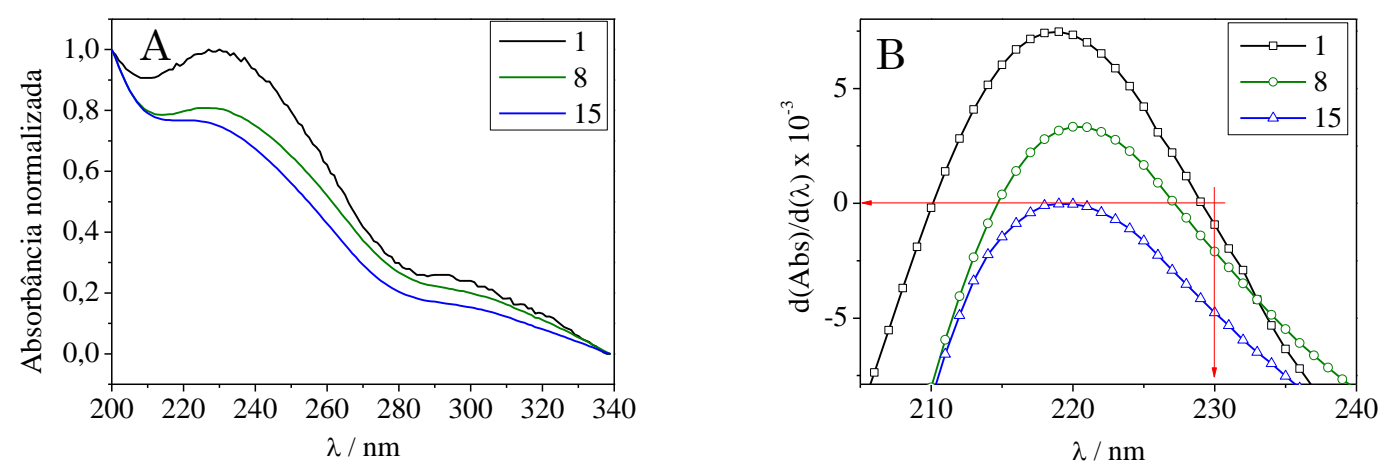

Figura 31: A) Espectro para diferentes bicamadas. B) Derivada em função do comprimento de onda.

Derivando o comprimento de onda em função da absorbância, fica mais simples a observação do comportamento da banda de absorção do filme de PAMAM-G4/GO, onde nota-se que o zero da derivada desloca-se para um valor em torno de $220 \mathrm{~nm}$ para quinze bicamadas, indicado pela seta vermelha na Figura 31.B. Este deslocamento para comprimento de ondas menores pode estar relacionado à mudança de comportamento do crescimento do filme automontado a partir da nona bicamada. Este deslocamento se torna mais evidente a partir da décima camada mostrada na Figura 31.B 
Na Figura 32, temos o aspecto dos filmes automontados em diferentes números de bicamadas.

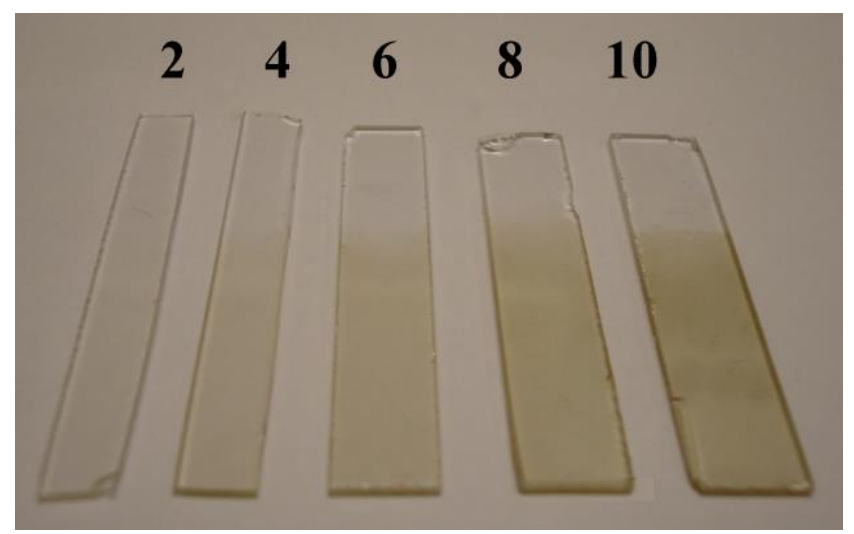

Figura 32: Filmes automontados, variando o número de bicamadas de 2 a 10 bicamadas.

\subsubsection{Espectroscopia FT-IR dos filmes automontados}

Espectroscopia no infravermelho também foi utilizada neste trabalho para determinar os tipos de interação entre as camadas dos polieletrólitos envolvidos na construção dos filmes automontados. Foram realizados experimentos de FT-IR dos filmes automontados de PAMAM-G4/GO comparando-se com espectros isolados de GO e PAMAM-G4, depositados por "drop casting" em silício. Os espectros são mostrados na Figura 33. Neste caso, as medidas foram realizadas variando-se de $600 \mathrm{~cm}^{-1}$ à $2000 \mathrm{~cm}^{-1}$, pois acima deste valor tem-se a sobreposição das bandas de $\mathrm{OH}, \mathrm{H}_{2} \mathrm{O}$, não sendo possível obter nenhuma informação relevante. 


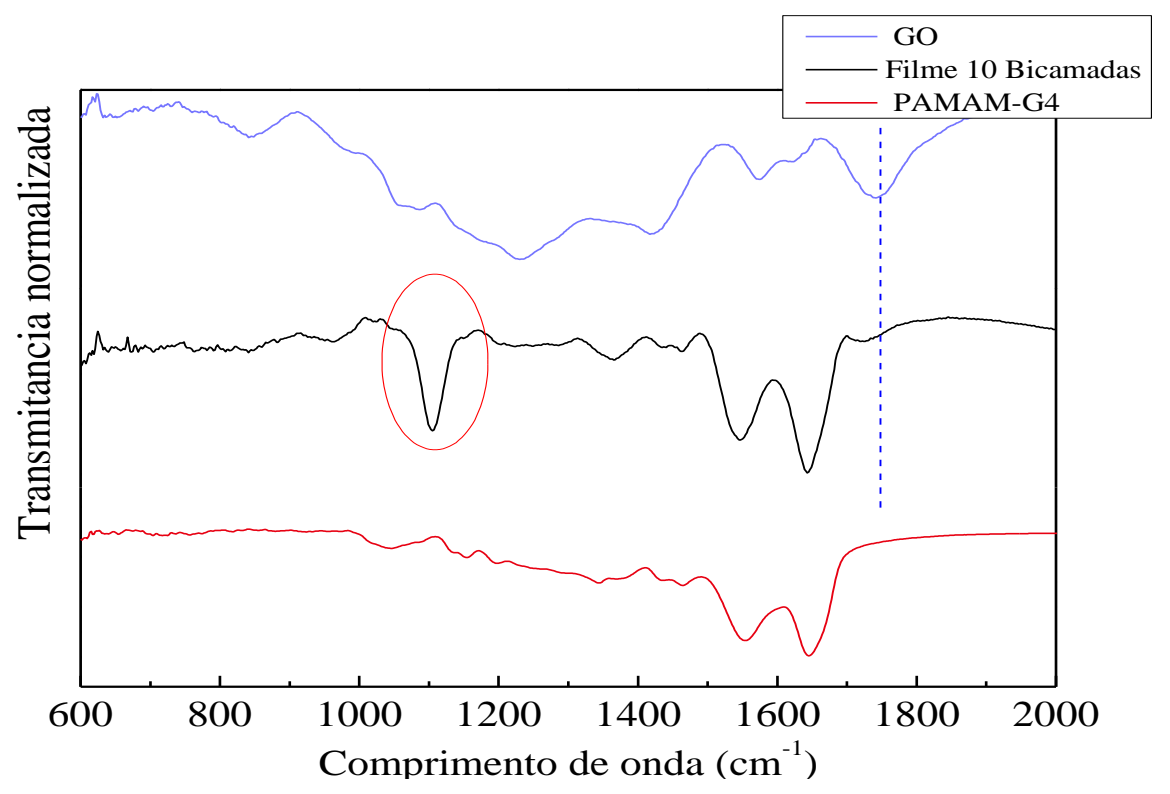

Figura 33: Espectro FT-IR, das amostras de PAMAM-G4, filme de 10 bicamadas de PAMAM-G4/GO e GO.

Como visto na Figura 33, temos os espectros para um filme de dez bicamadas de PAMAM-G4/GO, em comparação com os espectros de PAMAM-G4 e GO isoladamente. Podemos verificar a presença das bandas em $1644 \mathrm{~cm}^{-1}$ correspondente, à Amida I (estiramento $\mathrm{C}=\mathrm{O}$ ) e $1547 \mathrm{~cm}^{-1}$, correspondente à Amida II (deformação C-N). Já a banda correspondente a carbonila do grupo carboxílico do grafeno oxidado tem um deslocamento de aproximadamente $20 \mathrm{~cm}^{-1}$ no filme, em relação ao filme de "cast” de GO. Este deslocamento deve-se em princípio a interação entre esse grupo funcional com o PAMAM-G4. Também se observa uma diminuição significativa na intensidade desta banda. Uma possível explicação é a criação de ligações covalentes entre os grupos carboxílicos do GO e grupos amina do PAMAM-G4. Isto é corroborado pela presença de uma nova banda intensa em $1105 \mathrm{~cm}^{-1}$, indicada pelo circulo vermelho na Figura 33, esta banda é referente a ligações C-N (129). Liu e colaboradores utilizaram espectroscopia de fotoelétrons excitados por raios-x (XPS) e analise termogravimétrica (TGA) para mostrar a formação de ligações de C-N, durante a redução do grafeno oxidado, na presença de PAMAM de terceira geração em temperatura e pH específico (130). Este tipo de ligação é do tipo peptídica, mas não ocorre espontaneamente, sendo necessária uma energia para sua ativação, e em filmes automontados, as interações ocorrem essencialmente por interações eletrostáticas e pontes de hidrogênio. Ligações covalentes não são comuns a este 
tipo de filme, e uma possibilidade seria a presença de algum contaminante incorporado no GO e que estaria atuando como catalisador. Mais estudos são necessários para elucidar esse fato.

Já as bandas em $1623 \mathrm{~cm}^{-1}$ e $1574 \mathrm{~cm}^{-1}$ do grafeno oxidado são sobrepostas pelas bandas das amidas do PAMAM-G4, o que é devido ao fato da banda 1574 $\mathrm{cm}^{-1}$ do GO ser pouco infravermelho ativo, sendo bem melhor visualizada por espectroscopia Raman. As bandas referentes ao grupo funcional epóxido não estão presente no filme, desta forma existe a possibilidade de estar ocorrendo algum tipo de ligação referente a este grupo com o PAMAM-G4, também relacionado a presença a banda em $1105 \mathrm{~cm}^{-1}$.

$\mathrm{Na}$ Tabela 5, temos um resumo das bandas presentes no filme e nos componentes do filme isoladamente.

Tabela 5: Bandas referentes ao PAMAM-G4, filme PAMAM-G4/GO e GO.

\begin{tabular}{|c|c|c|c|}
\hline Banda $\left(\mathrm{cm}^{-1}\right)$ & PAMAM-G4 & Filme(PAMAM-4)/GO & GO \\
\hline 1742 & & & $\mathrm{C}=\mathrm{O}$ \\
\hline 1722 & & $\mathrm{C}=\mathrm{O}$ & \\
\hline 1644 & Amida I; estiramento $\mathrm{C}=\mathrm{O}$ & Amida I; estiramento $\mathrm{C}=\mathrm{O}$ & \\
\hline 1547 & Amida II; deformação C-N & Amida II; deformação C-N & \\
\hline 1464 & $\mathrm{H}-\mathrm{C}-\mathrm{H}$; dobramento angular & $\mathrm{H}-\mathrm{C}-\mathrm{H}$; dobramento angular & \\
\hline 1434 & $\begin{array}{l}\text { H-C-H; deformação } \\
\text { assimétrica }\end{array}$ & $\begin{array}{c}\text { H-C-H; deformação } \\
\text { assimétrica }\end{array}$ & \\
\hline 1420 & & & $\mathrm{O}-\mathrm{H}$ \\
\hline 1365 & & $\mathrm{O}-\mathrm{H}$ & \\
\hline 1343 & $\begin{array}{c}\mathrm{H}-\mathrm{C}-\mathrm{H} \text {; estiramento } \\
\text { simétrico }\end{array}$ & & \\
\hline $\begin{array}{l}1230 \\
1200\end{array}$ & & & $\mathrm{C}-\mathrm{O}-\mathrm{C}$ \\
\hline 1154 & $\mathrm{C}-\mathrm{C}$; estiramento simétrico & & \\
\hline 1105 & & $\mathrm{C}-\mathrm{N}$ & \\
\hline 1045 & $\begin{array}{l}\text { Amina terciaria } \mathrm{C}-\mathrm{N} \\
\text { estiramento simétrico }\end{array}$ & & \\
\hline 843 & & & $\mathrm{C}-\mathrm{O}-\mathrm{C}$ \\
\hline
\end{tabular}




\subsubsection{Microscopia de força atômica dos filmes automontados}

Foram realizadas medidas de microscopia de força atômica dos filmes automontados contendo uma e três bicamadas. A morfologia está diretamente ligada à sensibilidade dos filmes. Na Figura 34 temos as imagens para os filmes de uma e três bicamadas.
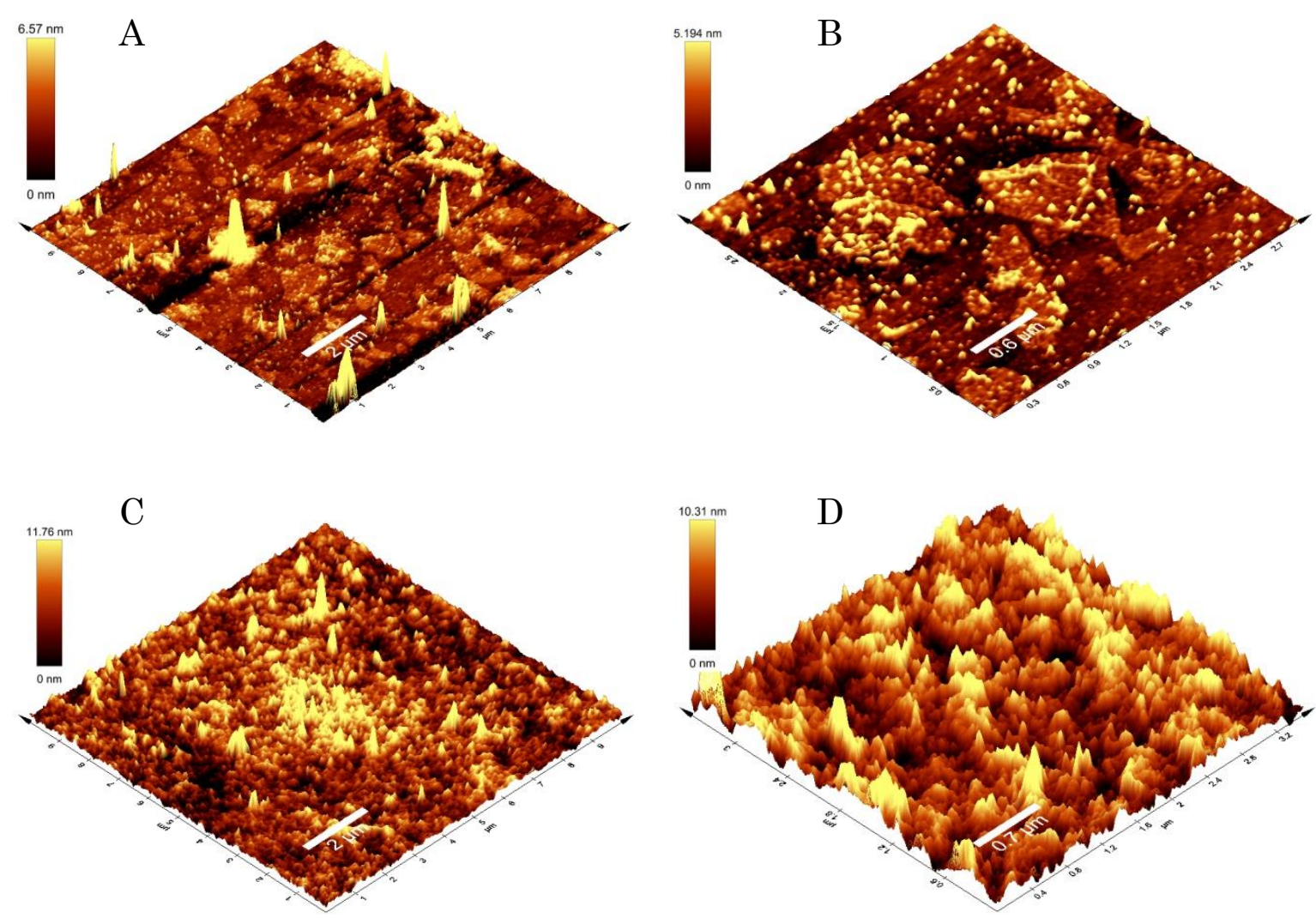

Figura 34: Microscopia de força atômica de filmes PAMAM-G4/GO: A) filme de 1 bicamada 10 x $10 \mu \mathrm{m}$ b) 1 bicamada área $3 \times 3 \mu \mathrm{m} \mathrm{C}$ ) filme de 3 bicamadas $10 \times 10 \mu \mathrm{m} \mathrm{D)} 3$ bicamadas área $3 \times 3 \mu \mathrm{m}$.

Na Figura 34.A e 34.B observamos a primeira camada de GO depositada, onde verifica-se a presença de folhas de GO. Traçando um perfil de rugosidade, temos a predominância de monocamada e bicamadas de grafeno oxidado. É interessante notar que para a primeira bicamada de PAMAM-G4/GO, existe uma auto-organização das folhas de GO no substrato. A partir da Figura 34.A, foi obtido um histograma com média de altura de cinquenta folhas de grafeno 
oxidado, escolhidas aleatoriamente na imagem, presentes no filme de uma bicamada, mostrado na Figura 35.B. Também foram analisados os comprimentos em relação ao eixo X e ao eixo Y, mostrado na Figura 35.C e D e da Figura 34.B, retirou-se a informação mostrada no histograma da Figura 35.A.
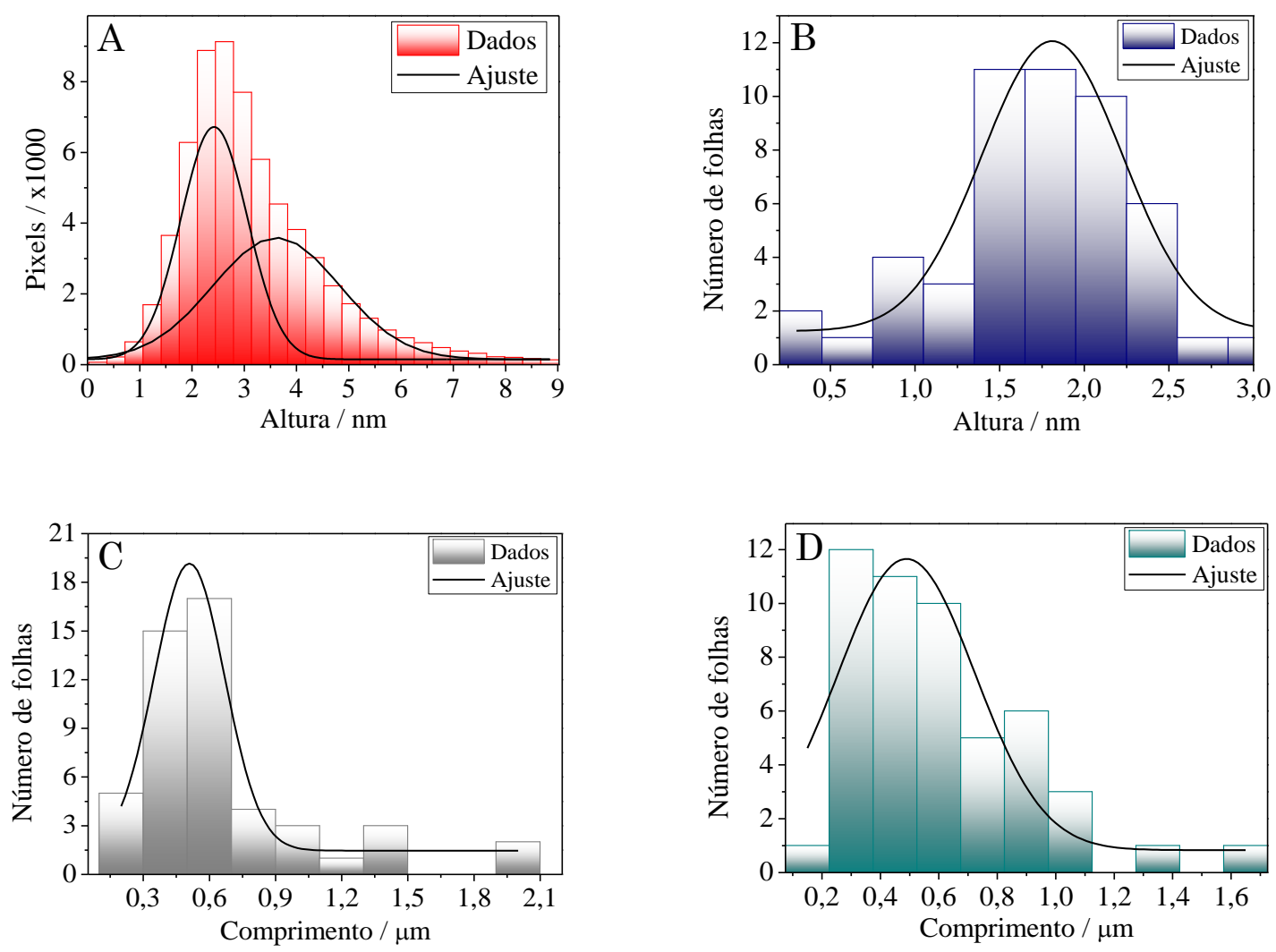

Figura 35: Histogramas: A) Número de pixels em função da altura, referente a figura 34.B. B) Distribuição de alturas de um conjunto de 50 folhas de GO presente na figura 34.A. C) Distribuição de comprimento no eixo X. D) Distribuição de comprimento no eixo y.

Com base nas análises de AFM inferimos que temos duas populações de altura, presentes na Figura 35.A, correspondendo a $2,4 \mathrm{~nm}$ e a $3,6 \mathrm{~nm}$. A primeira corresponde a altura média das folhas de GO, e a segunda, está relacionada a presença de PAMAM-G4. Observamos na Figura 35.B pontos mais claros, distribuídos entre 3,5 a $5 \mathrm{~nm}$ de altura e uma largura em torno de 50 a 80 $\mathrm{nm}$, formando pequenas esferas, o que indica a possível formação de aglomerados do dendrímero.

Pela observação da primeira bicamada adsorvida de GO, nota-se que a adsorção sobre uma superfície carregada positivamente é bastante eficiente na separação das camadas de GO, visto que em uma dispersão coloidal deste 
material é provável encontrar uma maior dispersão nas alturas das folhas. Com o ajuste gaussiano, a altura média foi estimada em torno de 1,8 $\mathrm{nm}$. Dividindo este valor pelo valor encontrado por difração de raios-x, e levando em consideração a rugosidade da superfície, temos que o número médio de camadas de GO no filme está em torno de 1 a 2.

As Figura 35.C e 36.D mostram a distribuição de tamanhos das folhas de GO nos eixos X e Y respectivamente, e observa-se que o tamanho médio em X e Y está em torno de $500 \mathrm{~nm}$, Com poucas folhas em torno de $1 \mu \mathrm{m}$. Nota-se também que o ajuste gaussiano se estende para valores abaixo de $100 \mathrm{~nm}$, podendo haver outra população de tamanho nessa região.

Na Figura 34.C e 35.D, temos uma imagem bem diferente da amostra de uma bicamada, onde não é mais possível diferenciar as folhas de grafeno isoladamente. Observa-se que houve uma grande mudança na morfologia, com o filme preenchendo todo o substrato, diferentemente da amostra com uma bicamada. Este fato está relacionado com o aumento da sensibilidade do filme PAMAM-G4/GO à mudanças de $\mathrm{pH}$, como será visto no próximo tópico, pois há um aumento da rugosidade, e assim uma área superficial específica maior. $\mathrm{Na}$ Tabela 6 temos os parâmetros de rugosidade para os filmes com uma e três bicamadas, onde $\boldsymbol{R}_{\mathbf{a}}$ é o parâmetro de rugosidade média e $\mathbf{R}_{\mathbf{r m s}}$, a rugosidade média quadrática.

Tabela 6: Parâmetros de rugosidade.

\begin{tabular}{l|cc}
\hline & 1 Bicamada & 3 Bicamadas \\
\hline $\mathbf{R}_{\mathrm{a}}(\mathrm{nm})$ & 0,51 & 2,58 \\
$\mathbf{R}_{\mathrm{rms}}(\mathbf{n m})$ & 0,66 & 3,60 \\
Min \& Máx (nm) & $-2,83 ; 4,65$ & $-10,60 ; 71,07$ \\
\hline
\end{tabular}




\subsection{Aplicação de filmes automontados de PAMAM-G4/GO como sensores potenciometricos.}

Visando uma aplicação para os filmes automontados de PAMAM-G4/GO em sensores, foi realizada a caracterização elétrica do sistema. Utilizando o sistema descrito em materiais e métodos, foram realizadas medidas de potenciometria, usando o AD620, no esquema mostrado na Figura 36.

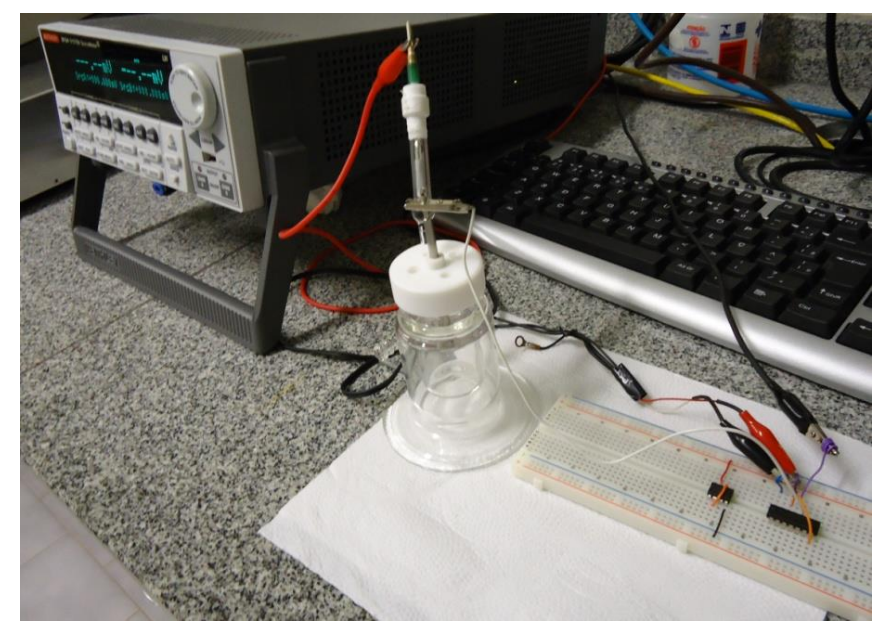

Figura 36: Esquema da montagem do experimento de potenciometria.

Utilizando soluções tampão comerciais, foram realizadas medidas de potencial em função do tempo, variando-se o pH de 2 a 12 . Na Figura 37 temos uma típica curva desse experimento para um filme de PAMAM G4/GO com três bicamadas depositadas sobre substratos de ITO. 
A)

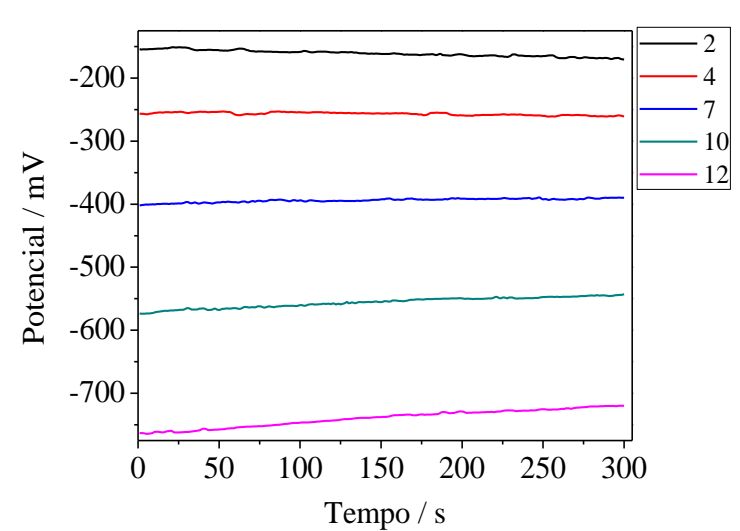

B)

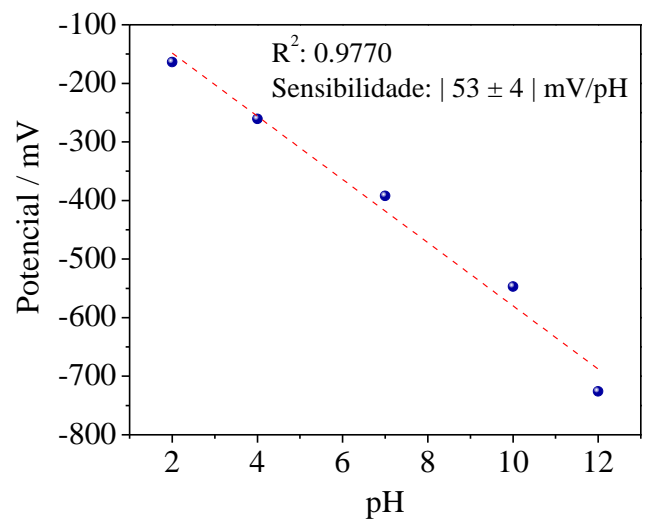

Figura 37: A) Curvas de resposta do sistema em função do tempo. B) Sensibilidade do filme de GO em ITO.

É conhecido que para um substrato de ITO em medidas potenciométricas, sua sensibilidade pode variar com o tempo, principalmente para soluções ácidas, que tem efeito corrosivo na sua superfície, além do aumento da sua função trabalho $(131,132)$. A Figura 38, mostra duas curvas de sensibilidade em função do tempo, com uma comparação entre um filme automontado com três bicamadas de PAMAM-G4/GO em ITO, e um eletrodo de ITO sem filme. Nota-se que apesar de o filme diminuir a sensibilidade do eletrodo, este é estável com o tempo. O ITO é um semicondutor nernstiano e diversas aplicações são relatadas na literatura (133), mas como demonstrado na Figura 38, este material possui um "drift" de potencial bastante acentuado, sendo difícil a reprodução dos mesmos resultados em condições que não sejam as mesmas.

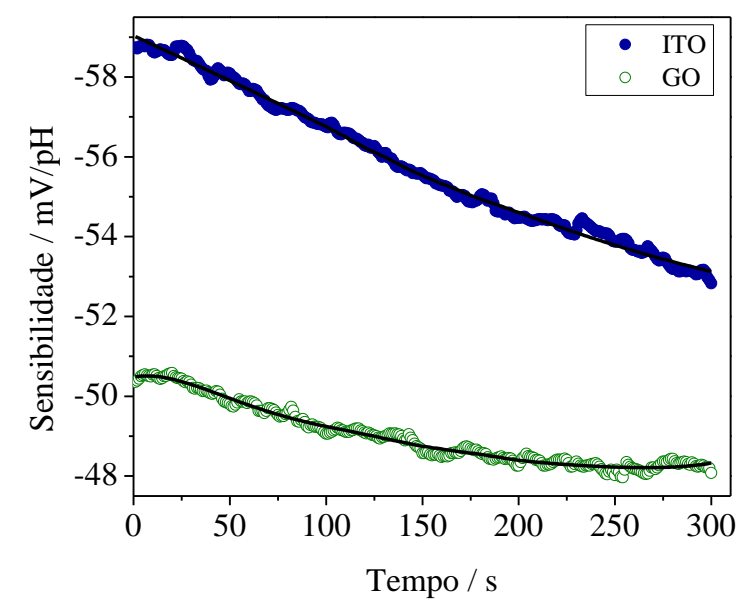

Figura 38: Sensibilidade em função do tempo para ITO limpo e um filme de três bicamadas de PAMAM$\mathrm{G} 4 / \mathrm{GO}$. 
Somente pelo uso do ITO, como visto na Figura 38, já é possível obter uma boa sensibilidade na variação de $\mathrm{pH}$, assim sendo, não é possível saber se a sensibilidade mostrada na Figura 38 é devido a presença do filme ou se essa sensibilidade é própria do ITO. Para verificar esse efeito, filmes de PAMAMG4/GO, foram montados em substratos com uma nanocamada de $\mathrm{Au} / \mathrm{Cr}$ depositadas por evaporação em vidro, a fim de mostrar a sensibilidade do filme, uma vez que o ouro é pouco sensível a mudanças de pH. Foi montado o mesmo experimento utilizado com ITO, e os resultados são mostrados na Figura 39, onde temos uma curva de resposta para um filme de três bicamadas de PAMAMG4/GO em um eletrodo de ouro e a curva de sensibilidade relacionada desta curva.

A)

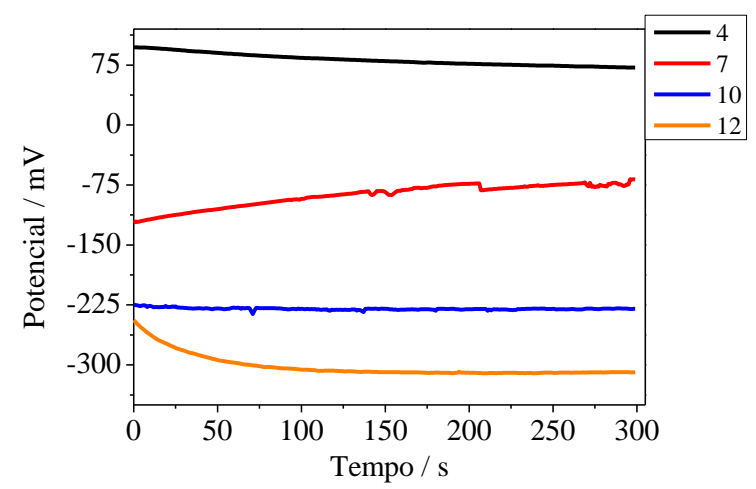

B)

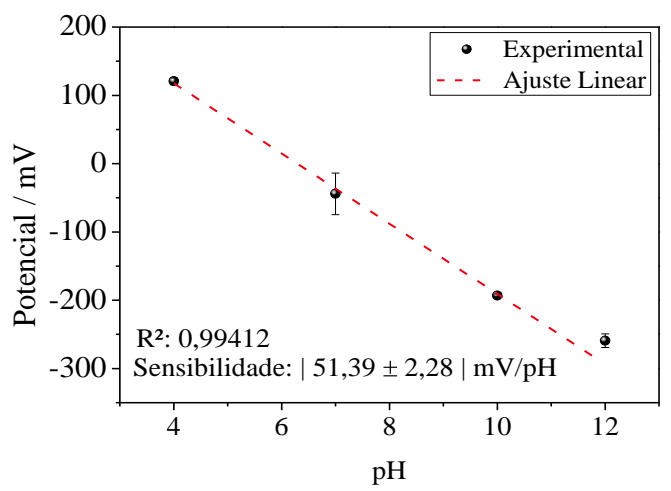

Figura 39: A) Curvas de resposta do sistema em função do tempo. B) Sensibilidade do filme para 5 bicamadas.

Com o objetivo de verificar a melhor arquitetura para se esses filmes, este procedimento foi repetido para diferentes números de filmes, três no total, com diferentes números de bicamadas, variando-se de 0 (eletrodo limpo) à 9 bicamadas. As medidas foram realizadas utilizando-se três filmes para cada número de bicamada. Estes resultados estão mostrados na Figura 40. 


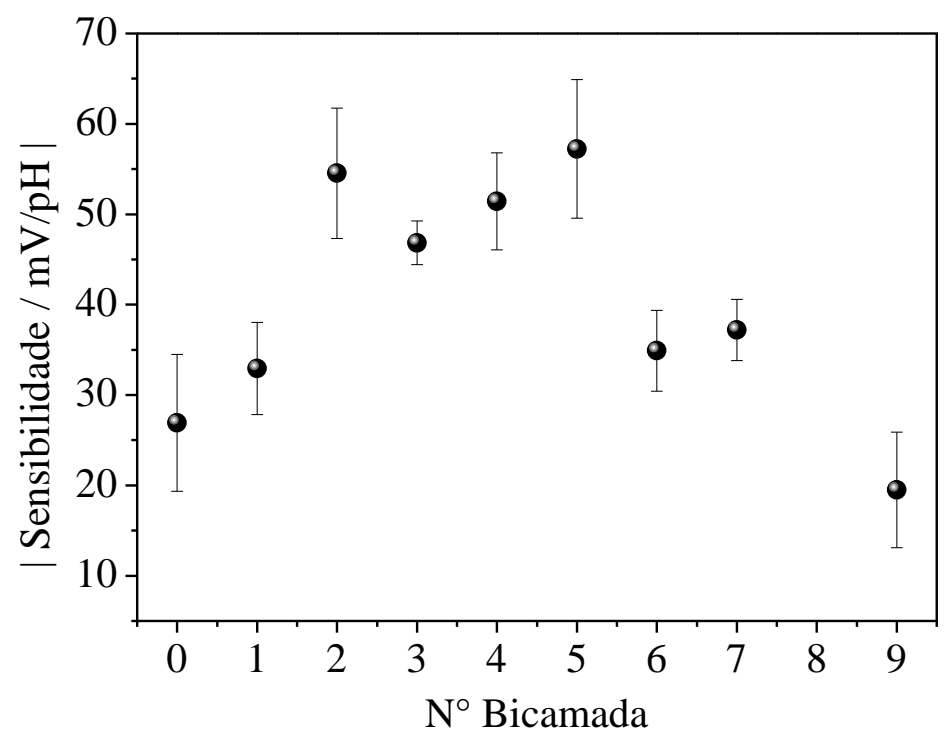

Figura 40: Resposta da sensibilidade em função do número de bicamadas de PAMAM-G4/GO.

Podemos verificar que os filmes de duas e cinco bicamadas possuem o melhor valor de sensibilidade, $54,54 \pm 7,22 \mathrm{mV} / \mathrm{pH}$, enquanto que para cinco bicamadas o valor foi de $57,23 \pm 7,67 \mathrm{mV} / \mathrm{pH}$. Mas como verificado, os filmes com duas bicamadas são mais instáveis, o que pode ser devido ao fato do filme não preencher completamente o eletrodo, restando algumas regiões expostas do eletrodo.

Na Figura 41 temos uma curva comparando a sensibilidade de um filme ao longo do tempo de duas bicamadas e de cinco bicamadas, demonstrando que o filme de duas bicamadas a sensibilidade diminui rapidamente com o tempo. 


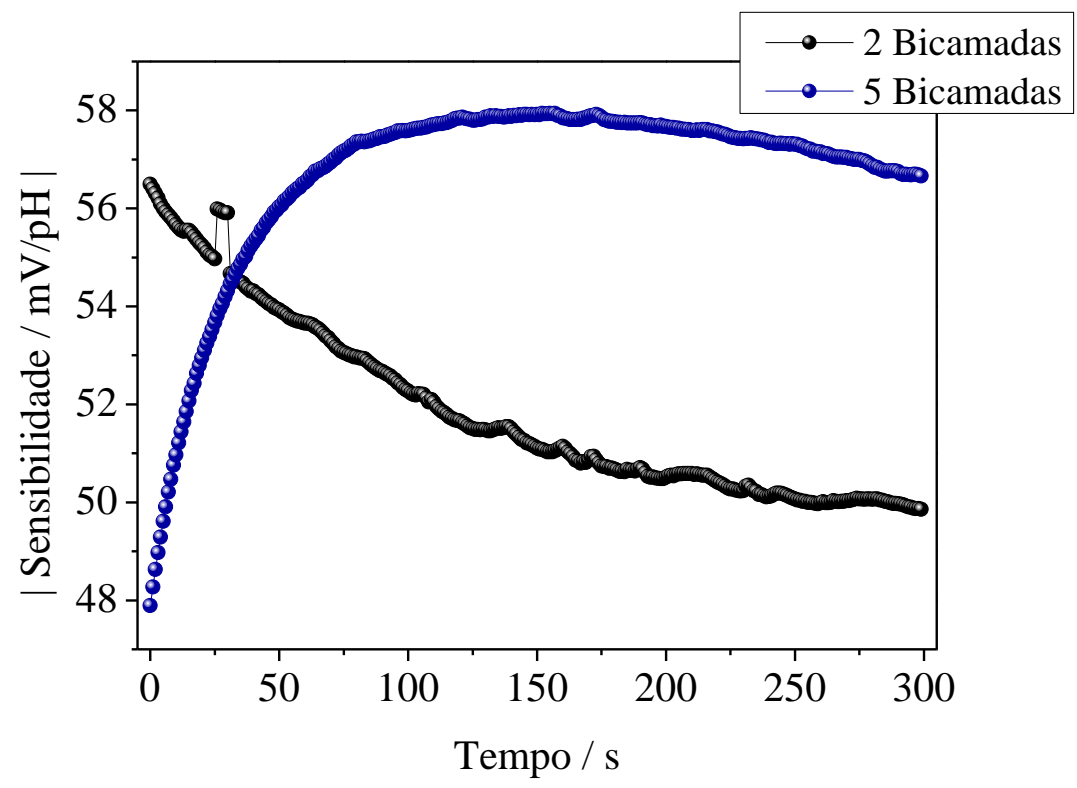

Figura 41: Comparação do modulo da sensibilidade ente um filme de duas bicamadas e cinco bicamadas ao longo do tempo.

O ponto de saturação ocorre em cinco bicamadas e a partir deste ponto a sensibilidade cai consideravelmente. O filme com quatro bicamadas também possui considerável sensibilidade, estando dentro do limite de erro das duas medidas $51,43 \pm 5,38 \mathrm{mV} / \mathrm{pH}$. Nota-se também que estes valores de sensibilidade são maiores que o do eletrodo de ouro puro, o que indica a melhor sensibilidade para um número de bicamadas é do sistema PAMAM-G4/GO, e não somente do ITO, no caso do experimento anterior.

Este sistema $\mathrm{Au}(\mathrm{PAMAM}-\mathrm{G} 4 / \mathrm{GO})_{5}$ também se mostrou estável e de rápida resposta, como mostra a Figura 42. 


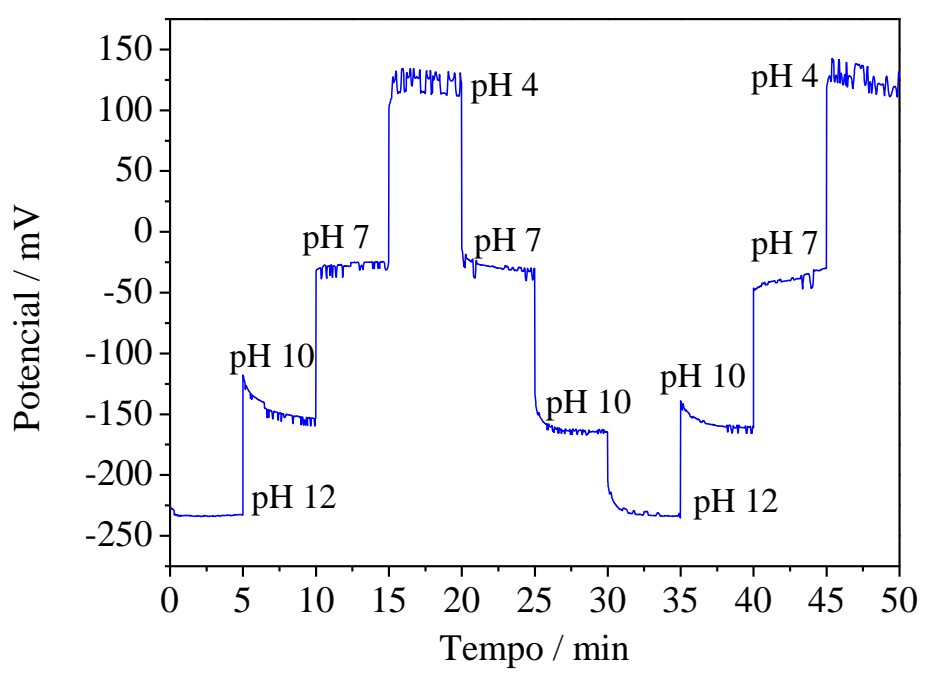

Figura 42: Repetibilidade do sistema GO/PAMAM-G4, a variação e $\mathrm{pH}$ de um $\mathrm{pH}$ básico para um $\mathrm{pH}$ ácido e na direção de um $\mathrm{pH}$ ácido para um $\mathrm{pH}$ básico. 


\section{Conclusões}

Processar e manter o controle das propriedades de materiais em escala nanométrica exige um profundo conhecimento de áreas interdisciplinares. $\mathrm{O}$ advento desta área ainda esta em seus primeiros passos, muito já se conhece, mas um longo caminho ainda é necessário percorrer, principalmente na obtenção desses nanomateriais em escala industrial, mantendo uma alta razão, qualidade/baixo-custo. Esta dissertação mostrou que o processamento de nanomateriais na forma de filmes ultrafinos é uma alternativa de processamento com diversas vantagens: Baixo custo, reprodutibilidade, repetibilidade e controle em nível molecular de propriedades.

A esfoliação química do grafite para obtenção de grafeno em sua forma oxidada foi eficiente na obtenção de amostras com qualidade, através da adição do ultrassom de ponta após a esfoliação química, onde foi possível separar o grafite não oxidado do GO, obtendo assim folhas em duas populações de tamanho no plano da folha: uma em torno de $500 \mathrm{~nm}$ e outra acima de $1 \mu \mathrm{m}$, além de ter diminuído a altura das folhas na direção Z. Isto conferiu a grande estabilidade

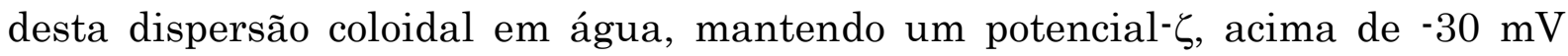
entre o $\mathrm{pH} 2$ e 12.

O crescimento dos filmes automontados de PAMAM-G4/GO ocoreu de forma não linear até 9 bicamadas, e a partir desta, de forma linear. Isto se deve a mudança na morfologia do filme com o aumento do número de bicamadas.

As medidas de potenciometria mostraram que o filme com três bicamadas de PAMAM-G4/GO, quando imobilizado sobre ITO, confere a este substrato uma estabilidade a mudança de $\mathrm{pH}$ em função do tempo, mas diminui a sua sensibilidade.

Já as medidas potenciométricas realizadas em substrato de $\mathrm{Au} / \mathrm{Cr}$, mostraram que a sensibilidade do filme PAMAM-G4/GO, é do tipo Nerstiana, com um valor em torno de $57 \mathrm{mV} / \mathrm{pH}$, verificando-se também que esta sensibilidade é comum para filmes acima de duas bicamadas, sendo mais estável para o filme contendo cinco bicamadas. 
Estes resultados mostram que este sistema possui alta performace no desenvolvimento de sensores químicos. Aliando o baixo custo de processamento com a qualidade dos materiais envolvidos. Este dispositivo pode ser usado como plataforma biossensorial, onde uma espécie biológica especifica pode se ligar facilmente ao GO, devido a suas terminações carboxílicas. Esta sensibilidade a mudanças de íons confere ao GO um forte candidato em biossensores, o que deverá ser explorado em trabalhos futuros. 


\section{Bibliografia}

1 FEYNMAN, R.P. Plenty of room at the bottom. 1959. Disponível

em: $<$ http://www.its.caltech.edu/ feynman/plenty.html $>$. Acesso em: 21 May 2012.

2 DANIEL, M.C.; ASTRUC, D. Gold nanoparticles: assembly, supramolecular chemistry, quantum-size-related properties, and applications toward biology, catalysis, and nanotechnology. Chemical Reviews, v. 104, n. 1, p. 293-346, Jan. 2004.

3 NOHYNEK, G. J. et al. Grey goo on the skin? Nanotechnology, cosmetic and sunscreen safety. Critical Reviews in Toxicology, v. 37, n. 3, p. 251-277, 2007.

4 CHEN, R. J. et al. Noncovalent functionalization of carbon nanotubes for highly specific electronic biosensors. Proceedings of the National Academy of Sciences, v. 100, n. 9, p. 4984-4989, Apr. 2003.

5 PERINOTO, A. C. et al. Biosensors for efficient diagnosis of leishmaniasis: innovations in bioanalytics for a neglected disease. Analytical Chemistry, v. 82, n. 23, p. 9763-9768, Dec. 2010.

6 TANS, S. J.; VERSCHUEREN, A. R. M.; DEKKER, C. Room-temperature transistor based on a single carbon nanotube. Nature, v. 393 , n. 6680 , p. 49-52, 1998.

7 PEPPAS, N. A. et al. Hydrogels in biology and medicine: from molecular principles to bionanotechnology. Advanced Materials, v. 18, n. 11, p. 1345-1360, June 2006.

8 CHIANG, C. K. et al. Electrical-conductivity in doped polyacetylene. Physical Review Letters, v. 39, n. 17, p. 1098-1101, 1977.

9 IIJIMA, S. Helical microtubules of graphitic carbon. Nature, v. 354, n. 6348, p. 56-58, Nov. 1991.

10 KROTO, H. W. et al. C60: buckminsterfullerene. Nature, v. 318, n. 6042, p. 162$163,1985$.

NOVOSELOV, K. S. et al. Electric field effect in atomically thin carbon films.

Science, v. 306, n. 5696, p. 666-669, Oct. 2004.

GEIM, A. K.; NOVOSELOV, K. S. The Rise of graphene. Nature Materials, v. 6, n. 3, p. 183-191, 2007.

NOVOSELOV, K. S. et al. Two-dimensional gas of massless dirac fermions in graphene. Nature, v. 438, n. 7065, p. 197-200, 2005. 
NOVOSELOV, K. S. et al. Room-temperature quantum hall effect in graphene. Science, v. 315, n. 5817, p. 1379, Mar. 2007.

ZHANG, Y. et al. Experimental observation of the quantum hall effect and Berry's phase in graphene. Nature, v. 438, n. 7065, p. 201-204, 2005.

STANKOVICH, S. et al. Graphene-based composite materials. Nature, v. 442, n. 7100, p. 282-286, July 2006.

SHAN, C. et al. Direct electrochemistry of glucose oxidase and biosensing for glucose based on graphene. Analytical Chemistry, v. 81, n. 6, p. 2378-2382, Mar. 2009.

WANG, Y. et al. Supercapacitor devices based on graphene materials. The Journal of Physical Chemistry C, v. 113, n. 30, p. 13103-13107, July 2009.

KULKARNI, D. D. et al. Graphene oxide-polyelectrolyte nanomembranes. Acs Nano, v. 4, n. 8, p. 4667-4676, Aug. 2010.

DECHER, G. Fuzzy nanoassemblies: toward layered polymeric multicomposites. Science, v. 277, n. 5330, p. 1232-1237, Aug. 1997.

RECOMENDAÇÃO da comissão de 18 de Outubro de 2011 sobre a definição de nanomaterial. Disponível em: $<$ http://eurlex.europa.eu/LexUriServ/LexUriServ.do? uri=OJ:L:2011:275:0038:0040:PT:PDF>. Acesso em: 28 set. 2012.

BUZEA, C.; PACHECO, I. I.; ROBBIE, K. Nanomaterials and nanoparticles: sources and toxicity. Biointerphases, v. 2, n. 4, p. MR17-MR71, Dec. 2007.

RODUNER, E. Size matters: why nanomaterials are different. Chemical Society Reviews, v. 35, n. 7, p. 583-592, 2006.

FRONDEL, C.; MARVIN, U. B. Lonsdaleite a hexagonal polymorph of diamond. Nature, v. 214, n. 5088, p. 587-\&, 1967.

LIN, Y. et al. Amorphous diamond: a high-pressure superhard carbon allotrope. Physical Review Letters, v. 107, n. 17, p. 175504, 2011.

ALIEV, A. E.; GARTSTEIN, Y. N.; BAUGHMAN, R. H. Mirage effect from thermally modulated transparent carbon nanotube sheets. Nanotechnology, v. 22, n. 43, p.435704-\&, Oct. 2011.

TADESSE, Y. et al. Hydrogen-fuel-powered bell segments of biomimetic jellyfish.

Smart Materials and Structures, v. 21, n. 4, p.045013-\&, Apr. 2012.

CHASTE, J. et al. A Nanomechanical mass sensor with yoctogram resolution.

Nature Nanotechnology, v. 7, n. 5, p. 300-303, May 2012.

PEIERLS, R. E. Quelques proprietes typiques des corpses solides. Annales de L' Institut Henry Poincare, v. 5, p. 45, 1935. 
LANDAU , L. D. Zur Theorie der phasenumwandlungen II. Physik Z.

Sowjetunion, v. 11, p. 9, 1937.

FRADKIN, E. Critical behavior of disordered degenerate semiconductors. I.

Models, symmetries, and formalism. Physical Review B, v. 33, n. 5, p. 3257-3262, 1986.

FRADKIN, E. Critical behavior of disordered degenerate semiconductors. II. Spectrum and transport properties in mean-field theory. Physical Review B, v. 33, n. 5 , p. 3263-3268, 1986.

DU, X. et al. Approaching ballistic transport in suspended graphene. Nature Nanotechnology, v. 3, n. 8, p. 491-495, 2008.

LIAO, L. et al. High-speed graphene transistors with a self-aligned nanowire gate. Nature, v. 467, n. 7313, p. 305-308, 2010.

WEB OF SCIENCE. Disponível em:<www.webofknowledge.com>. Acesso em: 26 May 2012.

WALLACE, P. R. The Band theory of graphite. Physical Review, v. 71, n. 9, p. 622-634, 1947.

SAITO, R.; DRESSELHAUS, G.; DRESSELHAUS, M.S. Tight binding calculation of molecules and solids. In: Physical properties of carbon nanotubes. Hackensakc: World Scientific, 1998. p.17-33.

KEDZIERSKI, J. et al. Epitaxial graphene transistors on sic substrates. IEEE Transactions on Electron Devices, v. 55, n. 8, p. 2078-2085, 2008.

EMTSEV, K. V. et al. Towards wafer-size graphene layers by atmospheric pressure graphitization of silicon carbide. Nature Materials, v. 8, n. 3, p. 203-207, 2009.

MOON, J. S. et al. Epitaxial-graphene rf field-effect transistors on si-face $6 \mathrm{H}$-SiC substrates. IEEE Electron Device Letters, v. 30, n. 6, p. 650-652, 2009.

2

DEDKOV, Y. S. et al. Rashba effect in the graphene/Ni(111) system. Physical Review Letters, v. 100, n. 10, p. 107602, 2008.

MARCHINI, S.; GÜNTHER, S.; WINTTERLIN, J. Scanning tunneling microscopy of graphene on $\mathrm{Ru}(0001)$. Physical Review B, v. 76, n. 7, p. 075429, 2007.

PLETIKOSIĆ, I. et al. Dirac cones and minigaps for graphene on $\operatorname{Ir}(111)$. Physical Review Letters, v. 102, n. 5, p. 056808, 2009.

LI, X. et al. Large-area synthesis of high-quality and uniform graphene films on copper foils. Science, v. 324, n. 5932, p. 1312-1314, June 2009. 
BAE, S. et al. Roll-to-roll production of 30-inch graphene films for transparent electrodes. Nature Nanotechnology, v. 5, n. 8, p. 574-578, 2010.

BRODIE, B. C. Sur le poids atomique du graphite. Annales de Chimie et de Physique, v. 59, p. 8, 1860.

STAUDENMAIER, L. Verfahren zur darstellung der graphitsäure. Berichte der deutschen chemischen Gesellschaft, v. 31, n. 2, p. 1481-1487, 1898.

HUMMERS, W. S.; OFFEMAN, R. E. Preparation of graphitic oxide. Journal of the American Chemical Society, v. 80, n. 6, p. 1339-1339, 1958.

BOEHM, H. P. et al. Das Adsorptionsverhalten sehr dunner kohlenstoff-folien. Zeitschrift Fur Anorganische Und Allgemeine Chemie, v. 316, n. 3-4, p. 119-127, 1962.

SUKANG, B. et al. Towards industrial applications of graphene electrodes. Physica Scripta, v. 2012, n. T146, p. 014024, 2012.

SHIN, H. J. et al. Efficient reduction of graphite oxide by sodium borohydride and its effect on electrical conductance. Advanced Functional Materials, v. 19, n. 12, p. 1987-1992, 2009.

PARK, S.; RUOFF, R. S. Chemical methods for the production of graphenes. Nature Nanotechnology, v. 4, n. 4, p. 217-224, 2009.

HE, H. Y. et al. A New structural model for graphite oxide. Chemical Physics Letters, v. 287, n. 1-2, p. 53-56, Apr. 1998.

RODRIGUEZ, A. M.; JIMENEZ, P. S. V. Some new aspects of graphite oxidation

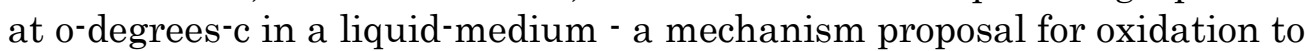
graphite oxide. Carbon, v. 24, n. 2, p. 163-167, 1986.

LERF, A. et al. Structure of graphite oxide revisited. The Journal of Physical Chemistry B, v. 102, n. 23, p. 4477-4482, June 1998.

PANDEY, D.; REIFENBERGER, R.; PINER, R. Scanning probe microscopy study of exfoliated oxidized graphene sheets. Surface Science, v. 602, n. 9, p. 1607-1613, 2008.

MORALES-NARVÁEZ, E.; MERKOÇI, A. Graphene oxide: graphene oxide as an optical biosensing platform. Advanced Materials, v. 24, n. 25, p. 3289-3289, 2012.

ABOUTALEBI, S. H. et al. Comparison of GO, GO/MWCNTs composite and MWCNTs as potential electrode materials for supercapacitors. Energy \& Environmental Science, v. 4, n. 5, p. 1855-1865, 2011.

YE, D. et al. Highly efficient electron field emission from graphene oxide sheets supported by nickel nanotip arrays. Nano Letters, v. 12, n. 3, p. 1265-1268, Mar. 2012. 
MIJATOVIC, D.; EIJKEL, J. C. T.; VAN DEN BERG, A. Technologies for nanofluidic systems: top-down vs. bottom-up-a review. Lab on a Chip, v. 5, n. 5, p. $492-500,2005$.

DECHER, G.; HONG, J. D.; SCHMITT, J. Buildup of ultrathin multilayer films by a self-assembly process: III. Consecutively alternating adsorption of anionic and cationic polyelectrolytes on charged surfaces. Thin Solid Films, v. 210/211, Part 2, n. 0, p. 831-835, 1992.

HAMMOND, P. T. Form and function in multilayer assembly: new applications at the nanoscale. Advanced Materials, v. 16, n. 15, p. 1271-1293, 2004.

OLIVEIRA JR., O. N. et al. Optical storage and surface-relief gratings in azobenzene-containing nanostructured films. Advances in Colloid and Interface Science, v. 116, n. 1-3, p. 179-192, 2005.

UNG, T.; LIZ-MARZÁN, L. M.; MULVANEY, P. Optical properties of thin films of Au@SiO2 particles. The Journal of Physical Chemistry B, v. 105, n. 17, p. 3441-3452, May 2001.

SANTOS, M. D. C. S. et al. Caracterização elétrica de filmes ultrafinos de PANI/PVS: material potencial para detecção de amônia em galpões de criação avícola. Polímeros, v. 20, p. 107-111, 2010.

HOOGEVEEN, N. G. et al. Formation and stability of multilayers of polyelectrolytes. Langmuir, v. 12, n. 15, p. 3675-3681, Jan. 1996.

LVOV, Y. M.; DECHER, G. Assembly of multilayer ordered films by alternating adsorption of oppositely charged macromolecules. Kristallografiya, v. 39, n. 4, p. 696-716, July/Aug. 1994.

LÖSCHE, M. et al. Detailed structure of molecularly thin polyelectrolyte multilayer films on solid substrates as revealed by neutron reflectometry. Macromolecules, v. 31, n. 25, p. 8893-8906, Dec. 1998.

SHIRATORI, S. S.; RUBNER, M. F. pH-Dependent thickness behavior of sequentially adsorbed layers of weak polyelectrolytes. Macromolecules, v. 33, n. 11, p. 4213-4219, May 2000.

MENDELSOHN, J. D. et al. Fabrication of microporous thin films from polyelectrolyte multilayers. Langmuir, v. 16, n. 11, p. 5017-5023, May 2000.

STOCKTON, W. B.; RUBNER, M. F. Molecular-level processing of conjugated polymers. 4. Layer-by-layer manipulation of polyaniline via hydrogen-bonding interactions. Macromolecules, v. 30, n. 9, p. 2717-2725, May 1997.

PONTES, R. S. et al. Non-equilibrium adsorbed polymer layers via hydrogen bonding. Physica Status Solidi (A), v. 173, n. 1, p. 41-50, 1999.

SHIMAZAKI, Y. et al. Preparation of the layer-by-layer deposited ultrathin film based on the charge-transfer interaction. Langmuir, v. 13, n. 6, p. 1385-1387, Mar. 1997. 
GRANDKE, T.; HESSE, J. Introduction. In: Sensors. New York: WileyVCH Verlag GmbH, 2008. p.1-16.

THEVENOT, D. R. et al. Electrochemical biosensors: recommended definitions and classification (Technical Report). Pure and Applied Chemistry, v. 71, n. 12, p. 2333-2348, Dec. 1999.

JANATA, J. et al. Chemical sensors. Analytical Chemistry, v. 70, n. 12, p. 179208, June 1998.

WIEMHÖFER, H.D.; CAMMANN, K. Specific features of electrochemical sensors. In: . Sensors. New York: Wiley-VCH Verlag GmbH, 2008. p.159189.

CUNNINGHAM, A. J. Introduction to bioanalytical sensors. New York: Wiley, 1998.

BAKKER, E.; BÜHLMANN, P.; PRETSCH, E. Carrier-based ion-selective electrodes and bulk optodes. 1. General characteristics. Chemical Reviews, v. 97, n. 8, p. 3083-3132, Dec. 1997.

BÜHLMANN, P.; PRETSCH, E.; BAKKER, E. Carrier-based ion-selective electrodes and bulk optodes. 2. Ionophores for potentiometric and optical sensors. Chemical Reviews, v. 98, n. 4, p. 1593-1688, June 1998.

BAGOTSKY, V. S. Thermodynamics of electrochemical systems. In: Fundamentals of electrochemistry. New York: John Wiley, 2005. p.33-50.

KONCKI, R. Recent developments in potentiometric biosensors for biomedical analysis. Analytica Chimica Acta, v. 599, n. 1, p. 7-15, 2007.

SKOOG, D. A. W., D. M.; HOLLER, F. J.; CROUCH, S. R. Fundamentos da quimica analitica. 8.ed. São Paulo: Cengage Learning, 2005.

KAHLERT, H. Functionalized carbon electrodes for $\mathrm{pH}$ determination. Journal of Solid State Electrochemistry, v. 12, n. 10, p. 1255-1266, 2008.

VÁZQUEZ, M.; BOBACKA, J.; IVASKA, A. Potentiometric sensors for Ag+ based on poly(3-octylthiophene) (POT). Journal of Solid State Electrochemistry, v. 9, n. 12 , p. 865-873, 2005.

LAKARD, B. et al. Potentiometric miniaturized $\mathrm{pH}$ sensors based on polypyrrole films. Sensors and Actuators B: chemical, v. 122, n. 1, p. 101-108, 2007.

VADGAMA, P.; CRUMP, P. W. Biosensors: recent trends. A review. Analyst, v. 117, n. 11, p. 1657-1670, 1992.

BERGVELD, P. Thirty years of ISFETOLOGY: what happened in the past 30 years and what may happen in the next 30 years. Sensors and Actuators B: Chemical, v. 88, n. 1, p. 1-20, 2003. 
VAN HAL, R. E. G.; EIJKEL, J. C. T.; BERGVELD, P. A Novel description of ISFET sensitivity with the buffer capacity and double-layer capacitance as key parameters. Sensors and Actuators B: chemical, v. 24, n. 1-3, p. 201-205, 1995.

MALVINO, P. M. Eletrônica. São Paulo: Pearson, 1987.

LOW cost low power instrumentation amplifier AD620. Disponível em: $<$ www.analog.com/static/imported-files/data_sheets/AD620.pdf $>$. Acesso em: 28 Sept. 2012.

YIN, L.T. et al. Study of indium tin oxide thin film for separative extended gate ISFET. Materials Chemistry and Physics, v. 70, n. 1, p. 12-16, 2001.

VIEIRA, N. C. S. Sensores e biossensores baseados em transistores de efeito de campo utilizando filmes automontados nanoestruturados. 2011. 120p. Tese (Doutorado) - Instituto de Física de São Carlos, Universidade de São Paulo, São Carlos, 2011.

ESTRELA, P. et al. Label-free detection of protein interactions with peptide aptamers by open circuit potential measurement. Electrochimica Acta, v. 53, n. 22, p. 6489-6496, 2008.

TUNG, V. C. et al. High-throughput solution processing of large-scale graphene. Nature Nanotechnology, v. 4, n. 1, p. 25-29, 2009.

SIQUEIRA, J. R. et al. Carbon nanotubes in nanostructured films: potential application as amperometric and potentiometric field-effect (bio-)chemical sensors. Physica Status Solidi (A), v. 206, n. 3, p. 462-467, 2009.

MOORES, A.; GOETTMANN, F. The Plasmon band in noble metal nanoparticles: an introduction to theory and applications. New Journal of Chemistry, v. 30, n. 8, p. 1121-1132, 2006.

HOLDE, K. E. H. J.; W. C.; HO,P. S. Principles of physical biochemistry. Upper Saddle River: Pearson Prentice Hall, 2006.

BRUST, M. et al. Self-assembled gold nanoparticle thin films with nonmetallic optical and electronic properties. Langmuir, v. 14, n. 19, p. 5425-5429, Sept. 1998.

CALLISTER JR., W. D. Fundamentals of materials science and engineering. $5^{\text {th }}$. New York: John Wiley, 2001.

STUART, B. H. Introduction. In: Infrared spectroscopy: fundamentals and applications. New York: John Wiley, 2005. p.1-13.

SMITH, E.; DENT, G. Introduction, basic theory and principles. In: Modern raman spectroscopy - a practical approach. New York: John Wiley, 2005. p.1-21. 

Infrared and raman spectroscopic imaging. New York: Wiley-VCH Verlag GmbH \& Co. KGaA, 2009. p.1-64.

GOLDSTEIN, J. et al. Scanning electron microscopy and x-ray microanalysis. $3^{\text {rd }}$. New York: [s.n.], 2003.

LADAM, G. et al. In Situ determination of the structural properties of initially deposited polyelectrolyte multilayers. Langmuir, v. 16, n. 3, p. 1249-1255, Feb. 2000. Physical Chemistry C, v. 115, n. 23, p. 11327-11335, June 2011.

LI, D. et al. Processable aqueous dispersions of graphene nanosheets. Nature Nanotechnology, v. 3, n. 2, p. 101-105, 2008.

SUN, X. et al. Monodisperse chemically modified graphene obtained by density gradient ultracentrifugal rate separation. Acs Nano, v. 4, n. 6, p. 3381-3389, June 2010. controlled thickness via density differentiation. Nano Letters, v. 9, n. 12, p. 40314036, Dec. 2009.

SONG, E. B. et al. Visibility and raman spectroscopy of mono and bilayer graphene on crystalline silicon. Applied Physics Letters, v. 96, n. 8, p. 081911081913, 2010. Applied Physics, v. 103, n. 12, p. 124302-124306, 2008. Physics and applications of graphene - experiments. Vienna: InTech Education, 2011. Cap. 5. groups). In: . Course notes on the interpretation of infrared and raman spectra. New York: John Wiley, 2004. p.163-178.

ACIK, M. et al. Unusual infrared-absorption mechanism in thermally reduced graphene oxide. Nature Materials, v. 9, n. 10, p. 840-845, 2010. oxide by zinc powder at room temperature. Carbon, v. 49, n. 15, p. 5389-5397, 2011. 
118 FUENTE, E. et al. Infrared spectroscopy of carbon materials: a quantum chemical study of model compounds. The Journal of Physical Chemistry B, v. 107, n. 26, p. 6350-6359, July 2003.

SHEN, J. et al. Layer-by-layer self-assembly of graphene nanoplatelets.

Langmuir, v. 25, n. 11, p. 6122-6128, June 2009.

WITEC. Disponível em:<www.witec.de>. Acesso em: 27 jun. 2012.

FERRARI, A. C. et al. Raman spectrum of graphene and graphene layers.

Physical Review Letters, v. 97, n. 18, p. 187401, 2006.

CANCADO, L. G. et al. General equation for the determination of the crystallite size L[sub a] of nanographite by raman spectroscopy. Applied Physics Letters, v. 88, n. 16, p. 163106-163103, 2006.

SAITO, R. et al. Raman spectroscopy of graphene and carbon nanotubes. Advances in Physics, v. 60, n. 3, p. 413-550, June 2011.

FERRARI, A. C.; ROBERTSON, J. Interpretation of raman spectra of disordered and amorphous carbon. Physical Review B, v. 61, n. 20, p. 14095-14107, 2000.

CASIRAGHI, C.; FERRARI, A. C.; ROBERTSON, J. Raman spectroscopy of hydrogenated amorphous carbons. Physical Review B, v. 72, n. 8, p. 085401, 2005.

KONKENA, B.; VASUDEVAN, S. Understanding aqueous dispersibility of graphene oxide and reduced graphene oxide through pKa measurements. The Journal of Physical Chemistry Letters, v. 3, n. 7, p. 867-872, Apr. 2012.

VEERBEEK, J.; REINHOUDT, D. N.; HUSKENS, J. Layer-by-layer assembly using host-guest interactions. In: Multilayer thin films. New York: Wiley-VCH Verlag GmbH \& Co. KGaA, 2012. p.83-97.

JIANG, X. et al. Basic law controlling the growth regime of layer-by-layer assembled polyelectrolyte multilayers. Macromolecular Chemistry and Physics, v. 209 , n. 2 , p. $175-183,2008$.

BIFENG, P. et al. Growth of multi-amine terminated poly(amidoamine) dendrimers on the surface of carbon nanotubes. Nanotechnology, v. 17, n. 10, p. $2483,2006$.

WU, T. et al. Graphene oxide reduced and modified by soft nanoparticles and its catalysis of the knoevenagel condensation. Journal of Materials Chemistry, v. 22, n. 11, p. $4772-4779,2012$.

TAHAR, R. B. H. et al. Tin doped indium oxide thin films: electrical properties. Journal of Applied Physics, v. 83, n. 5, p. 2631-2645, 1998.

BIANCHI, R. F. et al. Characterization of indium-tin-oxide films treated by different procedures: effect of treatment time in aqua regia solution. Materials Science and Engineering: C, v. 24, n. 5, p. 595-599, 2004. 
133 GRANQVIST, C. G.; HULTÅKER, A. Transparent and conducting ITO films: new developments and applications. Thin Solid Films, v. 411, n. 1, p. 1-5, 2002. 